\title{
Development of Polymer Gel Systems to Improve Volumetric Sweep and Reduce Producing Water/Oil Ratios
}

\author{
Annual Report \\ for the reporting period \\ $7 / 01 / 2004-6 / 30 / 2005$ \\ by \\ G. Paul Willhite, Stan McCool, Don W. Green \\ Min Cheng, Feiyan Chen
}

September 2005

Contract Number DE-FC26-02NT15363

Contract Dates 7/01/2002 - 12/31/2005

The University of Kansas Center for Research, Inc.

Tertiary Oil Recovery Project

Lawrence, KS 66045 


\section{Disclaimer}

This report was prepared as an account of work sponsored by an agency of the United States Government. Neither the United States Government nor any agency thereof, nor any of their employees, makes any warranty, express or implied, or assumes any legal liability or responsibility for the accuracy, completeness, or usefulness of any information, apparatus, product, or process disclosed, or represents that its use would not infringe privately owned rights. Reference herein to any specific commercial product, process, or service by trade name, trademark, manufacturer, or otherwise does not necessarily constitute or imply its endorsement, recommendation, or favoring by the United States Government or any agency thereof. The views and opinions of authors expressed herein do not necessarily state or reflect those of the United States Government or any agency thereof. 


\begin{abstract}
Gelled polymer treatments are applied to oil reservoirs to increase oil production and to reduce water production by altering the fluid movement within the reservoir. This report describes the results of the third year of a 42 month research program that is aimed at an understanding of gelation chemistry and the fundamental mechanisms that alter the flows of oil and water in reservoir rocks after a gel treatment. Work focused on a widely applied system in the field, the partially hydrolyzed polyacrylamide-chromium acetate gel. Gelation occurs by network formation through the crosslinking of polyacrylamide molecules as a result of reaction with chromium acetate. Pre-gel aggregates form and grow as reactions between chromium acetate and polyacrylamide proceed. A mathematical model that describes uptake and crosslinking reactions as a function of time was derived. The model was probability based and provides molecularweight averages and molecular-weight distributions of the pre-gel aggregates as a function of time and initial system conditions. A liquid chromatography apparatus to experimentally measure the size and molecular weight distributions of polymer samples was developed. The method worked well for polymer samples without the chromium crosslinker. Sample retention observed during measurements of gelant samples during the gelation process compromised the results. Other methods will be tested to measure size distributions of the pre-gel aggregates. Dissolution of carbonate minerals during the injection of gelants causes the $\mathrm{pH}$ of the gelant to increase. Chromium precipitates from solution at the higher $\mathrm{pH}$ values robbing the gelant of crosslinker. Experimental data on the transport of chromium acetate solutions through dolomite cores were obtained. A mathematical model that describes the transport of brine and chromium acetate solutions through rocks containing carbonate minerals was used to simulate the experimental results.
\end{abstract}




\section{Table of Contents}

Page No.

Abstract

iii

List of Figures

$\mathrm{V}$

List of Tables viii

Chapter 1 Introduction $\quad 1-1$

Chapter 2 Modeling the Gelation Process of a Polyacrylamide-Chromium(III)

Gel System Using the Theory of Branching Processes

Chapter 3 Measurement of Molecular Weight and Size Distributions of Polymers and Pre-Gel Aggregates Using an SEC-MALLS-RI Apparatus

Chapter 4 Transport of Brine and Chromium(III) Through Dolomite Rock

4-1

Chapter 5 Technology Transfer

$5-1$ 


\section{List of Figures}

Fig. No. Title

Page No.

2.1 Comparison of experimental data [Jain, et al., 2004] and calculated values (Model I) of chromium uptake at the gel time/point. $~ 5000 \mathrm{mg} / \mathrm{kg}$ polymer concentration and different initial chromium concentrations.

2.2 Comparison of experimental data [Jain, et al., 2004] and calculated values (Model I) of the unreacted chromium trimer concentrations. $~ 5000 \mathrm{mg} / \mathrm{kg}$ polymer concentration and different initial chromium concentrations.

2.3 Model I fit to the unreacted chromium trimer concentration[Jain, et al., 2004] as a function of time for different initial chromium concentrations; $\sim 5000 \mathrm{mg} / \mathrm{kg}$ polymer concentration; $\lambda=3.86$.

2.4 Model I fit to the unreacted chromium trimer concentration[Jain, et al., 2004] as a function of time for different initial polymer concentrations; $200 \mathrm{mg} / \mathrm{kg}$ chromium concentration.

2.5 Comparison of the calculated values (Model I) and the experimental data [Willhite, et al., 2002] of the molecular weight averages of pre-gel aggregates.

2.6 Molecular weight distributions of pre-gel aggregates as functions of time and conversion (Model II).

3.1 Experimental schematic of a SEC-MALLS-RI Setup.

$3.2 \mathrm{dn} / \mathrm{dc}$ values of gelants at different reaction times $\left(35^{\circ} \mathrm{C}\right.$; wavelength $690 \mathrm{~nm}$; in $1 \% \mathrm{KCl}, 0.01 \% \mathrm{NaN}_{3}$ solution).

3.3 Chromatograms for a monodispersed BSA run (1000 mg/kg, $100 \mu \mathrm{L})$.

3.4 MALLS and RI signals aligned for a monodispersed BSA run.

3.5 Molecular weight versus elution time for a BSA run.

3.6 Differential molecular weight distribution of BSA.

3.7 Chromatograms for paam6000K (200 mg/kg, $100 \mu \mathrm{L})$. 
Fig. No. Title

Page No.

3.8 Molecular weight versus elution time for paam6000K. 3-8

3.9 Differential molecular weight distribution of paam6000K. 3-9

3.10 Rms radius versus elution time for paam6000K. 3-9

3.11 Differential rms radius distribution of paam6000K. 3-10

3.12 Rms radius vs. Molar mass for paam6000 K. 3-11

3.13 Molecular weight versus elution time for two polymer lots of AlcoFlood 935.

3.14 Differential molecular weight distributions of two polymer lots of AlcoFlood 935.

3.15 Rms radius versus elution time for two polymer lots of AlcoFlood 935.

3.16 Differential rms radius distributions of two polymer lots of AlcoFlood 935.

3.17 Comparison of the experimental and calculated (Schulz-Zimm) differential molecular weight distributions of AlcoFlood 935, A2247BOV.

3.18 RI chromatograms for gelant runs (Mobile phase: $1 \% \mathrm{KCl}, 0.01 \% \mathrm{NaN}_{3}$ ).

3.19 MALLS chromatograms for gelant runs (Mobile phase: $1 \% \mathrm{KCl}, 0.01 \%$ $\mathrm{NaN}_{3}$ ).

3.20 RI chromatograms for polymer runs between the gelant injections.

3.21 RI chromatograms of gelant runs (Mobile phase: 0.2 M NaOAc, 0.01\% $\mathrm{NaN}_{3}$ ).

4.1 Schematic of equipment used for flow experiment.

4.2 Tracer test for Core C6.

4.3 The effluent chromium concentration when $200 \mathrm{ppm}$ chromium solution (acetate ion) was injected through dolomite Core B at $0.032 \mathrm{~mL} / \mathrm{min}$. 
Fig. No. Title

Page No.

4.4 The effluent $\mathrm{pH}$ when $200 \mathrm{ppm}$ chromium solution (acetate ion) was injected through dolomite Core B at $0.032 \mathrm{~mL} / \mathrm{min}$.

4.5 The effluent $\mathrm{pH}$ and chromium(III) concentration for runs C1-Flow0.032-1 and C2-Flow0.032-1.

4.6 The effluent calcium and magnesium concentrations for runs C1Flow0.032-1 and C2-Flow0.032-1 and the following brine postflood.

4.7 The effluent $\mathrm{pH}$ and chromium concentration for Run C6-Flow0.0056-1.

4.8 Calcium and magnesium concentrations in the effluent for Run C6Flow0.0056-1 and the following brine flush.

4.9 Comparison of the effluent $\mathrm{pH}$, calcium and magnesium concentrations for run C2-pH2.1-Flow-2 with the simulated results.

4.10 Comparison of the effluent $\mathrm{pH}$, calcium and magnesium concentrations for runs C2-KOAc-Flow1-3 and the simulated results. 


\section{List of Tables}

Table No. Title

Page No.

2.1 Compositions of gel systems [Jain et al., 2004] in $1 \% \mathrm{KCl}, 25{ }^{\circ} \mathrm{C}$.

2.2 Differential weight fraction distributions of pre-gel aggregates at different reaction times calculated by Model II. $5000 \mathrm{mg} / \mathrm{kg}$ polymer concentration and $100 \mathrm{mg} / \mathrm{kg}$ chromium concentration.

3.1 Molecular weight and size averages of samples.

3.2 Dn/dc of samples $\left(25{ }^{\circ} \mathrm{C}\right.$; wavelength - $690 \mathrm{~nm}$; in $1 \% \mathrm{KCl}, 0.01 \% \mathrm{NaN}_{3}$ solution).

3.3 Sample recovery and measured molecular weight and size averages of polymer Alcoflood 935, Lot 7158V (12 runs) and Lot A2247BOV (9 runs).

3.4 Sample recovery of gelant runs (200 mg/kg polymer concentration, 100 $\mu L)$.

3.5 System pressure after gelant injections (200 mg/kg polymer concentration, $100 \mu \mathrm{L}$ ).

4.1 Summary of properties of the dolomite cores.

4.2 Sequence of flow experiments in dolomite Core B. 4-6

4.3 Sequence of flow experiments in dolomite Core C1. 4-9

4.4 Sequence of flow experiments in dolomite Core C2. 4-9

4.5 Sequence of flow experiments in dolomite Core C3. 4-9

4.6 Sequence of flow experiments in dolomite Core C4. 4-10

4.7 Sequence of flow experiments in dolomite Core C5. 4-10

4.8 Sequence of flow experiments in dolomite Core C6. 4-10 
4.9 Steady-state values of the experimental and simulated results for flow experiments during the injection of chromium(III) acetate solution (200 ppm $\mathrm{Cr}, 1 \% \mathrm{KCl}$ ) into virgin cores.

4.10 Parameters and results of shut-in experiments; chromium(III) acetate solution (200 ppm Cr, $1 \% \mathrm{KCl})$. 


\section{Chapter 1}

\section{Introduction}

The research goals are to improve the effectiveness of polymer gels to increase volumetric sweep efficiency of fluid displacement processes and to reduce water production. Improvements in these areas have the potential to slow the decline rate in oil production from existing wells and to increase ultimate oil recovery from existing reservoirs. The research is based on laboratory experiments and conceptual and mathematical models developed from data interpretation. The program is organized into three tasks: (1) In-depth Treatment of Matrix Rock from Injection Wells, (2) Treatment of Production Wells to Control Water Production, and (3) Technology Transfer. This report describes work conducted under Tasks 1 and 3. Task 1 seeks to develop design tools to enable the evaluation of gelled polymer systems to treat high-permeability layers that are distant from injection wells when there is crossflow between layers. Components of Task 1 that are reported are (a) a fundamental study of the formation and characterization of pre-gel aggregates, and (b) investigation of the role of carbonate dissolution on the in-depth propagation of gelants.

Research focused on a gel system containing partially hydrolyzed polyacrylamide (HPAM) and chromium acetate, which is commonly applied in field treatments. Gels are formed by building a network through crosslinking polymer molecules. A crosslink is formed when two HPAM molecules react with one Cr(III) complex ion. These reactions are described by:

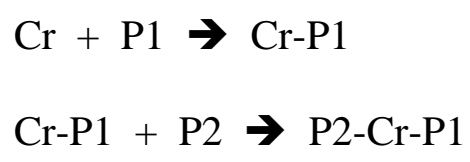

P1 and P2 represent different polymer molecules. The first reaction of polymer P1 with a chromium complex ion is commonly called the uptake reaction. The reaction with the second polymer P2 creates a crosslink between the two polymer molecules and is termed the crosslink reaction. As additional crosslinks occur, pre-gel aggregates form and grow in size.

A mathematical model was derived and presented in the previous annual report that describes the uptake and crosslinking reactions. The model was probability based and provides molecularweight averages and molecular-weight distributions of the pre-gel aggregates as a function of the conversion of reaction sites. Reaction models are generally more useful when time, rather than conversion, is the dependent parameter. In Chapter 2, the model was converted to be time dependent to calculate gel time and molecular-weight averages and distributions of pre-gel aggregates as a function of reaction time and initial system conditions.

Methods to measure the size and molecular weight distributions of pre-gel aggregates during the gelation process are described in Chapter 3. A liquid chromatography apparatus was employedthat used a size-exclusion column to fractionate samples before measurement with multi-angle laser light scattering and refractive index detectors. The method worked well for polymer samples without the chromium crosslinker. Sample retention was observed during 
measurements of gelant samples during the gelation process. Other methods will be tested to measure size distributions of the pre-gel aggregates.

Dissolution of carbonate minerals during the injection of gelants causes the gelant $\mathrm{pH}$ to increase. Chromium precipitates from solution at the higher $\mathrm{pH}$ values robbing the gelant of crosslinker. A mathematical model was developed and presented in the previous annual report that describes the transport of brine and chromium acetate solutions through rocks containing carbonate minerals. Phenomena considered in the model were convection, dispersion, kinetic reactions of carbonate dissolution and chromium precipitation, and chemical equilibria of aqueous components. The model simulated the steady-state and equilibrium results of experiments taken from the literature where brine and chromium acetate solutions are flowed through several rock types that contain carbonate minerals. Additional experimental data on the transport of chromium acetate solutions through dolomite cores were obtained. These data and simulations by the model are reported in Chapter 4 . 


\title{
Chapter 2
}

\section{Modeling the Gelation Process of a Polyacrylamide-Chromium(III) Gel System Using the Theory of Branching Processes}

\author{
Graduate Research Assistant: Min Cheng
}

\section{Introduction}

Aqueous gel systems produced by the crosslinking of partially hydrolyzed polyacrylamide (HPAM) with chromium(III) ions are used to improve volumetric sweep efficiency and reduce water production in oil reservoirs. Gelation is characterized by the growth of pre-gel aggregates. A pre-gel aggregate is defined as any soluble molecule containing one or more of the polymer molecules. Pre-gel aggregates continue to crosslink until they form a 3-dimensional network. Pre-gel aggregates formed during the in situ gelation are filtered and retained in the reservoir rocks, causing high flow resistance and impeding further penetration [McCool, et al., 1991; Bryant, et al., 1997]. Filtration is dependent on the size or molecular weight of pre-gel aggregates. A fundamental understanding of the pre-gel aggregate growth will improve the design of gel treatments.

The purpose of this work was to mathematically model the growth of pre-gel aggregates during the gelation of a polymer gel system. In the previous annual report [Willhite, et.al, 2004], the theory of branching processes (TBP) [Dusek, 1985, 1986, 1998, 2002; Huybrechts and Dusek, 1998] was applied to track the reaction process as a function of the conversion of the reactive sites on the polymer and/or chromium crosslinker. TBP Models I and II were developed to calculate the molecular weight quantities as a function of the conversion of the reactive sites up to a critical conversion that represents the gel point. The gel point is defined as the point where a sufficient number of reactions have occurred, such that one branched molecule with infinite molecular weight appears the first time. The gel point roughly corresponds to experimentally measured gel times.

Models are usually more applicable when time, rather than conversion, is the independent variable. In this chapter, the TBP models were extended by the incorporation of a relationship between the conversion of functional groups (reactive sites on the molecules) and the reaction time based on a previous kinetic study of the chromium-polymer uptake reaction for a polyacrylamide-chromium(III) acetate gel system [Jain, et al., 2004]. Through the extended model, one can estimate the bulk gel time of a gel system and the molecular weight averages and distributions of pre-gel aggregates as functions of reaction times and initial conditions (concentrations of polymer and crosslinker, molecular weight and degree of hydrolysis of the polymer, etc).

\section{Models Describing Gelation of a HPAM - Chromium(III) Gel System} Review of TBP Models I and II. TBP Model I provides mathematical expressions for the molecular weight averages and Model II provides expressions for the molecular weight distributions of pre-gel aggregates, both as a function of the conversion of the reactive sites on the molecules. Reactive sites on molecules are termed functional groups and the number of 
functional groups on a molecule is its functionality. Two general assumptions were applied in both models: (1) The functional groups have the same and independent reactivity. (2) There is no intra-molecular crosslinking (cyclization).

TBP Models I and II were developed based on different descriptions of the gel system. In Model I described by Willhite et al. [2004], the starting chemical system is composed of two components: partially hydrolyzed polyacrylamide (HPAM) molecules (Unit A; primary polymer) and chromium(III) acetate trimer (Unit B). The HPAM molecules are considered to be polydispersed, and the functional groups (carboxylate groups) along the polymer backbone are randomly distributed. Polydispersity of the primary polymer is described by known values of the number-average and weight-average molecular weights (or degree of polymerization). HPAM chains are crosslinked by the reactions between carboxylate groups and chromium acetate trimer that has $f_{B}$ functional groups. A value of $f_{B}$ equal to two was usually used to give the chromium trimer two sites to react with the carboxylate groups on the polymer. Alternating reactions are assumed, which means only HPAM can react with chromium trimer. No polymer-polymer or trimer-trimer reactions are allowed.

The gelation process is described by two ligand exchange reactions in Equations 2.1 and 2.2.

$$
\begin{aligned}
& \mathrm{Cr}_{3}(\mathrm{~L})_{\mathrm{n}}+\mathrm{P} 1-\mathrm{CO}_{2}^{-} \rightarrow \mathrm{Cr}_{3}(\mathrm{~L})_{\mathrm{n}-1}\left(\mathrm{P} 1-\mathrm{CO}_{2}^{-}\right)+\mathrm{L} \\
& \mathrm{Cr}_{3}(\mathrm{~L})_{\mathrm{n}-1}\left(\mathrm{P} 1-\mathrm{CO}_{2}^{-}\right)+\mathrm{P} 2-\mathrm{CO}_{2}^{-} \rightarrow\left(\mathrm{P} 2-\mathrm{CO}_{2}^{-}\right) \mathrm{Cr}_{3}(\mathrm{~L})_{\mathrm{n}-2}\left(\mathrm{P} 1-\mathrm{CO}_{2}^{-}\right)+\mathrm{L}
\end{aligned}
$$

$\mathrm{L}$ represents any ligand like an acetate ion or water; P1 and P2 represent different polymer molecules and the $-\mathrm{CO}_{2}{ }^{-}$represents one functional group on each of the polymers in these equations. The first reaction of a polymer (P1) with the chromium complex is commonly called the uptake reaction. The reaction of a second polymer (P2) with the chromium complex creates a crosslink between the polymers and is termed the crosslink reaction.

Examples of some of the important expressions of Model I are reviewed. The conversion at the gel point where the first appearance of a molecule with infinite molecular weight occurs is called the critical conversion. The critical conversions of carboxylate groups and the chromium functional groups are, respectively:

$$
\begin{aligned}
& \alpha_{c r i t, A}=\left[\frac{1}{x_{A}\left(P_{w 0}-1\right)\left(f_{B}-1\right) r_{A}}\right]^{1 / 2} \\
& \alpha_{c r i t, B}=\left[\frac{r_{A}}{x_{A}\left(P_{w 0}-1\right)\left(f_{B}-1\right)}\right]^{1 / 2}
\end{aligned}
$$

where, $r_{A}=\frac{n_{A} x_{A} P_{n 0}}{n_{B} f_{B}}$

$r_{A}$ is the initial molar ratio of carboxylate groups to chromium functional groups; $\alpha_{c r i t, A}$ and $\alpha_{c r i t, B}$ are the critical conversions of carboxylate groups and chromium functional groups at the gel point, respectively; $f_{B}$ is the functionalities of chromium trimer, $f_{B}=2 ; n_{A}$ and $n_{B}$ are the initial number fractions of polymer and chromium trimer, respectively; $x_{A}$ is the degree of hydrolysis of 
primary polymer; $P_{n 0}$ and $P_{w 0}$ are the number- and weight- average degree of polymerization of the primary polymer, repectively.

The conversions of carboxylate groups and the chromium functional groups are related according to the following equation.

$$
\alpha_{B}=r_{A} \alpha_{A}
$$

The number-average molecular weight of pre-gel aggregates as a function of $\alpha_{B}$ is:

$$
M_{n-a g g}=\frac{n_{A} M_{n 0}+n_{B} M_{B}\left[1-\left(1-\alpha_{B}\right)^{f_{B}}\right]}{1-n_{B} f_{B} \alpha_{B}-n_{B}\left(1-\alpha_{B}\right)^{f_{B}}}
$$

The weight-average molecular weight of the pre-gel aggregates is:

$$
M_{w-a g g}=\frac{M_{w}-w_{B} M_{B}\left(1-\alpha_{B}\right)^{f_{B}}}{1-w_{B}\left(1-\alpha_{B}\right)^{f_{B}}}
$$

where

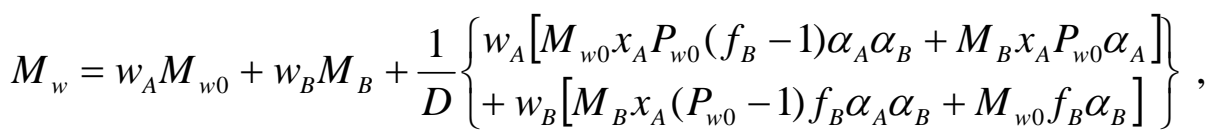

$$
\begin{aligned}
& D=1-x_{A}\left(P_{w 0}-1\right)\left(f_{B}-1\right) \cdot \alpha_{A} \alpha_{B}
\end{aligned}
$$

and $w_{A}, w_{B}$ are the initial weight fractions of polymer and chromium trimer, respectively; $M_{n 0}$ and $M_{w 0}$ are the number- and weight-average molecular weight of the primary polymer, respectively. $M_{w}$ can be also represented as a function of either $\alpha_{A}$ or $\alpha_{B}$ through the substitution of Equation 2.6.

The expressions given above for Model I simulate the various averages of molecular weight and the value of conversion at the gel point, or critical conversion. The critical conversion is dependent only on initial parameters of the gel system and the various molecular-weight averages are dependent on the initial parameters and conversion (independent variable).

In Model II described by Willhite et al. [2004], the gel system was simplified in that the starting reactant is polydispersed HPAM only, without the chromium crosslinker. Polymer chains are crosslinked hypothetically by the formation of bonds between two carboxylate groups on two different polymer molecules. The primary (initial) polymer chains follow a Schulz-Zimm distribution and the carboxylate groups are randomly distributed along the polymer molecules. Differential molecular weight distributions (or distributions of degree of polymerization) of pregel aggregates are calculated as a function of the conversion of carboxylate groups, $\alpha$, by Model II. The Schulz-Zimm distribution is given by 


$$
w(0, x)=\left[\frac{\sigma^{\sigma}}{P_{n 0}^{\sigma+1} \Gamma(\sigma)}\right] x^{\sigma} \exp \left(-\frac{\sigma}{P_{n 0}} x\right)
$$

where $x$ is the degree of polymerization of an $x$-mer; $w(0, x)$ is the initial weight fraction distribution of the primary polymer, or the differential weight fraction of an $x$-mer at conversion zero; $\Gamma$ is the standard mathematical gamma function; and $\sigma$ is a parameter related to polydispersity index of the polymer, PI, according to

$$
P I=M_{w 0} / M_{n 0}=P_{w 0} / P_{n 0}=(\sigma+1) / \sigma
$$

The critical conversion of functional (carboxylate) groups at the gel point, $\alpha_{\text {crit }}$, is [Dusek, 1998]:

$$
\alpha_{c r i t}=\frac{1}{x_{A}\left(P_{w 0}-1\right)}
$$

The differential weight fraction of an $x$-mer at conversion $\alpha, w(\alpha, x)$, is given by Equation 2.14 [Vojta and Dusek, 1980],

$$
w(\alpha, x) \approx x^{-1} \ln (2) \sum_{i=1}^{N} V_{i} W(\alpha, Z)=x^{-1} \ln (2) \sum_{i=1}^{N} V_{i} W\left(\alpha, \exp \left(-i x^{-1} \ln (2)\right)\right.
$$

where $Z=\exp (-p)=\exp \left(-i x^{-1} \ln (2)\right)$,

$$
\begin{aligned}
& p=-\ln (Z)=i x^{-1} \ln (2), \\
& i=1,2, \ldots N . \\
& V_{i}=(-1)^{i+N / 2} \sum_{k=[(i+1) / 2]}^{\min (i, N / 2)} \frac{k^{N / 2}(2 k) !}{(N / 2-k) ! k !(k-1) !(i-k) !(2 k-i) !}
\end{aligned}
$$

$V_{i}$ are constants that only depend on $i$ and an even number $N$. The symbol [ ] in Equation 2.15 designates the integer part of the number.

To solve Equation 2.14, values for $W(\alpha, Z)$ are required. $W(\alpha, Z)$ is calculated by Equation 2.16.

$$
W(\alpha, Z)=\left[\frac{\sigma}{P_{n 0}\left(\sigma / P_{n 0}+p-\ln \beta\right)}\right]^{\sigma+1}
$$

where $\beta=1-x_{A}+x_{A}(1-\alpha+\alpha u)$ and

$$
u=\frac{1}{\beta}\left[\frac{\sigma}{P_{n 0}\left(\sigma / P_{n 0}+p-\ln \beta\right)}\right]^{\sigma+1}
$$

At any conversion $\alpha$ between 0 and $\alpha_{\text {crit }}$, Equation 2.17 was solved numerically, followed by evaluation of $W(\alpha, Z)$ by Equation 2.16. Then $w(\alpha, x)$ was obtained by Equation 2.14 for $\mathrm{N}=16$. 
The molecular weight distribution calculated by Model II can be translated to the conditions of the reaction system of Model I, which is a better representation of a gel polymer system, through Equation 2.18 when the number of crosslinks in both models is the same.

$$
\alpha=\alpha_{B}^{2} / r_{A}=r_{A} \alpha_{A}^{2}
$$

The utility of Equation 2.18 is the ability to determine the differential molecular weight distributions of pre-gel aggregates at any value of the conversions selected in Model I.

Kinetic Extension for Model I. A relationship between the conversion of functional groups and reaction time is required to transform the TBP models as functions of time. An empirical rate expression for the time dependence of the conversion of chromium functional group, $\alpha_{B}$, was written based on the stoichiometry of the reaction where only one carboxylate group can react with only one chromium functional group.

$$
\frac{\mathrm{d} \alpha_{B}}{\mathrm{~d} t}=k C_{A f}{ }^{a} C_{B f}{ }^{b}=k\left[C_{A f 0}-C_{B f 0} \cdot \alpha_{B}\right]^{a}\left[C_{B f 0}\left(1-\alpha_{B}\right)\right]^{b}
$$

where $a$ and $b$ are the reaction orders with respect to carboxylate group and chromium functional group, repectively; $k$ is the reaction rate constant at $25^{\circ} \mathrm{C}$; $t$ is reaction time in hours; $C_{A f}$ and $C_{B f}$ are the concentrations of unreacted carboxylate groups and chromium functional groups in $\mathrm{mol} / \mathrm{kg}$, respectively; $C_{A f 0}$ and $C_{B f 0}$ are the initial concentrations of carboxylate groups and chromium functional groups in $\mathrm{mol} / \mathrm{kg}$.

The kinetic extension of Model I relies on the regression of experimental data [Jain, et al., 2004] to determine the fitting parameters in Equation 2.19. Two relationships were required to apply Model I and Equation 2.19 to the experimental data. First, a relationship between the type of experimental data and Model I parameters was derived. This relationship includes a correction factor that addresses intra-molecular crosslinking that was measured in the experiments and not included in the model. Second, a relationship between $\alpha_{B}$ and time was required so that the lefthand side of Equation 2.19 could be evaluated.

The previous kinetic study of the chro mium-polymer uptake reaction [Jain, et al., 2004] measured the concentration of unreacted chromium trimers as a function of time. This concentration in the Model I is given by Equation 2.20.

$$
C_{B 0}-C_{B 0}\left(b_{1}+b_{2}\right)=C_{B 0}-C_{B 0}\left[2\left(1-\alpha_{B}\right) \alpha_{B}+\alpha_{B}^{2}\right]=C_{B 0}\left[1-\left(2 \alpha_{B}-\alpha_{B}^{2}\right)\right]
$$

where $b_{1}$ and $b_{2}$ are the number or weight fractions of chromium trimers which have one and two reacted functional groups, respectively, $b_{1}=2\left(1-\alpha_{B}\right) \alpha_{B}, b_{2}=\alpha_{B}^{2} ; C_{B 0}$ is the initial chromium trimer concentration in $\mathrm{mol} / \mathrm{kg}$.

The TBP models assume no intra-molecular crosslinking while the experimental data represents both inter- and intra-molecular crosslinking. To address this difference, a correction factor, $\lambda$, 
was introduced in Equation 2.20 to give

$$
C_{B 0}-\lambda C_{B 0}\left(b_{1}+b_{2}\right)=C_{B 0}\left[1-\lambda\left(2 \alpha_{B}-\alpha_{B}^{2}\right)\right]
$$

where $\lambda$ represents the ratio of the number of reacted chromium trimers in the experimental data to the number of reacted chromium trimers in Model I. The value of $\lambda$ was determined by comparing the reacted chromium concentration at the gel point in Model I to experimental data of the reacted chromium concentration at the experimental gel time.

The experimental chromium uptake data of Series I and II experiments [Jain, et al., 2004] were used and the data ranges are shown in Table 2.1. Assuming the gel point corresponds to the experimental gel time determined by viscosity measurement, the experimental and calculated chromium uptake (reacted chromium trimer; $C_{B 0}\left(b_{1}+b_{2}\right)$ ) concentrations at the gel time/point in Series I are plotted in Figure 2.1. The experimental values are about 3.86 times the values calculated in Model I. In the Model I, only the uptake and inter-molecular crosslinking reactions are considered, however, in the experimental data additional amounts of chromium trimer (or carboxylate groups) participate in intra-molecular crosslinking reactions (cyclization), i.e., two carboxylate groups on the same polymer molecule are crosslinked through a chromium trimer. Therefore, this coefficient 3.86, designated $\lambda$, represents the intra-molecular crosslinking effect and should be at least a function of the polymer concentration and the degree of hydrolysis. For a specific polymer lot, the degree of hydrolysis is a constant, so $\lambda$ was made a function of the polymer concentration and is assumed to be constant through the reaction process.

Table 2.1 - Compositions of gel systems [Jain et al., 2004] in 1\% KCl, $25{ }^{\circ} \mathrm{C}$.

\begin{tabular}{cccc}
\hline Series & $\mathrm{Cr}_{3}(\mathrm{mg} / \mathrm{kg})$ & Polymer $(\mathrm{mg} / \mathrm{kg})$ & $\mathrm{pH}$ \\
\hline $\mathrm{I}$ & $250-20$ & $\sim 5000$ & $\sim 4.9$ \\
$\mathrm{II}$ & 200 & $7530-3550$ & $\sim 4.9$ \\
\hline
\end{tabular}

Figure 2.2 shows the comparisons of experimental and modeled unreacted chromium concentrations for several gel systems in Series I. In Figure 2.2, the squares are experimental data points: concentration versus reaction time. The lines represent Model I according to Equation 2.21. The upper limits for two x-axes in Figure 2.2 are the gel time for the time axis and $\alpha_{c r i t, B}$, for the conversion axis, representing a linear relationship between $\alpha_{B}$ and time. Results of Equation 2.21 match the data well according to this linear relationship. Conversion is often linear with time for many reactions at small values of conversion. This linear relationship was represented by the following equation.

$$
\alpha_{B} / \alpha_{\text {crit, } B}=t / t_{\text {gel time }}
$$

where $t$ is the reaction time and $t_{\text {gel time }}$ is the measured gel time. Equation 2.22 is used to obtain $d \alpha_{B} / d t$ in Equation 2.19. Differentiation of Equation 2.22 gives the required value:

$$
d \alpha_{B} / d t=\alpha_{\text {crit, } B} / t_{\text {gel time }}
$$




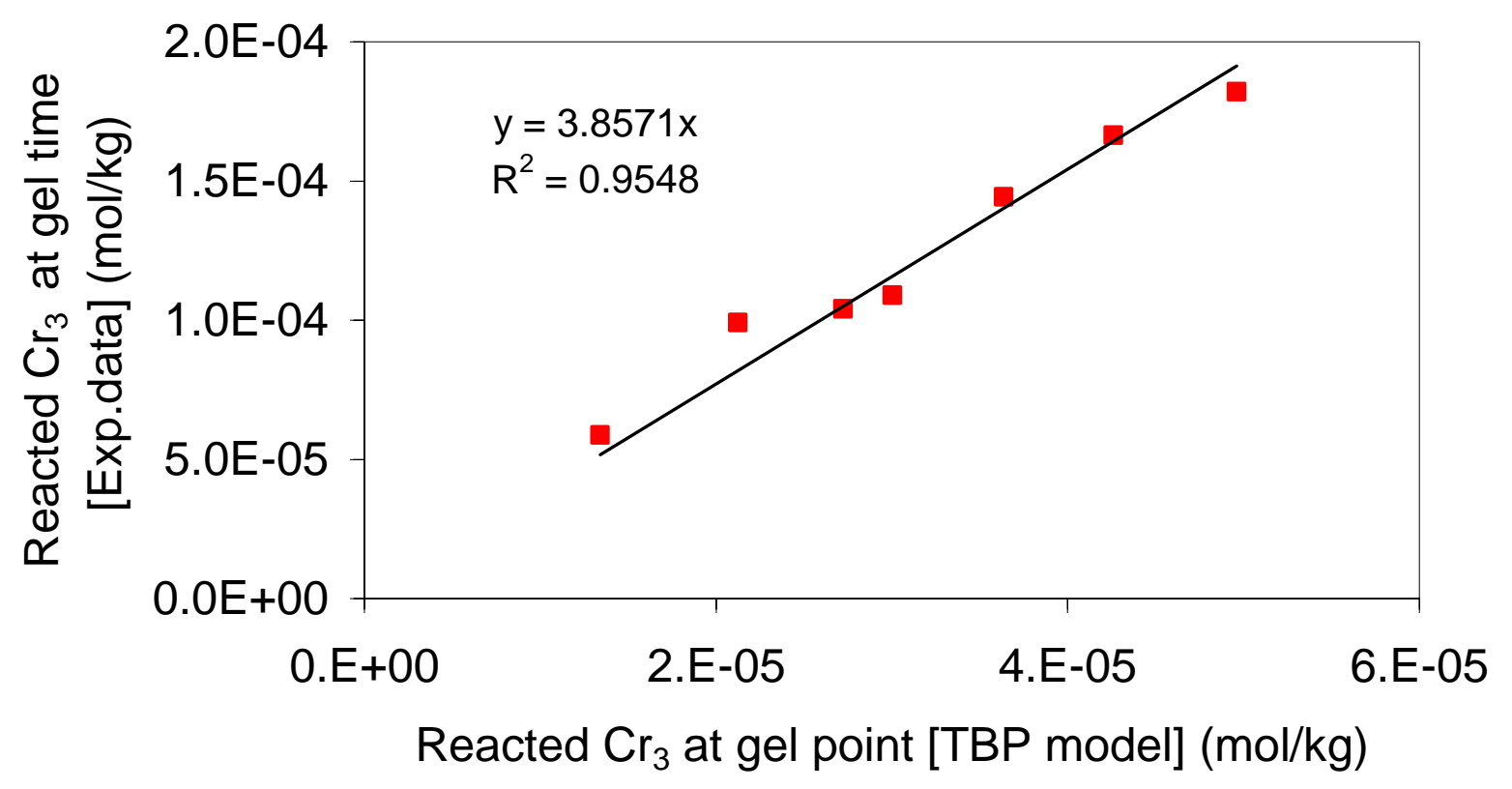

Figure 2.1 - Comparison of experimental data [Jain, et al., 2004] and calculated values (Model I) of chromium uptake at the gel time/point. $~ 5000 \mathrm{mg} / \mathrm{kg}$ polymer.
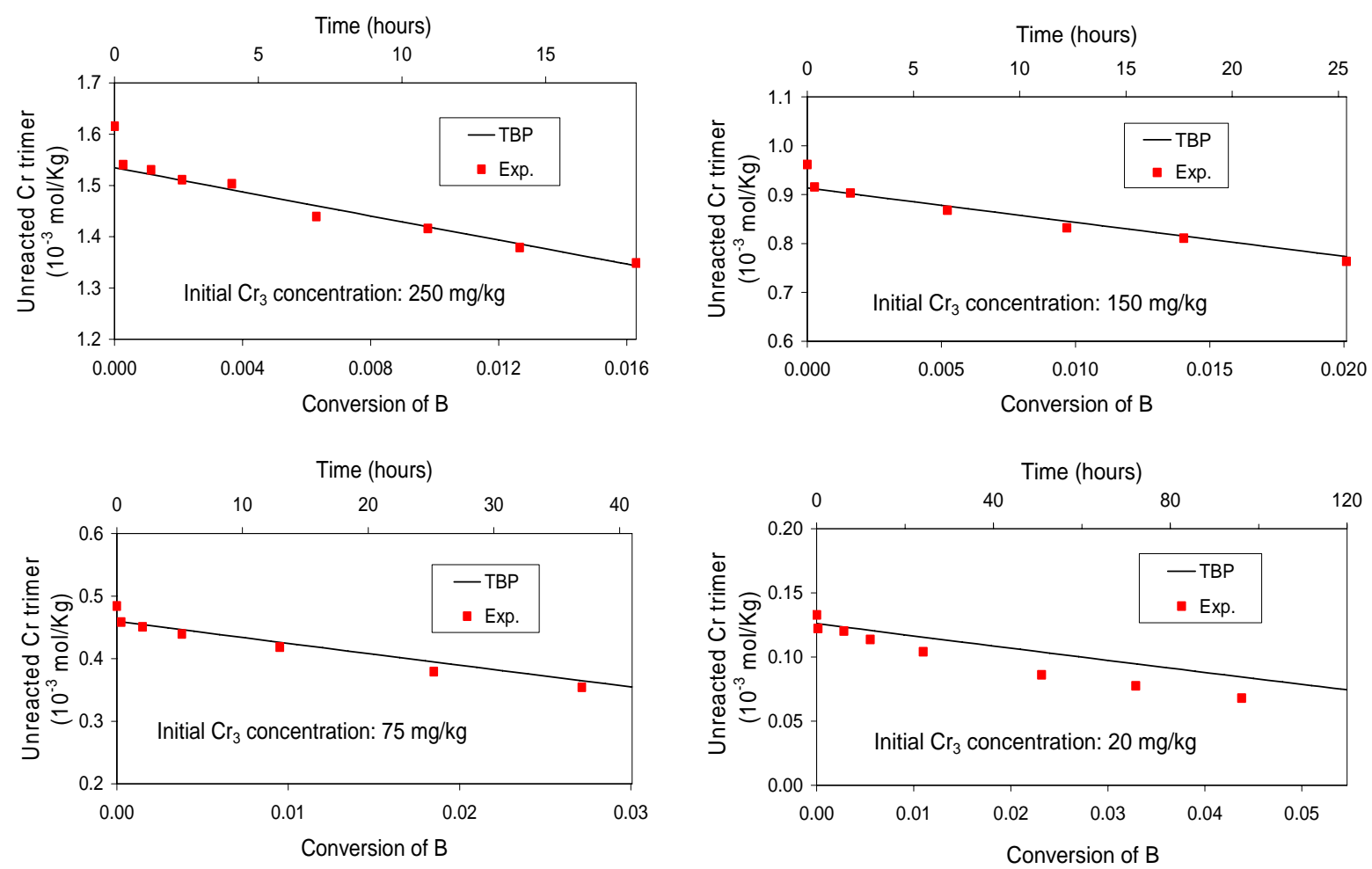

Figure 2.2 - Comparison of experimental data [Jain, et al., 2004] and calculated values (Model I) of the unreacted chromium trimer concentrations. $\sim 5000 \mathrm{mg} / \mathrm{kg}$ polymer and different initial chromium concentrations. 
Applying Equation 2.23 for each gel system in Series I and II experiments of Jain et al.[2004], the rate constant, $k$, and the reaction orders, $a$ and $b$, in Equation 2.19 were regressed by processing data at each measurement time for all runs giving the relationship

$$
\frac{\mathrm{d} \alpha_{B}}{\mathrm{~d} t}=k\left[C_{A f 0}-C_{B f 0} \cdot \alpha_{B}\right]^{2.07}\left[C_{B f 0}\left(1-\alpha_{B}\right)\right]^{0.23}
$$

where $k=98.46 \mathrm{~h}^{-1}(\mathrm{~mol} / \mathrm{kg})^{-2.30}$

The regression yielded a multiple - $\mathrm{R}$ of 0.976 and an $\mathrm{R}^{2}$ of 0.953 . Integration of Equation 2.24 from 0 to any selected time gives a value for $\alpha_{B}\left(<\alpha_{B, \text { crit }}\right)$. Knowing $\alpha_{B}$, the unreacted chromium concentrations can be calculated by Equation 2.21 and molecular weight averages can be calculated by Equations $2.7-2.10$. The gel time for a given system is determined by integrating Equation 2.24 up to the time when $\alpha_{B}$ corresponds to the critical conversion $\alpha_{c r i t, B}$ (as calculated by Equation 2.4).

Figures 2.3 and 2.4 present a comparison of calculated and experimental uptake data where the unreacted chromium concentration is plotted as a function of reaction time. For gel systems with $5000 \mathrm{mg} / \mathrm{kg}$ polymer, $\lambda=3.86$; for gel systems with different polymer concentrations, $\lambda$ was assumed to be inversely proportional to the polymer concentration. It can be seen the model fits the experimental data reasonably well.

Kinetic Extension for Model II. The procedure to determine the time that corresponds to the conversion, $\alpha$, in Model II was: (1) select a time value, (2) integrate Equation 2.24 from 0 to the selected time to determine $\alpha_{B}$, and (3) determine $\alpha$ by Equation 2.18. Then the differential distribution of molecular weight of the system at a given $\alpha$ can be calculated through Equations $2.14-2.17$.

\section{Results and Discussion}

Input parameters required for the models, which are the initial conditions for the experimental gel system, are as follows:

- Weight-average molecular weight of polymer, $M_{w 0}: 6.64 \times 10^{6} \mathrm{~g} / \mathrm{mol}$ for polyacrylamide, AlcoFlood 935, Lot A2247BOV.

- Primary polymer follows Schulz-Zimm distribution with $\sigma=1$, then Schulz-Zimm distribution is reduced to the most probable distribution, or Flory distribution.

$$
w(0, x)=\frac{x}{P_{n 0}{ }^{2}} \exp \left(-\frac{x}{P_{n 0}}\right)
$$

- Degree of hydrolysis of polymer, $x_{A}: 10 \%$.

- Concentration of polymer, $c_{A}: 5000 \mathrm{mg} / \mathrm{kg}$.

- Molecular weight of chromium trimer, $M_{B}: 3 \times 52=156 \mathrm{~g} / \mathrm{mol}$.

- Functionality of chromium trimer: $f_{B}=2$. 


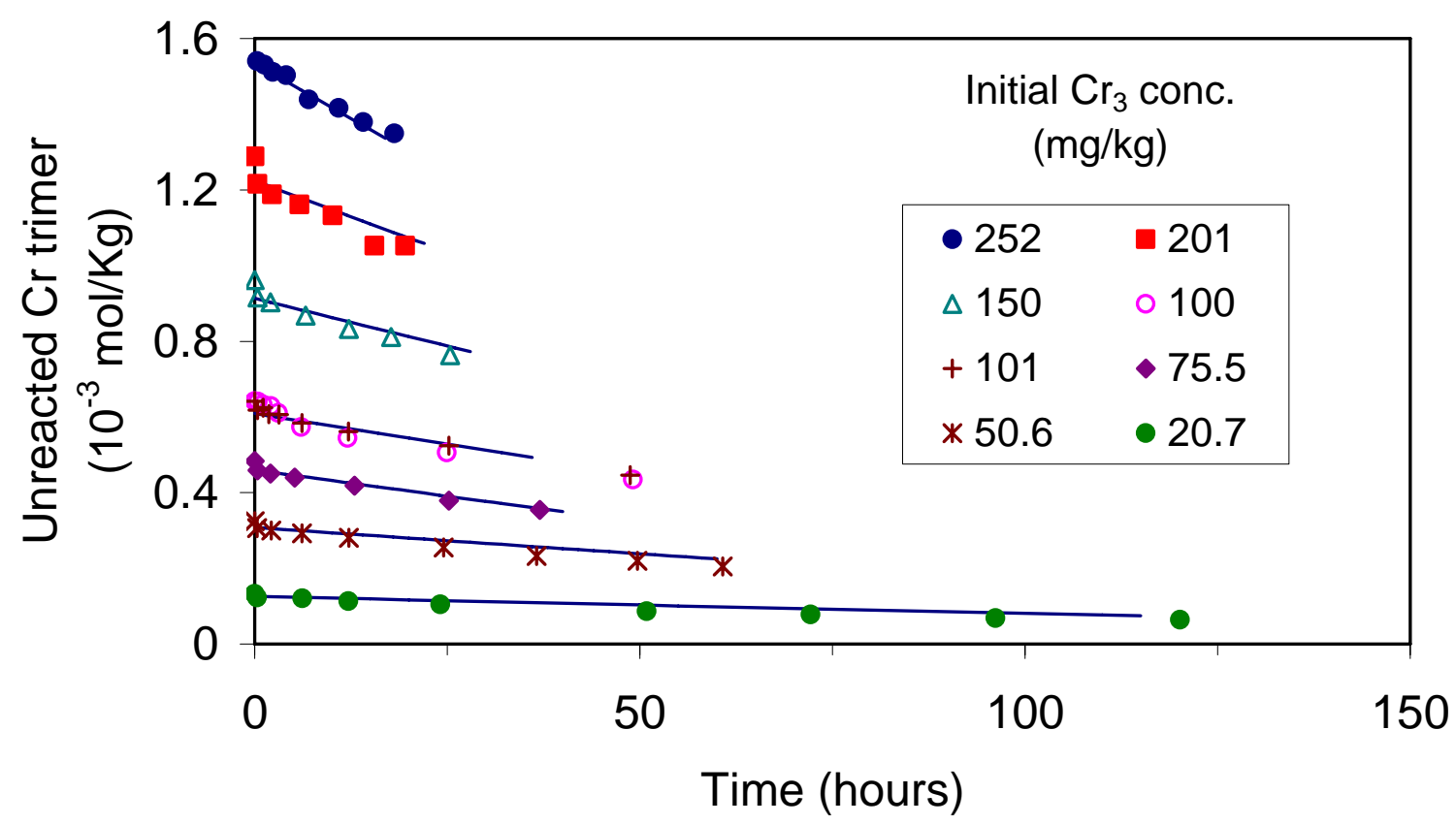

Figure 2.3 - Model I fit to the unreacted chromium trimer concentration[Jain, et al., 2004] as a function of time for different initial chromium concentrations; $5000 \mathrm{mg} / \mathrm{kg}$ polymer concentration.

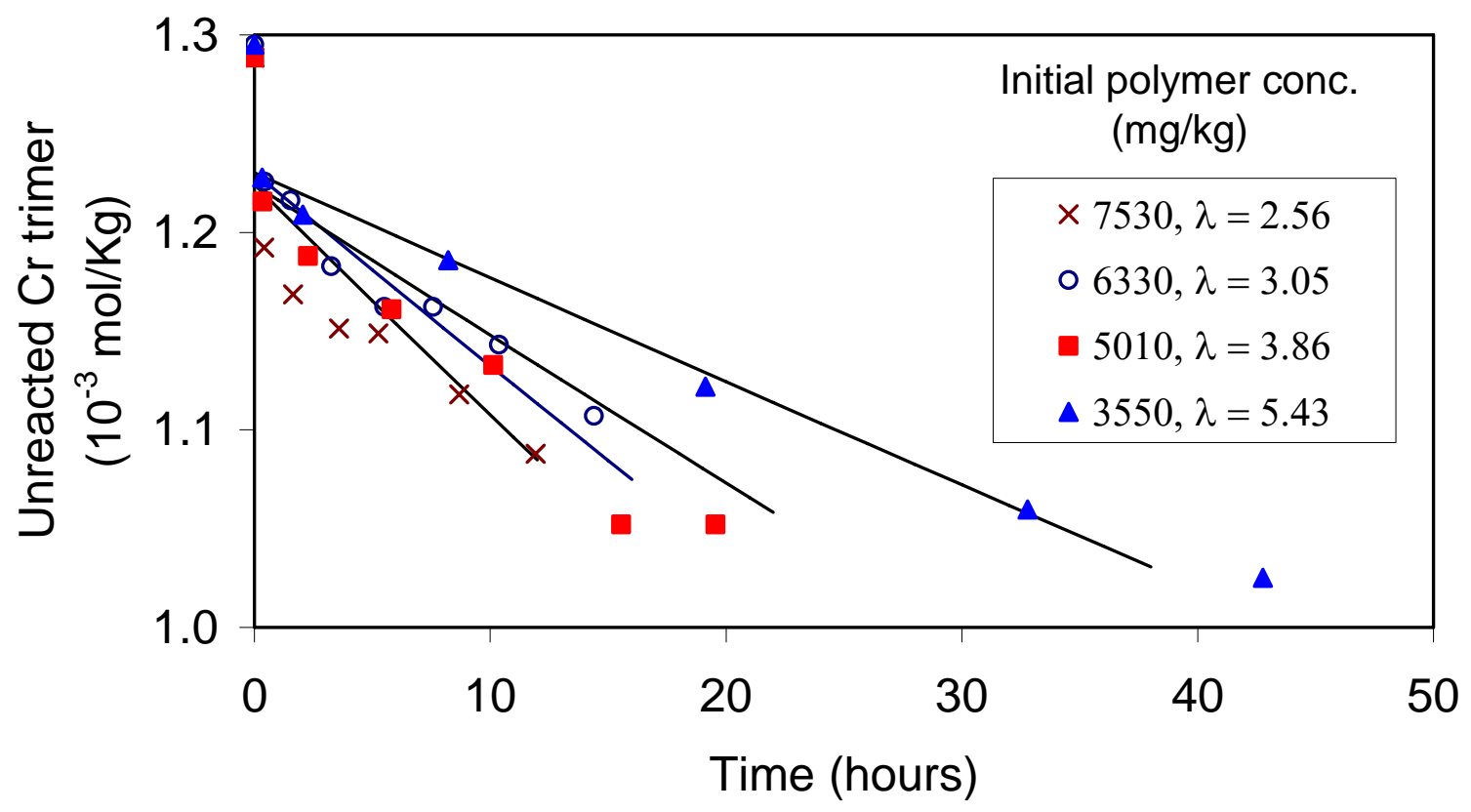

Figure 2.4 - Model I fit to the unreacted chromium trimer concentration[Jain, et al., 2004] as a function of time for different initial polymer concentrations; $200 \mathrm{mg} / \mathrm{kg}$ chromium concentration. 
- Concentration of chromium trimer, $c_{B}: 100 \mathrm{mg} / \mathrm{kg}$ (95 mg/kg in the calculation, a 95\% initial chromium concentration is used in the calculation to keep the consistency with the kinetic study [Jain, et al., 2004]).

This gel system is the same with that presented in previous annual report [Willhite, et al., 2004]. The weight-average molecular weights of pre-gel aggregates were measured as a function of reaction time by a multi-angle laser light scattering (MALLS) instrument [Willhite, et al., 2002]. Experimental and calculated weight-average molecular weights of the pre-gel aggregates are plotted in Figure 2.5. The calculated weight-average molecular weight of pre-gel aggregates fits reasonably well with the experimental data in the first 26 hours. After 26 hours, the model predicts a rapid increase in weight-average molecular weight, but the experiment results didn't show such a tendency. The MALLS measurements were terminated at the experimental gel time (determined by viscosity measurements) due to large uncertainty of the results. Large uncertainties in the experimental data are consistent with the presence of very large molecules which would translate to increased values of the weight-average molecular weight.

Viscosity as a function of time for the same gel system is also shown in Figure 2.5. The calculated and experimental gel times are 36 hours and 31 hours, respectively. The development of the viscosity and the weight-average molecular weight are similar, increasing slowly in the initial stage, then increasing sharply near the gel time. During the gelation process, the larger the molecules become, the higher their expectancy for participation in further crosslinking by virtue of their high functionalities. That is, larger pre-gel aggregates are increasing in size faster than the small aggregates since the larger aggregates have more reactive sites. The rapid development and growth of large molecules as the gel time is approached results in an abrupt increase in the viscosity of the gelant (Note the log scale for viscosity in the figure). A relationship between viscosity and the weight-average molecular weight may provide a method to explain the viscosity behavior of gel system quantitatively in future work.

In Figure 2.6, the molecular weight (or degree of polymerization) distributions of the pre-gel aggregates calculated by Model II are shown as a function of conversion and time. The left axis goes with the bottom axis; the top axis goes with the right axis in Figure 2.6. The differential weight-fraction $w(\alpha, x)$ as functions of the degree of polymerization, $x$, and molecular weight, $x M_{0}\left(M_{0}\right.$ is the molecular weight of the monomer), at different reaction times are plotted. With increasing times, the weight fraction of "short" chains $\left(x<1.5 \times 10^{5}\right)$ decreases, while the weight fraction of the "mid-length" chains $\left(x=1.5 \times 10^{5}-4 \times 10^{5}\right)$ increases initially and then decreases, and the weight fraction of "long" chains $\left(x>4 \times 10^{5}\right)$ increases continually. Numerical values of selected fractions of chains are given in Table 2.2. The difference between one and the sum given in Table 2.2 indicates the weight fraction of chains with a degree of polymerization greater than $5 \times 10^{5}$. The model predicts a long "tail" of crosslinked molecules with high molecular weight. Further experiments are needed to validate the model. Experimental work is underway to determine the molecular weight and size distributions of pre-gel aggregates using a fractionator (separation of sample) with laser light scattering and refractive index detectors (measurement of molecular weight and size). 


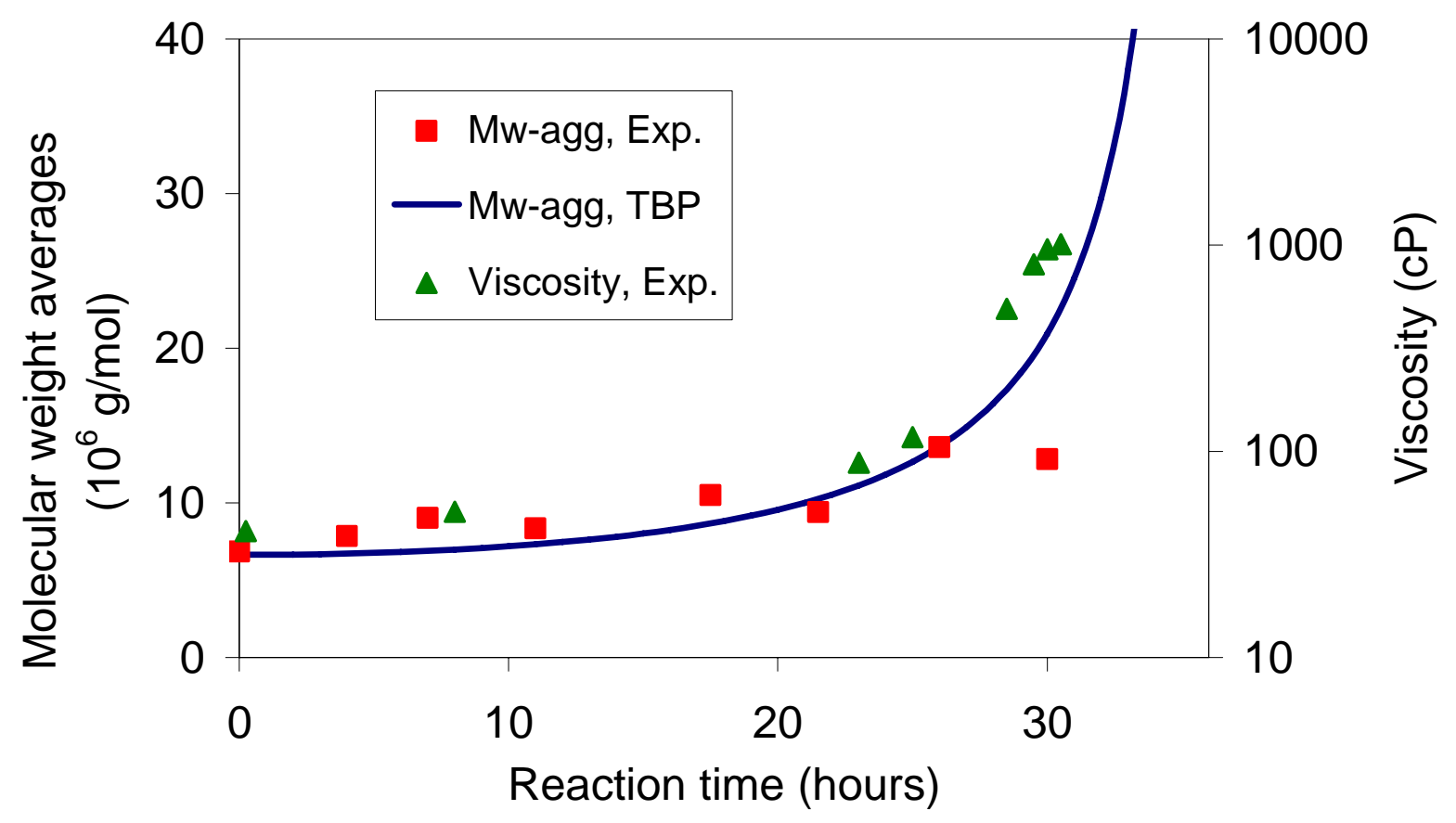

Figure 2.5 - Comparison of the calculated values (Model I) and the experimental data [Willhite, et al., 2002] of the molecular weight averages of pre-gel aggregates.

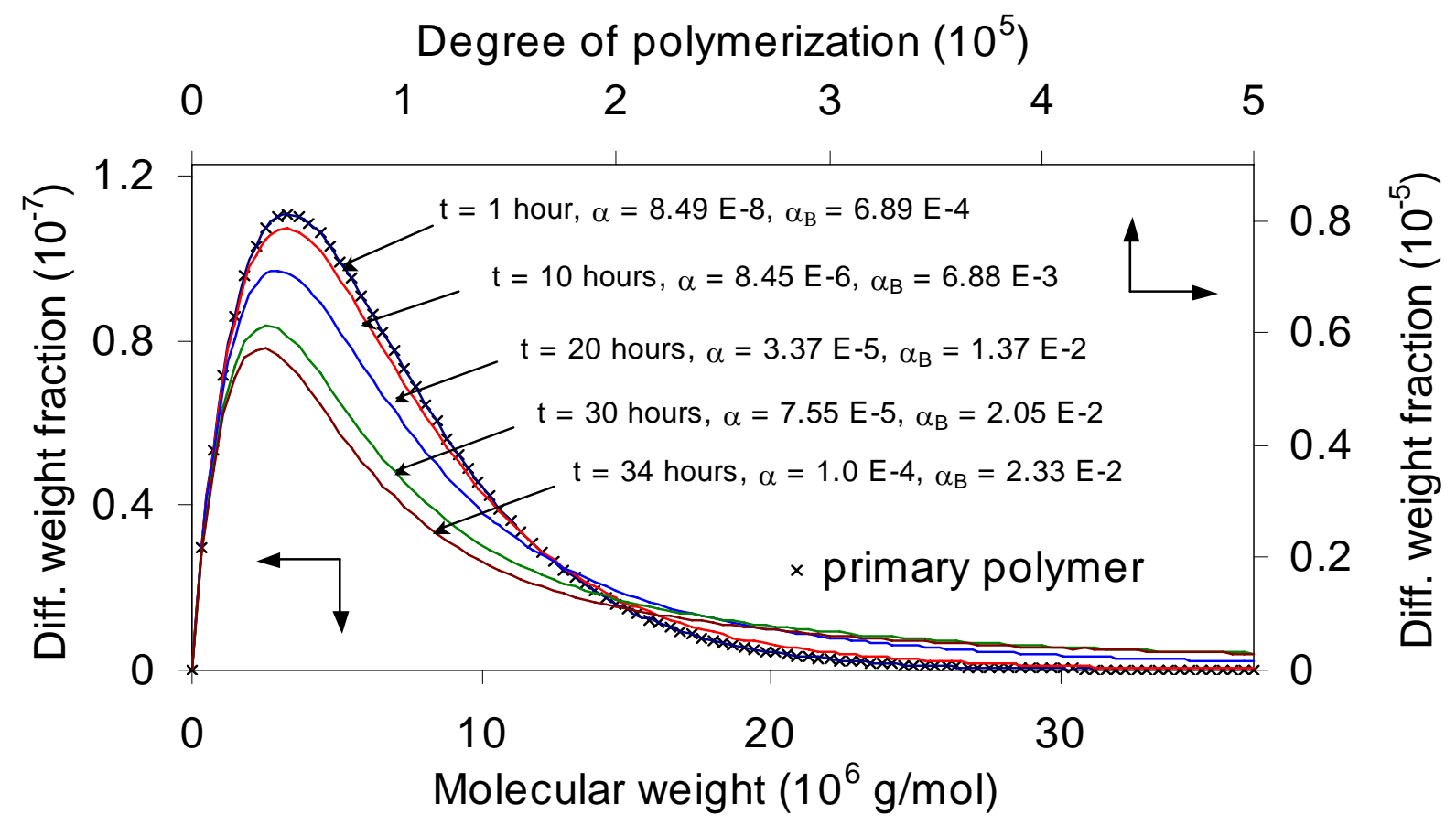

Figure 2.6 - Molecular weight distributions of pre-gel aggregates as functions of time and conversion (Model II). 
Table 2.2 - Differential weight fraction distributions of pre-gel aggregates at different reaction times calculated by Model II. $5000 \mathrm{mg} / \mathrm{kg}$ polymer concentration and $100 \mathrm{mg} / \mathrm{kg}$ chromium concentration, $25^{\circ} \mathrm{C}$.

\begin{tabular}{|c|c|c|c|c|c|c|c|}
\hline \multirow{3}{*}{$\begin{array}{c}\text { Degree of } \\
\text { polymerization } \\
\left(10^{5}\right)\end{array}$} & \multirow{3}{*}{$\begin{array}{c}\text { Molecular } \\
\text { weight } \\
\left(10^{6} \mathrm{~g} / \mathrm{mol}\right)\end{array}$} & \multicolumn{6}{|c|}{ weight fraction distribution } \\
\hline & & \multirow[t]{2}{*}{ polymer } & \multicolumn{5}{|c|}{ time (hours) } \\
\hline & & & 1 & 10 & 20 & 30 & 34 \\
\hline$<0.5$ & $0 \sim 3.67$ & 0.303 & 0.303 & 0.295 & 0.274 & 0.244 & 0.231 \\
\hline $0.5 \sim 1.0$ & $3.7 \sim 7.3$ & 0.345 & 0.345 & 0.329 & 0.286 & 0.226 & 0.200 \\
\hline $1.0 \sim 1.5$ & $7.3 \sim 11.0$ & 0.195 & 0.195 & 0.188 & 0.165 & 0.128 & 0.111 \\
\hline $1.5 \sim 2.0$ & $11.0 \sim 14.7$ & 0.092 & 0.092 & 0.094 & 0.093 & 0.079 & 0.069 \\
\hline $2.0 \sim 2.5$ & $14.7 \sim 18.3$ & 0.039 & 0.039 & 0.046 & 0.056 & 0.054 & 0.048 \\
\hline $2.5 \sim 3.0$ & $18.3 \sim 22.0$ & 0.016 & 0.016 & 0.023 & 0.036 & 0.039 & 0.036 \\
\hline $3.0 \sim 3.5$ & $22.0 \sim 25.7$ & 0.006 & 0.006 & 0.011 & 0.024 & 0.030 & 0.028 \\
\hline $3.5 \sim 4.0$ & $25.7 \sim 29.3$ & 0.002 & 0.002 & 0.006 & 0.017 & 0.024 & 0.023 \\
\hline $4.0 \sim 4.5$ & $29.3 \sim 33.0$ & 0.001 & 0.001 & 0.003 & 0.012 & 0.019 & 0.019 \\
\hline $4.5 \sim 5.0$ & $33.0 \sim 36.7$ & 0.000 & 0.000 & 0.002 & 0.009 & 0.016 & 0.016 \\
\hline$>5.0$ & $>36.7$ & 0.000 & 0.000 & 0.004 & 0.029 & 0.141 & 0.220 \\
\hline \multicolumn{2}{|c|}{$\begin{array}{l}\text { weight-average molecular weight } \\
\qquad\left(10^{6} \mathrm{~g} / \mathrm{mol}\right) \rightarrow\end{array}$} & 6.64 & 6.65 & 7.19 & 9.56 & 20.9 & 53.4 \\
\hline
\end{tabular}

\section{Conclusions}

1. Two TBP models were developed to calculate the critical conversions of functional groups at the gel point and molecular weight averages and distributions of pre-gel aggregates as functions of conversion.

2. A relationship between the conversion of chromium functional groups and the reaction time was developed based on a previous kinetic study of the chromium-polymer uptake reaction for a polyacrylamide-chromium(III) acetate gel system [Jain, et al., 2004].

3. The calculated weight-average molecular weights of pre-gel aggregates as a function of reaction time agree with the experimental data determined using a multi-angle laser light scattering technique. The development of viscosity shows a similar tendency with the calculated weight-average molecular weight.

4. The calculated molecular weight distributions of pre-gel aggregates predict a long "tail” of crosslinked molecules with high molecular weight with increasing reaction time.

\section{Nomenclature}

$a, b \quad-\quad$ Reaction orders with respect to carboxylate group and chromium functional group

$b_{i} \quad-\quad$ Number or weight fractions of chromium trimers which have $i$ reacted functional groups, respectively. $i=0,2$

$c_{A}, c_{B} \quad-\quad$ Initial mass concentrations of polymer and chromium trimer, respectively

$f_{B} \quad-$ Functionalities of chromium trimer, $f_{B}=2$

$n_{A}, n_{B} \quad-$ Initial number fractions of polymer and chromium trimer, respectively.

$k \quad-\quad$ Reaction rate constant at $25^{\circ} \mathrm{C}, k=98.46 \mathrm{~h}^{-1}(\mathrm{~mol} / \mathrm{kg})^{-2.30}$

$r_{A} \quad-$ The initial molar ratio of carboxylate groups to chromium functional groups.

$t \quad-\quad$ Reaction time in hours 


$$
\begin{aligned}
& w_{A}, w_{B} \quad-\text { Initial weight fractions of polymer and chromium trimer, respectively. } \\
& w(0, x) \quad-\text { Initial weight fraction distribution (primary chain distribution) at } \alpha=0 \\
& w(\alpha, x) \quad \text { - Weight fraction distribution at conversion } \alpha \\
& x \quad-\quad \text { Degree of polymerization of an } \mathrm{x} \text {-mer } \\
& x_{A} \quad-\text { Degree of hydrolysis of primary polymer, assuming } x_{A}=10 \% \\
& C_{A f} \quad-\quad \text { Concentration of carboxylate group on polymer in mol } / \mathrm{kg} \text {. } \\
& C_{A f 0} \quad-\text { Initial concentration of carboxylate group on polymer in } \mathrm{mol} / \mathrm{kg} \text {. } \\
& C_{B 0} \quad-\quad \text { Initial chromium trimer concentration in } \mathrm{mol} / \mathrm{kg} \text {. } \\
& C_{B f} \quad-\text { Concentration of chromium trimer functional group in } \mathrm{mol} / \mathrm{kg} \text {. } \\
& C_{B f 0} \quad-\quad \text { Initial concentration of chromium trimer functional group in } \mathrm{mol} / \mathrm{kg} \\
& M_{0} \quad \text { - Molecular weight of the monomer } \\
& M_{B} \quad-\quad \text { Molecular weight of the chromium trimer } \\
& M_{n 0} \quad \text { - Number-average molecular weight of the primary polymer } \\
& M_{n-a g g} \quad \text { - Number-average molecular weight of pre-gel aggregates } \\
& M_{w 0} \quad \text { - Weight-average molecular weight of the primary polymer } \\
& M_{w} \quad \text { - Weight-average molecular weight of the entire gel system } \\
& M_{\text {w-agg }} \quad \text { - Weight-average molecular weight of pre-gel aggregates } \\
& P I \quad-\text { Polydispersity index PI }=\mathrm{P}_{\mathrm{w} 0} / \mathrm{P}_{\mathrm{n} 0}=\mathrm{M}_{\mathrm{w} 0} / \mathrm{M}_{\mathrm{n} 0} \\
& P_{n 0} \quad-\quad \text { Number-average degree of polymerization of the primary polymer } \\
& P_{w 0} \quad-\quad \text { Weight-average degree of polymerization of the primary polymer } \\
& \alpha \quad-\quad \text { Conversions of carboxylate groups on polymer in Model II } \\
& \alpha_{c r i t}-\text { Critical conversions of carboxylate groups on polymer at gel point in } \\
& \alpha_{A}, \alpha_{B}-\text { Conversions of carboxylate groups on polymer and chromium functional } \\
& \text { groups, respectively, in Model I } \\
& \alpha_{c r i t, A}-\text { Critical conversions of carboxylate groups on polymer and chromium } \\
& \alpha_{c r i t, B} \quad \text { functional groups at gel point, respectively, in Model I } \\
& \lambda-\text { - An empirical parameter representing the effect of intra-molecular } \\
& \text { crosslinking. } \\
& \sigma \quad-\text { A parameter related to polydispersity index, } \mathrm{PI}=(\sigma+1) / \sigma
\end{aligned}
$$

\section{References}

1. Bryant, S. L., Borghi, G. P., Bartosek, M. and Lockhart, T. P.: "Experimental Investigation on the Injectivity of Phenol-Formaldehyde/Polymer Gelants," paper SPE 37244 presented at the 1997 SPE International Symposium on Oilfield Chemistry, Houston, Texas, 18-21 Feb., 1997.

2. Dusek, K.: "Formation-Structure Relationships in Polymer Networks", Br. Polym. J., 17(1985), 185-189.

3. Dusek, K.: "Network Formation in Curing of Epoxy Resins", Adv. Polym. Sci., (1986) 78, 1-57.

4. Dusek, K.: "Network Formation Involving Polyfunctionl Polymer Chains", Chapter 3 of Polymer Networks: Principles of Their Formation Structure and Properties, editor: R. F. T. Stepto, Thomson Science, London (1998). 
5. Dusek K. and Duskova-Smrckova, M.: Crosslinking and Polymer Networks, DTW Associates Course (2002).

6. Huybrechts, J. and Dusek, K.: "Star Oligomers with Different Reactivity in Low VOC Polyurethane Coatings: Part III”, Surface Coating International, (1998) 5, 234-239.

7. Jain, R., McCool, C.S., Green, D.W., Willhite, G. P., and Michnick, M.J.: "Reaction Kinetics of the Uptake of Chromium(III) Acetate by Polyacrylamide”, SPE 89399, presented at the 2004 SPE/DOE Fourteenth Symposium on Improved Oil Recovery, Tulsa, Oklahoma, U.S.A, 17-21 April 2004.

8. McCool, C.S., Green, D.W. and Willhite, G. P.: "Permeability Reduction Mechanisms Involved in In-Situ Gelation of a Polyacrylamide/ Chromium (VI)/Thiourea System," SPE 17333, SPE Reservoir Engineering (Feb.1991), 77-83.

9. Vojta, V. and Dusek, K.: "Calculation of the Molecular Weight Distribution of Crosslinked Polymer Chains Using the Theory of Branching Processes”, Br. Polym. J., (1980) 12, 1-4.

10. Willhite, G. P., Green, D.W. and McCool, C.S.: "Increased Oil Recovery from Mature Oil Fields using Gelled Polymer Treatments,” Annual Report for June 1999 - June 2002, Report No. 99BC15209-5, Contract No. DE-AC26-99BC15209, US DOE, Washington, DC (Dec 2002).

11. Willhite, G. P., Green, D.W. and McCool, C.S.: "Development of Polymer Gel Systems to Improve Volumetric Sweep and Reduce Producing Water/Oil Ratios” Annual Report for July 2003 - June 2004, Report No. 02NT15363-4, Contract No. DE-FC26-02NT15363, US DOE, Washington, DC (Dec 2004). 


\title{
Chapter 3
}

\section{Measurement of Molecular Weight and Size Distributions of Polymers and Pre-Gel Aggregates Using an SEC-MALLS-RI Apparatus}

\author{
Graduate Research Assistant: Min Cheng
}

\section{Introduction}

In Chapter 2, a model was presented to estimate the bulk gel time of a gel system, and to calculate the molecular weight averages and distributions of pre-gel aggregates as functions of reaction time and initial conditions (concentrations of polymer and crosslinker, molecular weight and degree of hydrolysis of the polymer, etc). The calculated weight-average molecular weights of pre-gel aggregates as a function of reaction time agreed with the experimental data determined using a multi-angle laser light scattering technique [Willhite et al., 2002]. The model also predicted a decreasing weight fraction of small molecules and an increasing weight fraction of big molecules, i.e., a long "tail” of crosslinked polymer molecules with high molecular weights. Experimental data are required to validate the model results.

The objective of this work was to develop methods to measure the molecular weight and size distributions of pre-gel aggregates as a function of reaction time. An experimental apparatus composed of a size exclusion chromatography (SEC) column, a multi-angle laser light scattering (MALLS) detector and a refractive index (RI) detector was developed to measure the absolute molecular weight and root mean square (rms) radius distributions of polymers. Experimental challenges hindered the progress in achieving the same type of data for the pre-gel aggregates. Further work is required to evaluate the use of a flow field-flow fractionator (FFFF) for the separation of pre-gel aggregates.

\section{Experimental Equipment and Procedures}

Polymers and Gel System. Bovine serum albumin (BSA, A-1900, Sigma Chemical Co., St. Louis, MO), which contained 98\% BSA monomer, was used to determine the inter-detector delay volume. Three polyacrylamide samples were tested. One was a polyacrylamide standard, paam6000K (PSS-USA Inc., Warwick, RI). The others were polyacrylamide Alcoflood 935, Lots $7158 \mathrm{~V}$ and A2247 BOV. The number- and weight-average molecular weights, $M_{n 0}$ and $M_{w 0}$, and the z-average rms radius, $R_{z}$, of these samples are listed in Table 3.1.

The gel system consisted of $5000 \mathrm{mg} / \mathrm{kg}$ polyacrylamide Alcoflood 935 (Lot A2247BOV) and $100 \mathrm{mg} / \mathrm{kg}$ chromium(III) at a temperature of $25^{\circ} \mathrm{C}$. The solvent used to prepare polymer and chromium stock solution was a $1 \% \mathrm{KCl}, 0.01 \%$ sodium azide $(\mathrm{w} / \mathrm{w})$ aqueous solution filtrated through a $0.02 \mu \mathrm{m}$ membrane. The solvent was also used as the mobile phase (carrier solvent) in the measurement of the molecular weight and size distributions. A $6667 \mathrm{mg} / \mathrm{kg}$ polymer stock solution was prepared and filtrated through a $1 \mu \mathrm{m}$ screen filter. A $400 \mathrm{mg} / \mathrm{kg}$ chromium stock solution was diluted from an aqueous solution of 50\% chromium(III) acetate (McGean-Rohco, Inc., Lot 40086816). The chromium stock solution was prepared and filtrated through a $0.02 \mu \mathrm{m}$ filter immediately before mixing with the polymer stock. Then the polymer and chromium stock 
Table 3.1 - Molecular weight and size averages of samples.

\begin{tabular}{lcccl}
\hline & $\begin{array}{c}\boldsymbol{M}_{\boldsymbol{n} \mathbf{0}} \\
(\mathrm{g} / \mathrm{mol})\end{array}$ & $\begin{array}{c}\boldsymbol{M}_{\boldsymbol{w} \mathbf{0}} \\
(\mathrm{g} / \mathrm{mol})\end{array}$ & $\begin{array}{c}\boldsymbol{R}_{\mathbf{z}} \\
(\mathrm{nm})\end{array}$ & \\
\hline BSA monomer & $6.67 \times 10^{4}$ & $6.67 \times 10^{4}$ & $<10$ & From Wyatt Tech. Corp. \\
\hline paam6000K & $2.46 \times 10^{6}$ & $5.55 \times 10^{6}$ & $/$ & Cited value (PSS-USA Inc.) \\
\hline $\begin{array}{l}\text { AlcoFlood 935, } \\
\text { Lot 7158V }\end{array}$ & $/$ & $5.26 \times 10^{6}$ & 181.7 & $\begin{array}{l}\text { Measured in batch mode } \\
\text { [Willhite et al.,2002] }\end{array}$ \\
$\begin{array}{l}\text { AlcoFlood 935, } \\
\text { Lot A2247BOV }\end{array}$ & $/$ & $6.64 \times 10^{6}$ & 216.8 & \\
\hline
\end{tabular}

solutions were mixed at the ratio of 3:1 on a weight basis to form a gelant with $5000 \mathrm{mg} / \mathrm{kg}$ polymer and $100 \mathrm{mg} / \mathrm{kg}$ chromium(III) concentrations. The acetate-to-chromium(III) molar ratio was 3.0. The gelant was kept at $25^{\circ} \mathrm{C}$ by a temperature-controlled water bath. The gel time of this gel system was 30 -31 hours as determined by the time the viscosity reached $1000 \mathrm{cp}$ by periodic viscosity measurements.

Equipment. Polymer molecules in a sample need to be separated according to their size (or molecular weights) in order to determine the distributions of molecular weight and size. In this work a Shodex SUGAR KS 807 column and its guard column KS 807G (JMScience Inc., Grand Island, NY) were used as a fractionator. The SUGAR KS 807 column is a newly released SEC column which is designed to separate the water-soluble polymers with ultra-high molecular weights. The KS 807 column has an internal diameter of $8 \mathrm{~mm}$ and a length of $30 \mathrm{~cm}$. The packing material is sulfonated polystyrene divinylbenzene copolymer with sulfo( $\left.\mathrm{Na}^{+}\right)$as the functional group. The particle size of the packing material is $30 \mu \mathrm{m}$ and the average pore size is $4000 \AA$. The theoretical plate number of a KS 807 analytical column should be $>4000$, and the exclusion limit is $200 \times 10^{6} \mathrm{~g} / \mathrm{mol}$ tested with pullulan. The temperature of the column oven was set at $30{ }^{\circ} \mathrm{C}$.

A DAWN EOS ${ }^{\mathrm{TM}}$ (Wyatt Technology Corporation, Santa Barbara, CA) detector was used to measure the absolute molecular weight distributions of polymers and the pre-gel aggregates. This instrument employs the multi-angle light scattering (MALLS) technique and the light scattering theory can be found elsewhere [Wyatt, 1993]. There are two operation modes: batch mode for measuring the weight-average molecular weight and z-average rms radius of unfractionated samples. This mode was employed in a previous study [Willhite, et al., 2002]; inline mode for measuring the molecular weight and size distributions of fractionated samples. This mode was used in this work. This MALLS detector does not have temperature control and was operated at room temperature (about $23^{\circ} \mathrm{C}$ ).

The mass detector used was an Optilab DSP (Wyatt Technology Corporation, Santa Barbara, $\mathrm{CA}$ ) interferometer (refractive index [RI] detector). The Optilab was operated offline to determine the refractive index increment $(\mathrm{dn} / \mathrm{dc})$ of the polymer, which was required to compute the concentration of the polymer from the RI signals. The Optilab was also operated inline with the SEC column and the MALLS detector for the measurement of the concentrations of fractionated polymer fractions. The cell temperature of the RI detector was set at $35{ }^{\circ} \mathrm{C}$ in order to stabilize the RI baseline. 
Procedures. A schematic of the SEC-MALLS-RI setup is shown in Figure 3.1. Mobile phase containing $1 \% \mathrm{KCl}$ and $0.01 \%$ sodium azide was degassed and pumped at a flow rate of 0.5 $\mathrm{mL} / \mathrm{min}$ from the solution reservoir through a digital pressure gauge, a $0.02 \mu \mathrm{m}$ inline filter and then through the sample injection valve, the SEC columns, MALLS and RI detectors sequentially. For the measurement of polyacrylamide samples, usually a $400 \mathrm{mg} / \mathrm{kg}$ polymer stock was prepared first then diluted to $200 \mathrm{mg} / \mathrm{kg}$ with the mobile phase. For the measurement of pre-gel aggregates, an aliquot was periodically removed from the gelant and diluted to 200 $\mathrm{mg} / \mathrm{kg}$ (polymer concentration) with mobile phase. The diluted sample was injected manually to load a $100 \mu \mathrm{L}$ sample loop and the sample was injected into the system and carried by the mobile phase through the column and detectors. Polydispersed polymer molecules were separated according to their sizes while passing through the SEC columns. The fractionated polymer then passed through the MALLS and RI detectors, and the corresponding signals were recorded and processed by ASTRA software (Wyatt Technology Corporation, Santa Barbara, CA) to give the molecular weight and size distributions.

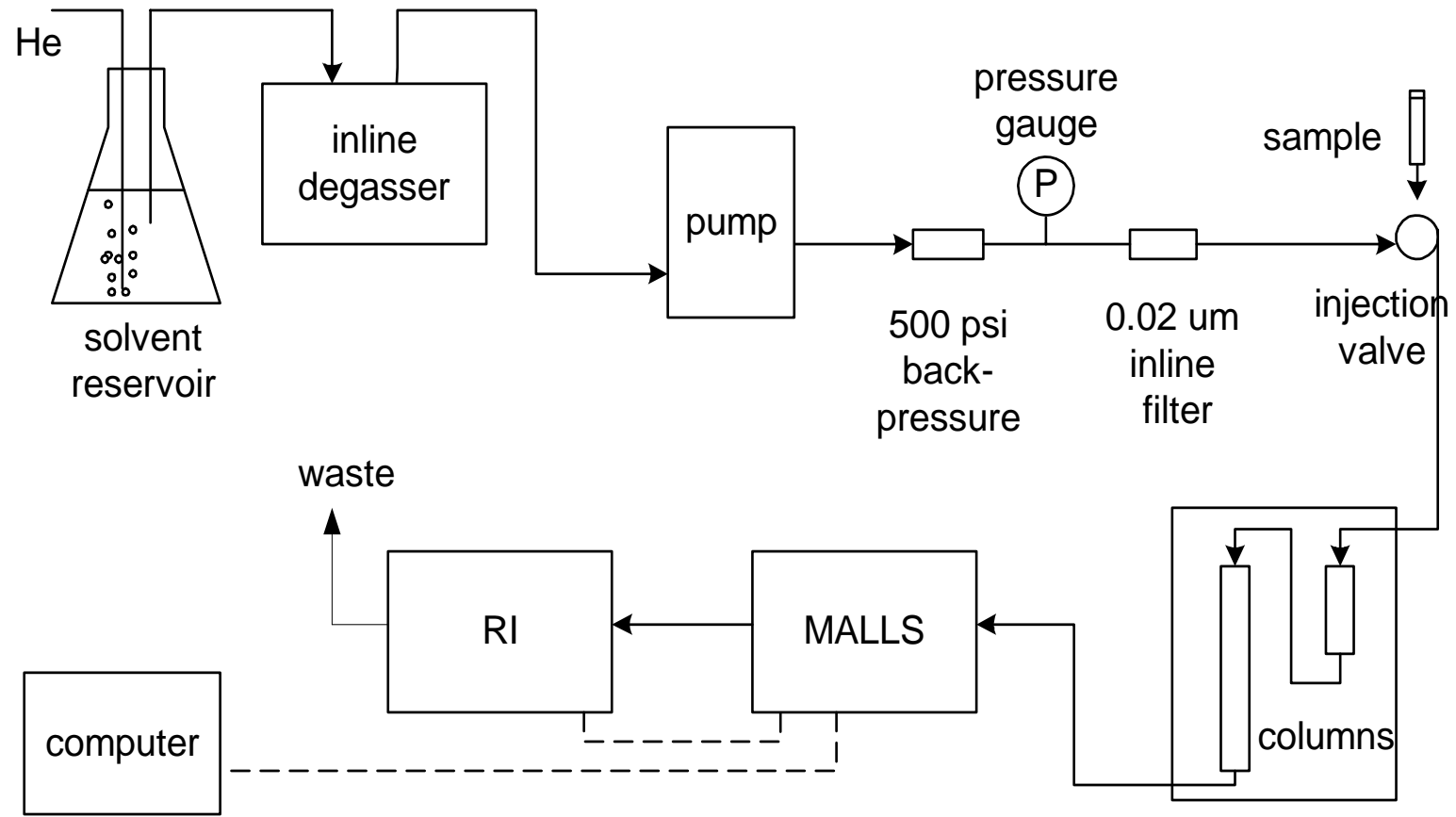

Figure 3.1 - Experimental schematic of a SEC-MALLS-RI Setup.

\section{Results and Discussion}

$\mathbf{d n} / \mathbf{d c}$ Measurements. The specific refractive index increment, dn/dc, is the change in the refractive index of a solution relative to the change of the solute (polymer) concentration. The $\mathrm{dn} / \mathrm{dc}$ value depends on the wavelength of the incident light, the polymer-solvent pair and the molecular weight of the polymer. Generally, the dn/dc value increases with increasing molecular weight up to a certain value and then is constant at higher values [DAWN Course Manual, 1998]. The molecular weights of the polymers in this study are high and the dn/dc can be considered constant. Table 3.2 shows the $\mathrm{dn} / \mathrm{dc}$ values of the samples used in this work. The $\mathrm{dn} / \mathrm{dc}$ values are close for three polyacrylamide samples with weight-average molecular weights of about 5 $6 \times 10^{6} \mathrm{~g} / \mathrm{mol}$. 
Table 3.2 - Dn/dc of samples $\left(25^{\circ} \mathrm{C}\right.$; wavelength - $690 \mathrm{~nm}$; in $1 \% \mathrm{KCl}, 0.01 \% \mathrm{NaN}_{3}$ solution).

\begin{tabular}{lcl}
\hline & dn/dc (mL/g) & \\
\hline BSA & 0.185 & From Wyatt Tech. Corp. \\
paam6000K & 0.178 & [Wang, 2003] \\
AlcoFlood 935, Lot 7158V & 0.182 & [Wang, 2003] \\
AlcoFlood 935, Lot A2247BOV & 0.179 & this work \\
\hline
\end{tabular}

The dn/dc values of the pre-gel aggregates were measured and are shown in Figure 3.2 as a function of reaction time. The dn/dc value of the gelant is a bit higher than that of the polymer, probably due to the presence of chromium(III) acetate in the solvent. The $\mathrm{dn} / \mathrm{dc}$ values are constant up to 10 hours and then increase gradually.

Inter-detector Delay Volume. The delay volume between the MALLS and RI detectors is required in order to match the two measurements for the same fractionated polymer sample. This was accomplished by running a monodispersed standard (polydispersity index $<1.05$ ) of known molecular weight and with a known dn/dc value. A monodispersed BSA sample that contained $98 \%$ monomer, a molecular weight of $6.67 \times 10^{4} \mathrm{~g} / \mathrm{mol}$ and a dn/dc value of $0.185 \mathrm{~mL} / \mathrm{g}$ was used. Retention of BSA on the column was significant so the run was conducted with only the guard column to achieve a clear sample peak. Figure 3.3 shows the chromatogram for a BSA run. The MALLS peak is on the left side (lower elution time) of the RI peak due to the inter-detector volume. The peak maximum of the light scattering signal was aligned accurately with the peak maximum of the RI signal using an inter-detector delay volume of $0.148 \mathrm{~mL}$ as shown in Figure 3.4 .

The BSA run was analyzed by the processing software ASTRA. The parameters used were: Debye plot, Zimm formalism, 4-18 detectors, detector fit degree $=1$, result fit degree $=1$. In Figure 3.5, the RI signal and molecular weight are plotted as a function of elution time. The RI signal represents the mass eluted. The measured molecular weight is almost a flat horizontal line (the solid line represents the fitted data) indicating a monodispersed sample. The small curvatures at the ends of the molecular weight curve are due to band broadening caused by the delay volume between the detectors. The calculated number- and weight-average molecular weights were $6.701 \times 10^{4}$ and $6.702 \times 10^{4} \mathrm{~g} / \mathrm{mol}$, respectively, very close to the cited value. The measured polydispersity index was $1.000 \pm 0.003$. The molecular weight distribution of BSA is shown in the Figure 3.6. The distribution is very sharp indicating the monodispersity of the BSA sample. The measured size distribution is unreliable for the BSA sample since BSA is smaller than the MALLS detector can measure which is about $10 \mathrm{~nm}$.

\section{Molecular Weight and Size Distributions of Polymers}

Polyacrylamide Standard. A polyacrylamide standard, paam6000K (PSS-USA Inc., Warwick, $\mathrm{RI}$ ), was used to test the system using a high molecular weight polymer. Sample retention was also observed for this and other polymers. No sample peak appeared in the first 5-6 injections. Then the sample recovery or the area under the RI sample peak increased with successive injections. After about 15-20 injections, a stable RI sample peak was obtained. 


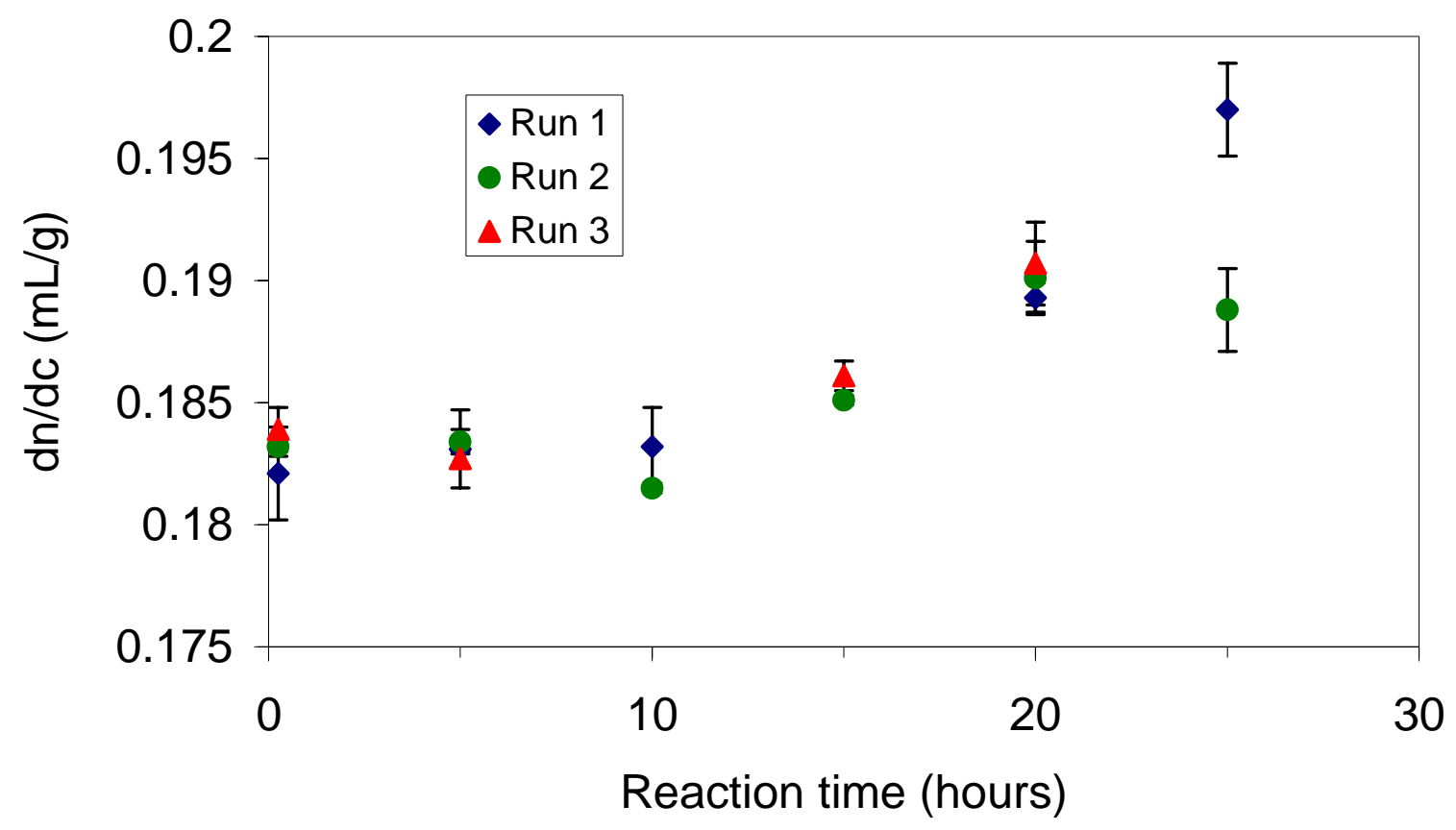

Figure $3.2-$ dn/dc values of the gelant as a function of reaction time.
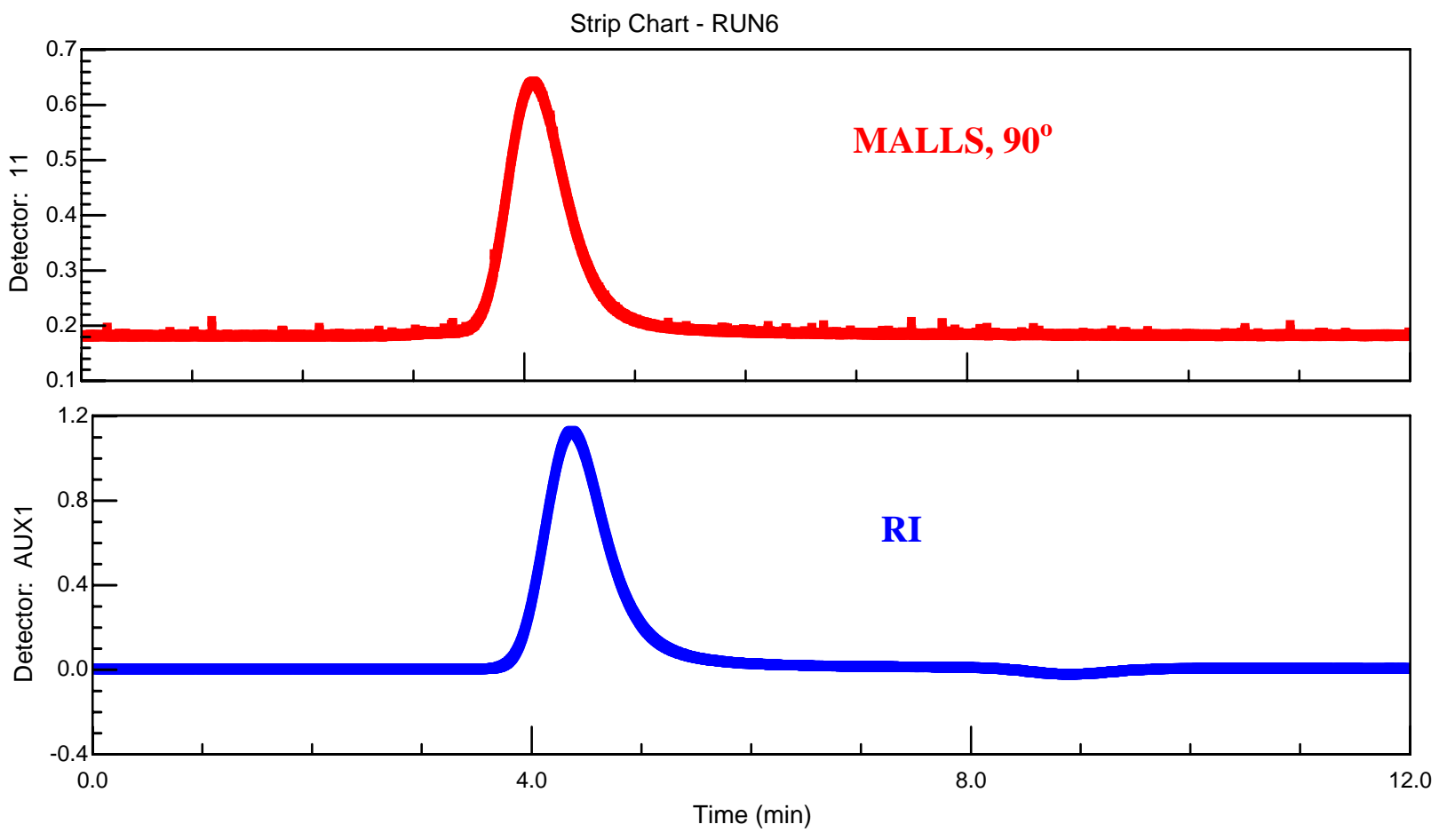

Figure 3.3 - Chromatograms for a monodispersed BSA run $(1000 \mathrm{mg} / \mathrm{kg}, 100 \mu \mathrm{L})$. 


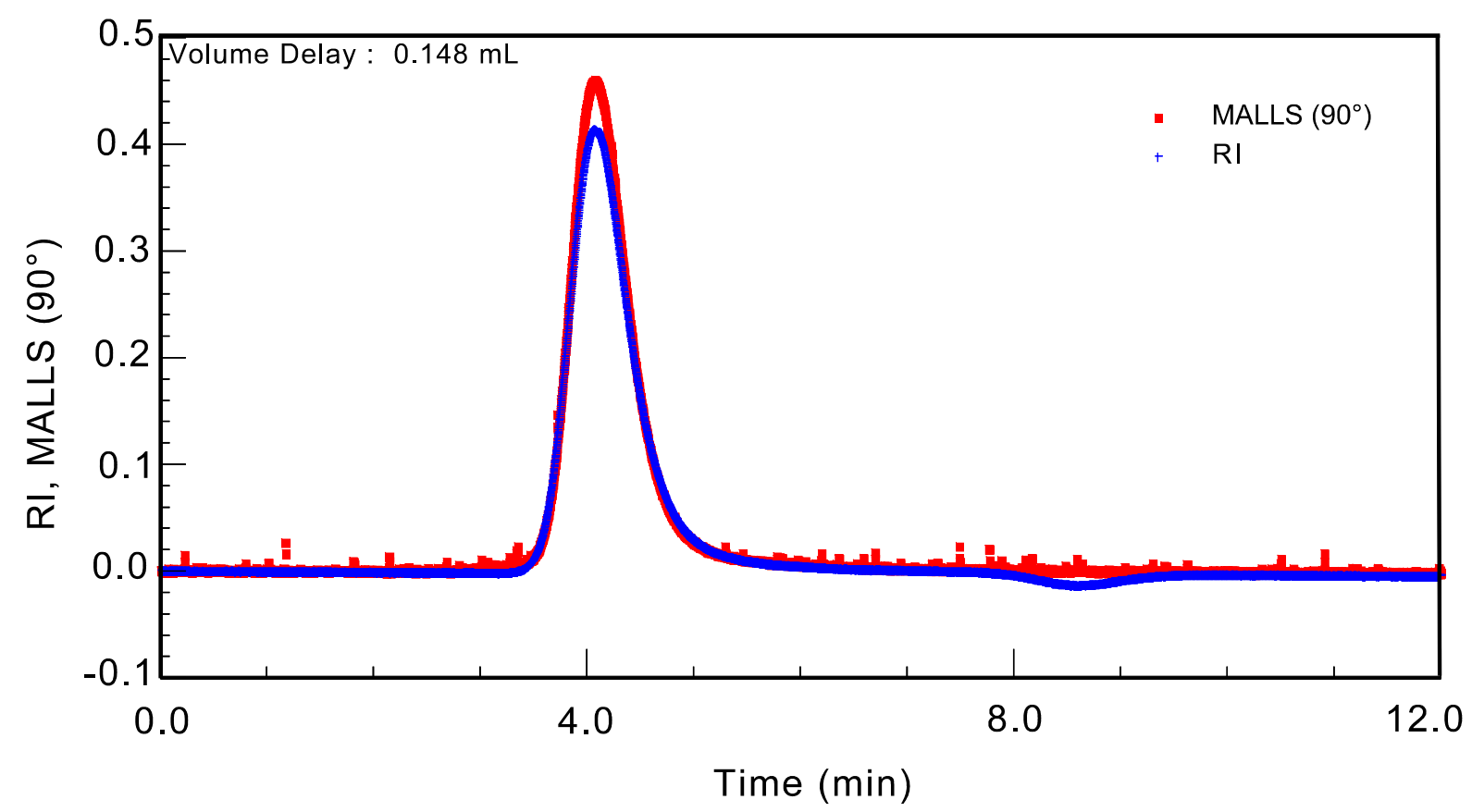

Figure 3.4 - MALLS and RI signals aligned for a monodispersed BSA run.

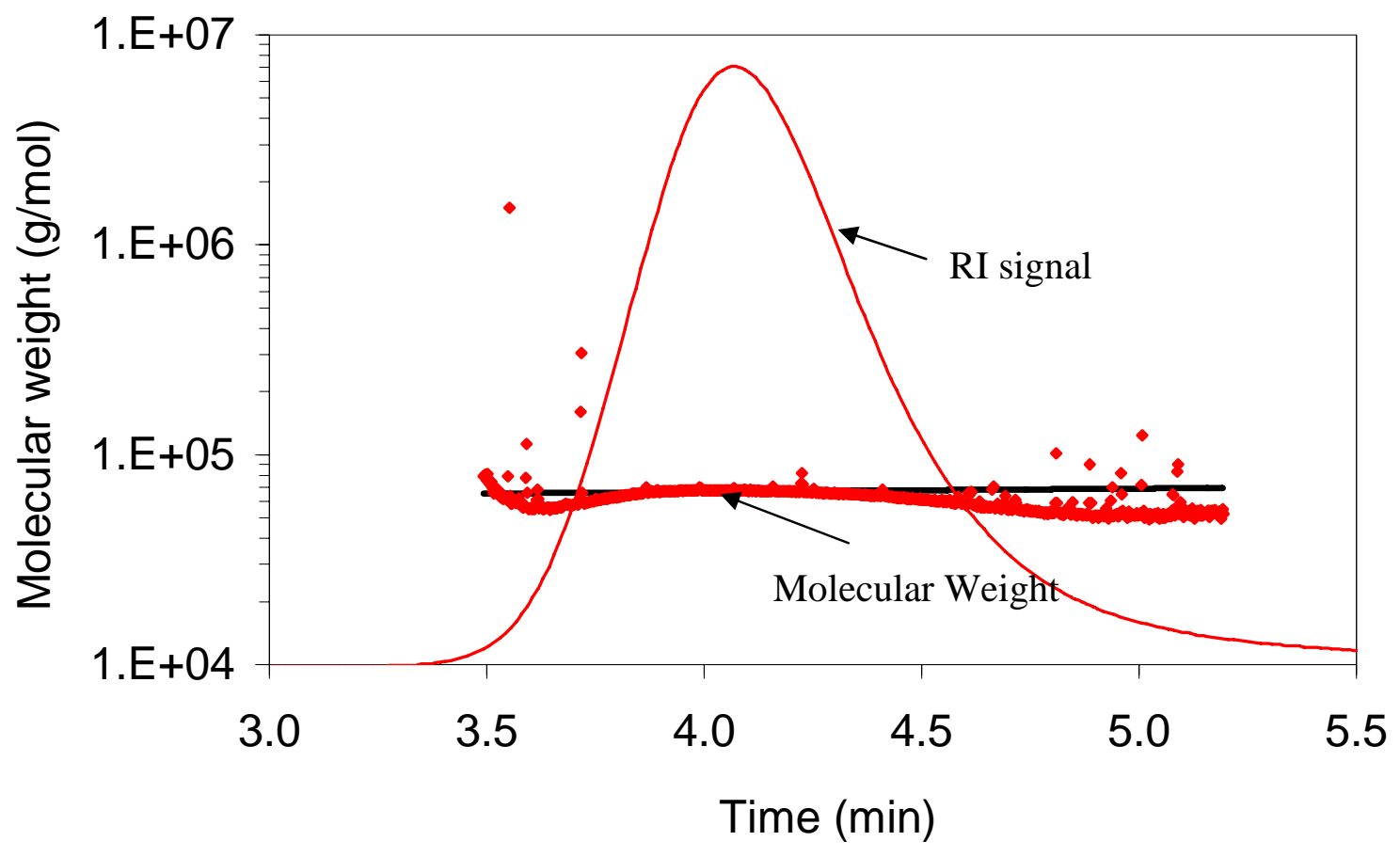

Figure 3.5 - Molecular weight versus elution time for a BSA run. 


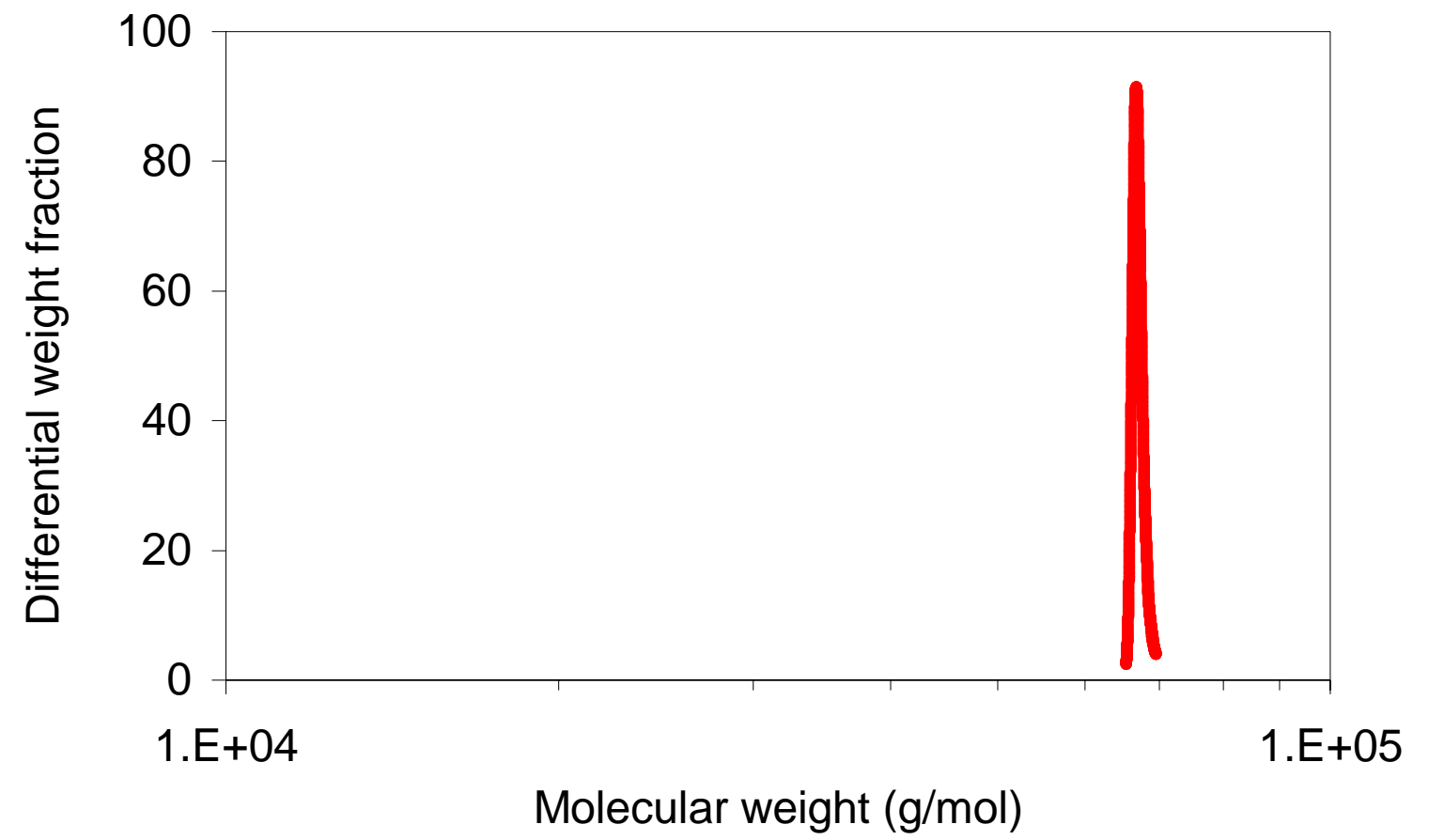

Figure 3.6 - Differential molecular weight distribution of BSA.

The chromatogram for paam6000K is shown in Figure 3.7. There are two RI peaks and one MALLS peak. The second RI peak is negative and occurred near the end of the data collection. This peak is called a "salt peak" or a "solvent peak" and it appears at the total inclusion volume of the column. The RI detector is very sensitive to small changes in the inorganic salt content of the liquids and it is difficult to match the same salt content in the injected sample as in the mobile phase. The salt peak can be positive or negative. The salt peak overlapped a small portion of the polymer peak. During data processing, a small amount of the smaller sized polymer is excluded which also affects sample recovery calculation. The average sample recovery for the paam $6000 \mathrm{~K}$ was $77 \%$ after the columns were saturated.

The ASTRA processing parameters for paam6000K are the same with those for BSA: Debye plot, Zimm formalism, 4-18 detectors, detector fit degree $=1$, result fit degree $=1$. The measured number-average molecular weight $\left(M_{n 0}\right)$ was $2.47 \times 10^{6} \mathrm{~g} / \mathrm{mol}(2.4 \%)$, the weight-average molecular weight $\left(M_{w 0}\right)$ was $4.83 \times 10^{6} \mathrm{~g} / \mathrm{mol}(1.3 \%)$ and the z-average rms radius was 194.8 $\mathrm{nm}(1.1 \%)$. The value in parenthesis designates the relative standard deviation. The measured molecular weights were close to the cited values given in Table 3.1.

The measured molecular weight as a function of elution time and the molecular weight distributions of seven runs are shown in Figures 3.8 and 3.9. The corresponding graphs for the rms radius are shown in Figures 3.10 and 3.11. These results show the elution progression from big molecules with higher molecular weight and larger size through successively smaller molecules. The molecular weight of paam6000K ranges from $\sim 0.5 \times 10^{6} \mathrm{~g} / \mathrm{mol}$ to $15 \times 10^{6}$ 
Strip Chart - RUN23
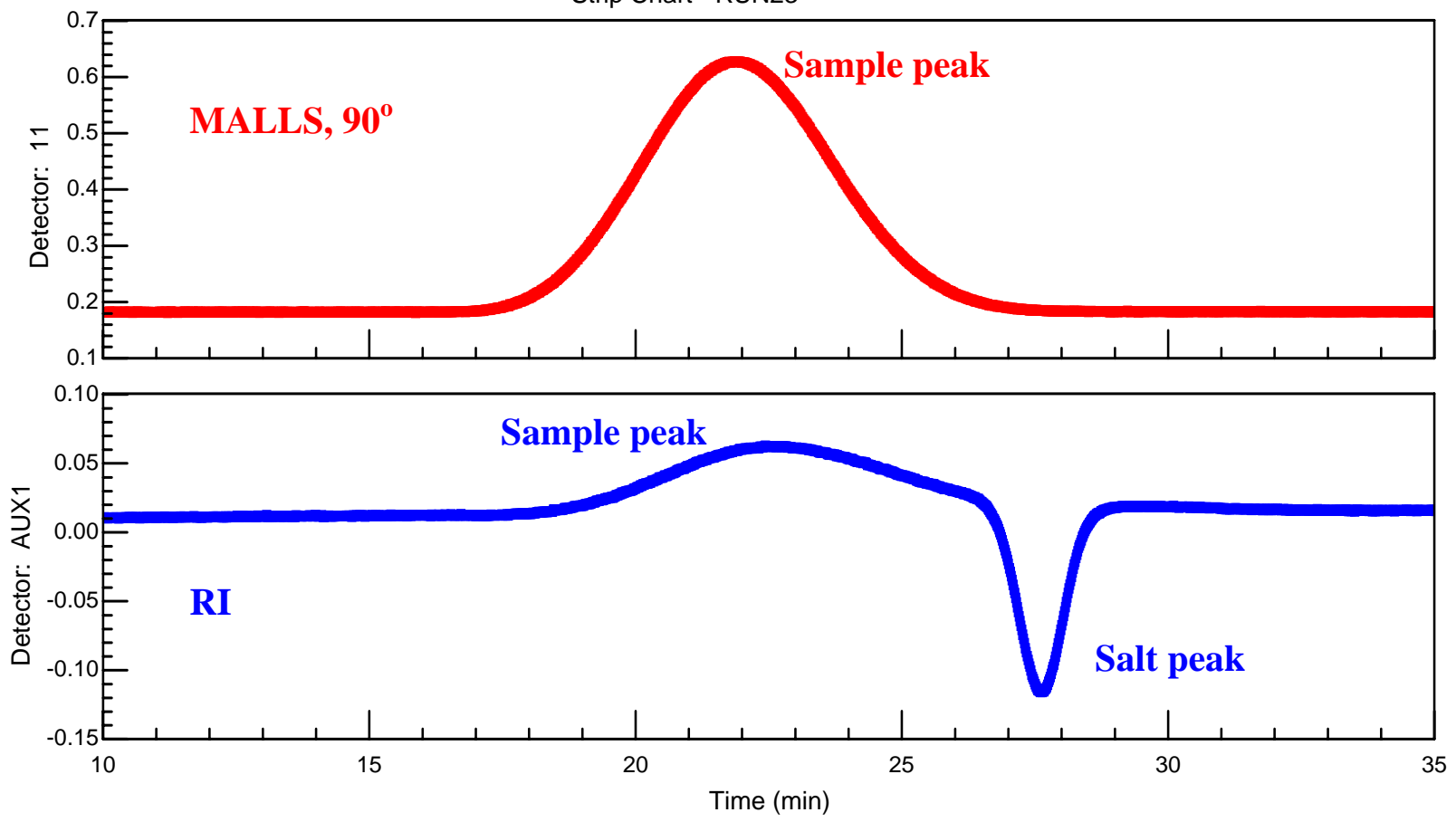

Figure 3.7 - Chromatograms for paam6000K (200 mg/kg, $100 \mu \mathrm{L})$.

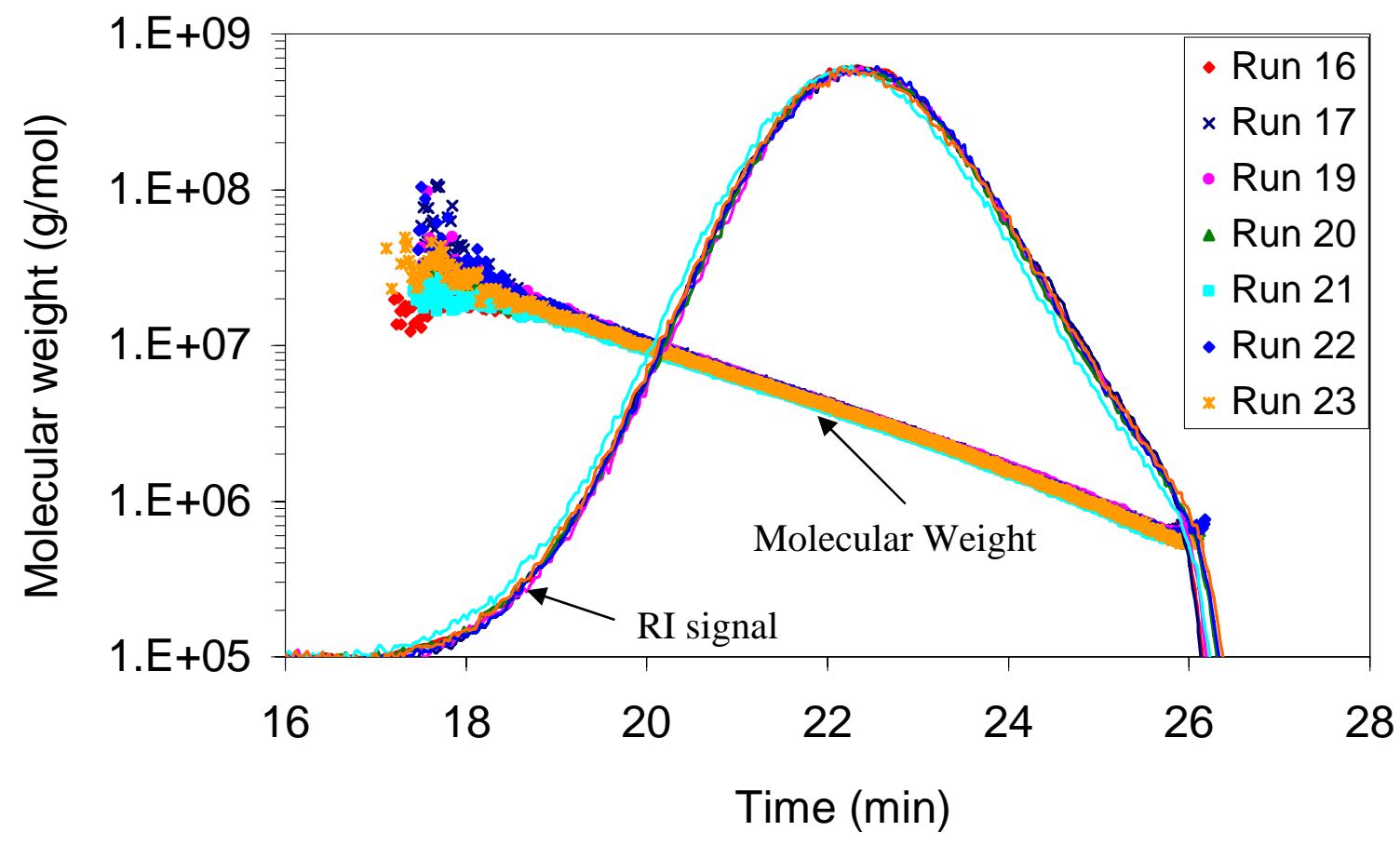

Figure 3.8 - Molecular weight versus elution time for paam6000K. 


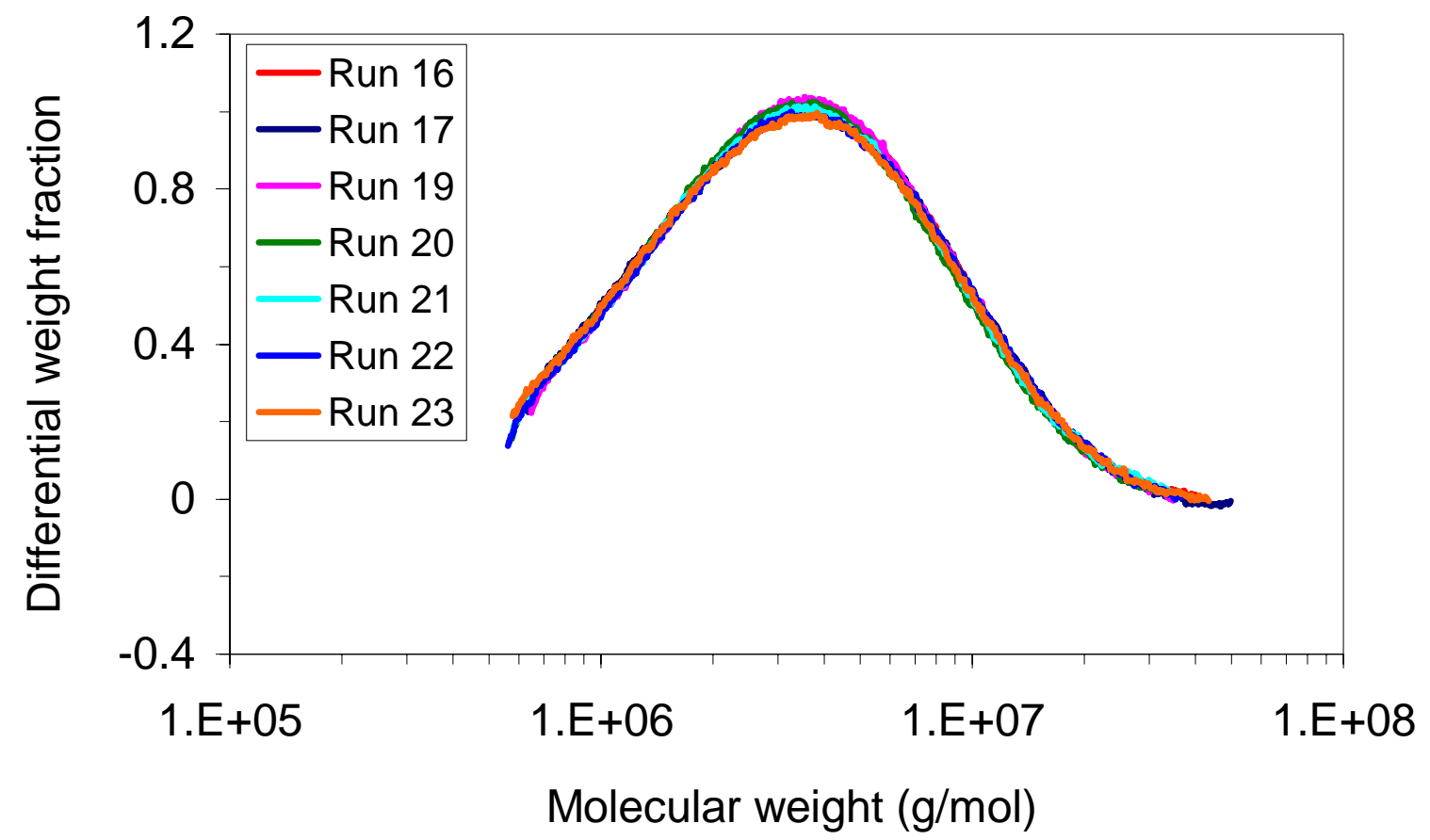

Figure 3.9 - Differential molecular weight distribution of paam6000K.

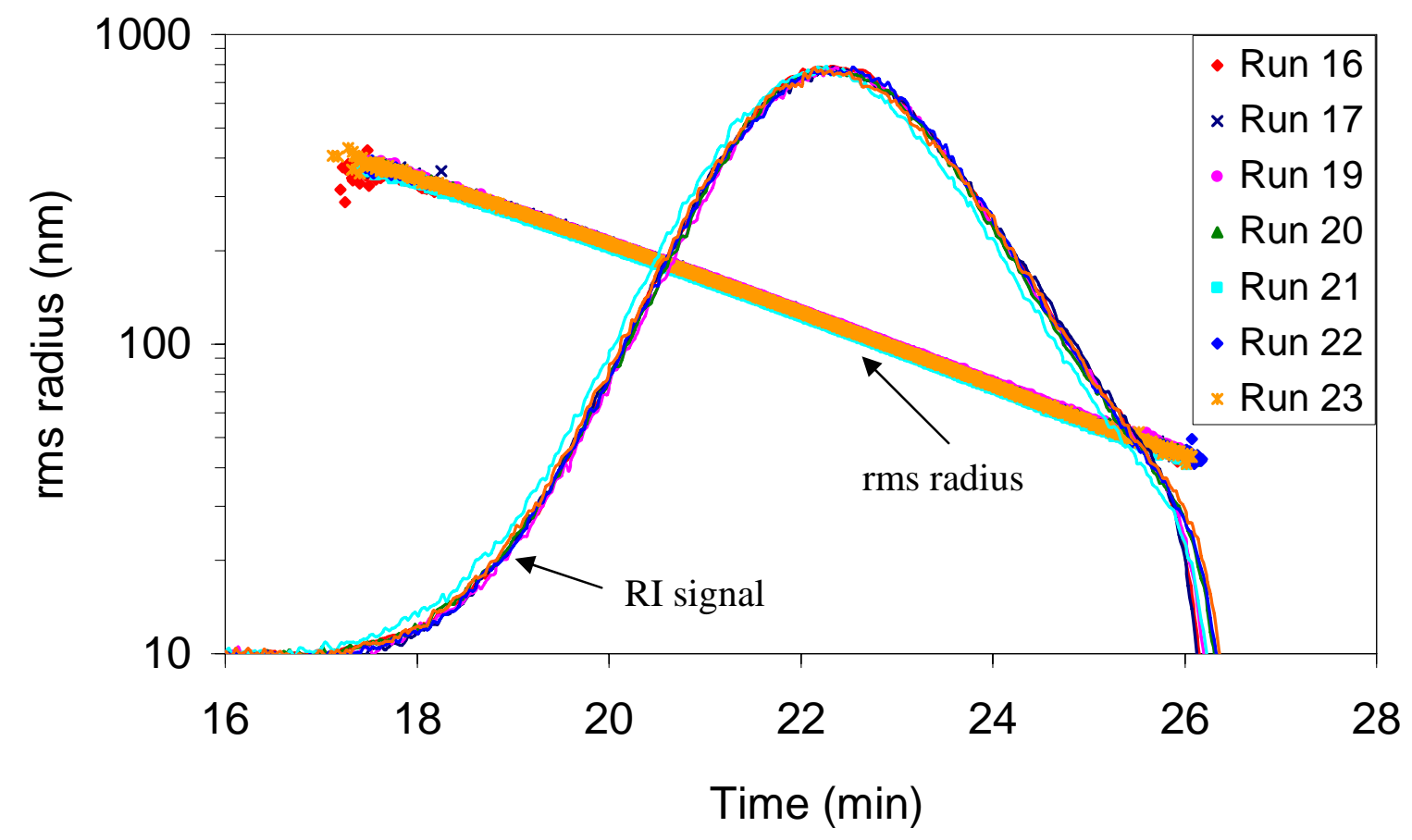

Figure 3.10 - Rms radius versus elution time for paam6000K. 


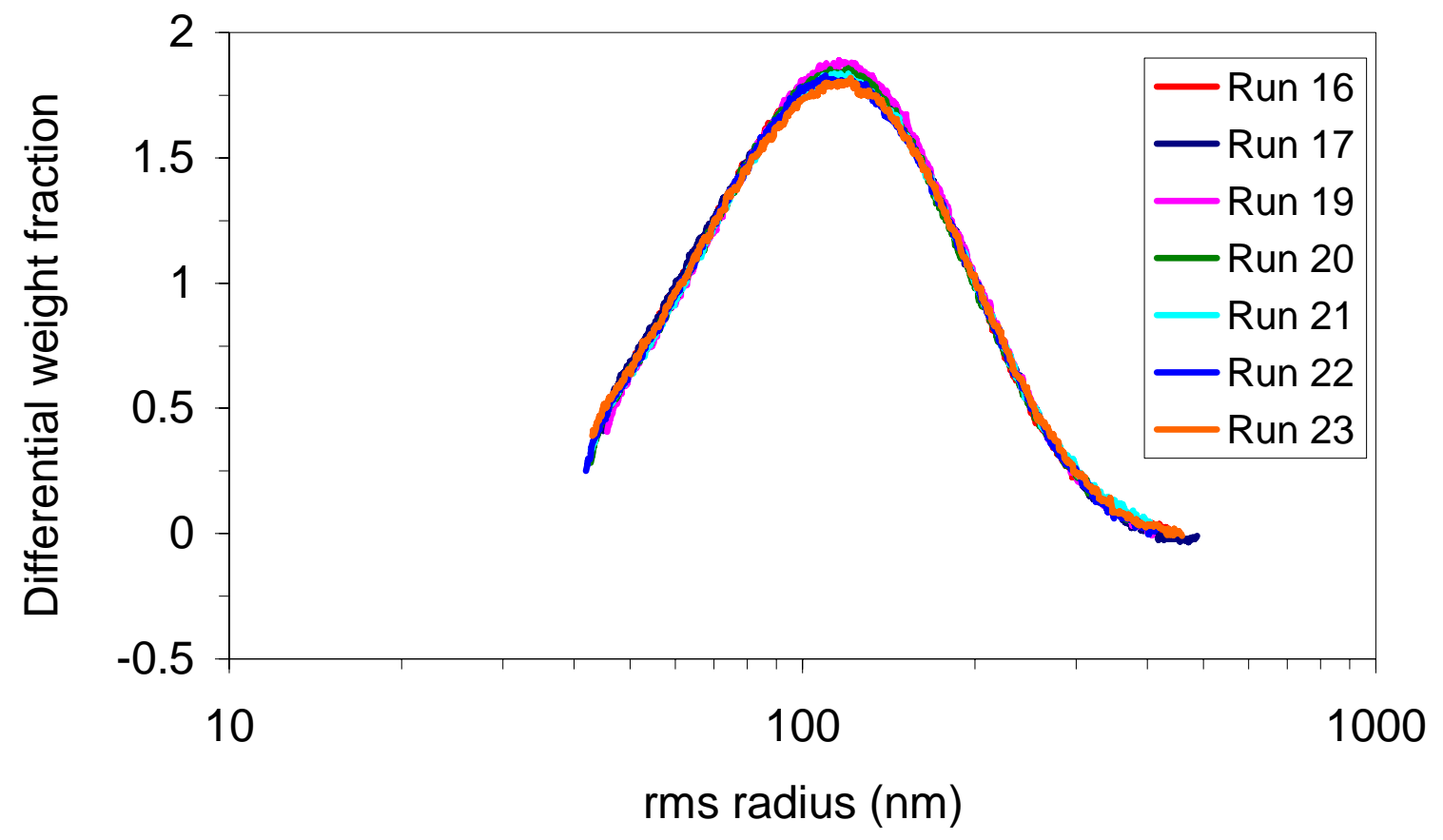

Figure 3.11 - Differential rms radius distribution of paam6000K.

$\mathrm{g} / \mathrm{mol}$. The rms radius ranges from $\sim 40 \mathrm{~nm}$ to $\sim 400 \mathrm{~nm}$. Distribution curves of seven runs overlay well, indicating good data reproducibility.

The rms radii are plotted against molecular weight (log-log) for paam6000K in Figure 3.12. The slope gives information about the conformation of the molecules. For rod-like molecules, the slope should be approximately 1.0, for spherical molecules the slope is about 0.33 , and for random coil molecules the slope ranges from 0.5 to 0.6. The average slope in Figure 3.12 is 0.56, which means that paam6000K molecules are random coils.

AlcoFlood 935. The molecular weight and size distributions of two lots (7158V and A2247BOV) of Alcoflood 935 were measured. Alcoflood 935 is a partially hydrolyzed polyacrylamide with the degree of hydrolysis about $10 \%$.

The ASTRA processing parameters for Alcoflood 935 are: Debye plot, Berry formalism, 4-16 detectors, detector fit degree $=2$, result fit degree $=1$. The plotting formalism and the fit order were selected based on the appearance (how well the data is fit by looking at the Debye plot) and the uncertainty (which combination gives the lowest uncertainty). Table 3.3 gives the average sample recovery, weight-average molecular weight and z-averaged rms radius for these two polymer lots. The value in parenthesis designates the relative standard deviation. The weightaverage molecular weights and $\mathrm{z}$-averaged rms radii measured by the inline mode are comparable to the values measured by the batch mode that were given in Table 3.1.

Molecular weights of the two polymer lots as a function of the elution time is shown in Figure 3.13 and the molecular weight distribution curves are shown in Figure 3.14. Similar graphs of the 


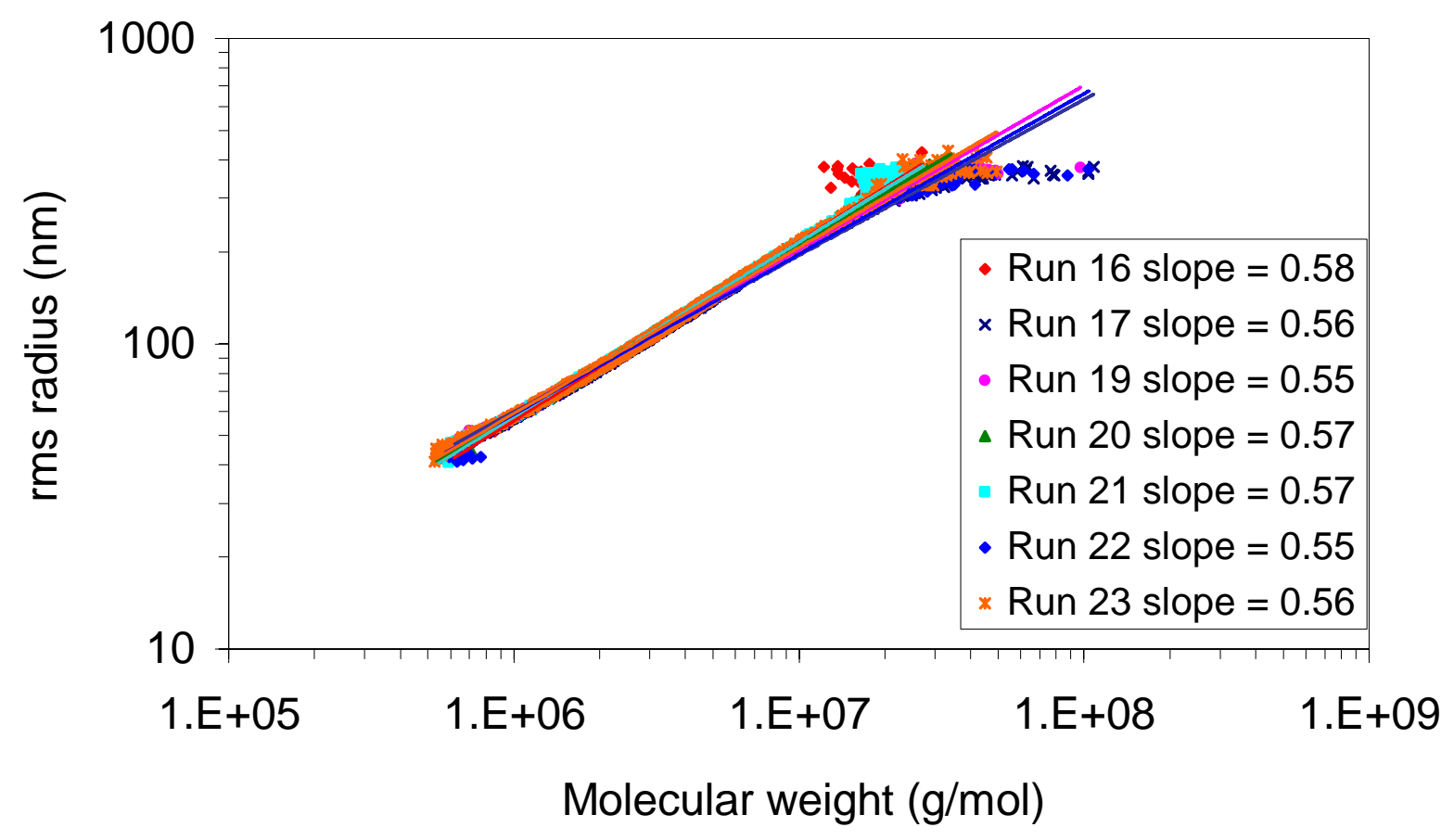

Figure 3.12 - Log-log plot of rms radius versus molecular weight for paam6000K.

Table 3.3 - Sample recovery and measured molecular weight and size averages of polymer Alcoflood 935, Lot 7158V (12 runs) and Lot A2247BOV (9 runs).

\begin{tabular}{lccc}
\hline & $\begin{array}{c}\text { Sample recovery } \\
(\%)\end{array}$ & $\begin{array}{c}\boldsymbol{M}_{\boldsymbol{w} 0} \\
(\mathrm{~g} / \mathrm{mol})\end{array}$ & $\begin{array}{c}\boldsymbol{R}_{\mathbf{z}} \\
(\mathrm{nm})\end{array}$ \\
\hline $\begin{array}{l}\text { AlcoFlood 935, } \\
\text { Lot 7158V }\end{array}$ & $83(7.4 \%)$ & $4.79 \times 10^{6}(2.7 \%)$ & $189.0(1.2 \%)$ \\
$\begin{array}{l}\text { AlcoFlood 935, } \\
\text { Lot A2247BOV }\end{array}$ & $89(3.5 \%)$ & $6.08 \times 10^{6}(2.8 \%)$ & $207.6(2.1 \%)$ \\
\hline
\end{tabular}

Numbers in parenthesis denote the relative standard deviation.

rms radii are shown in Figures 3.15 and 3.16. Polymer Lot A2247BOV has a higher average molecular weight, a higher average rms radius, and a wider distribution than Lot 7158V.

The rms radii are plotted against molecular weight (log-log) for the two Alcoflood 935 lots in Figure 3.17.The slopes were 0.47 and 0.48 for Lots $7158 \mathrm{~V}$ and A2247BOV, respectively, indicating the Alcoflood 935 polycarylamide is a random coil polymer with some branching since the slopes were just under 0.50 . 


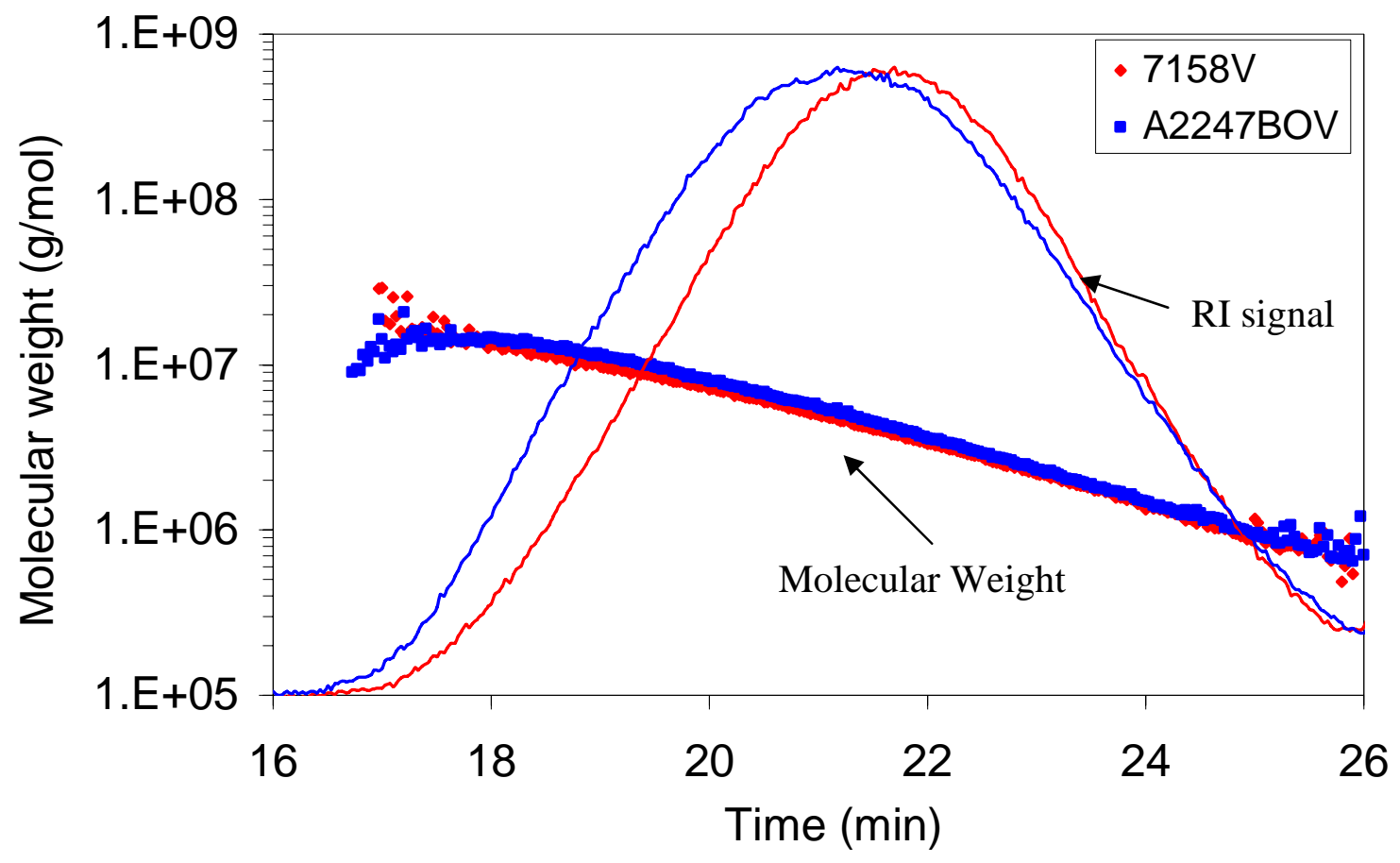

Figure 3.13 - Molecular weight versus elution time for two polymer lots of AlcoFlood 935.

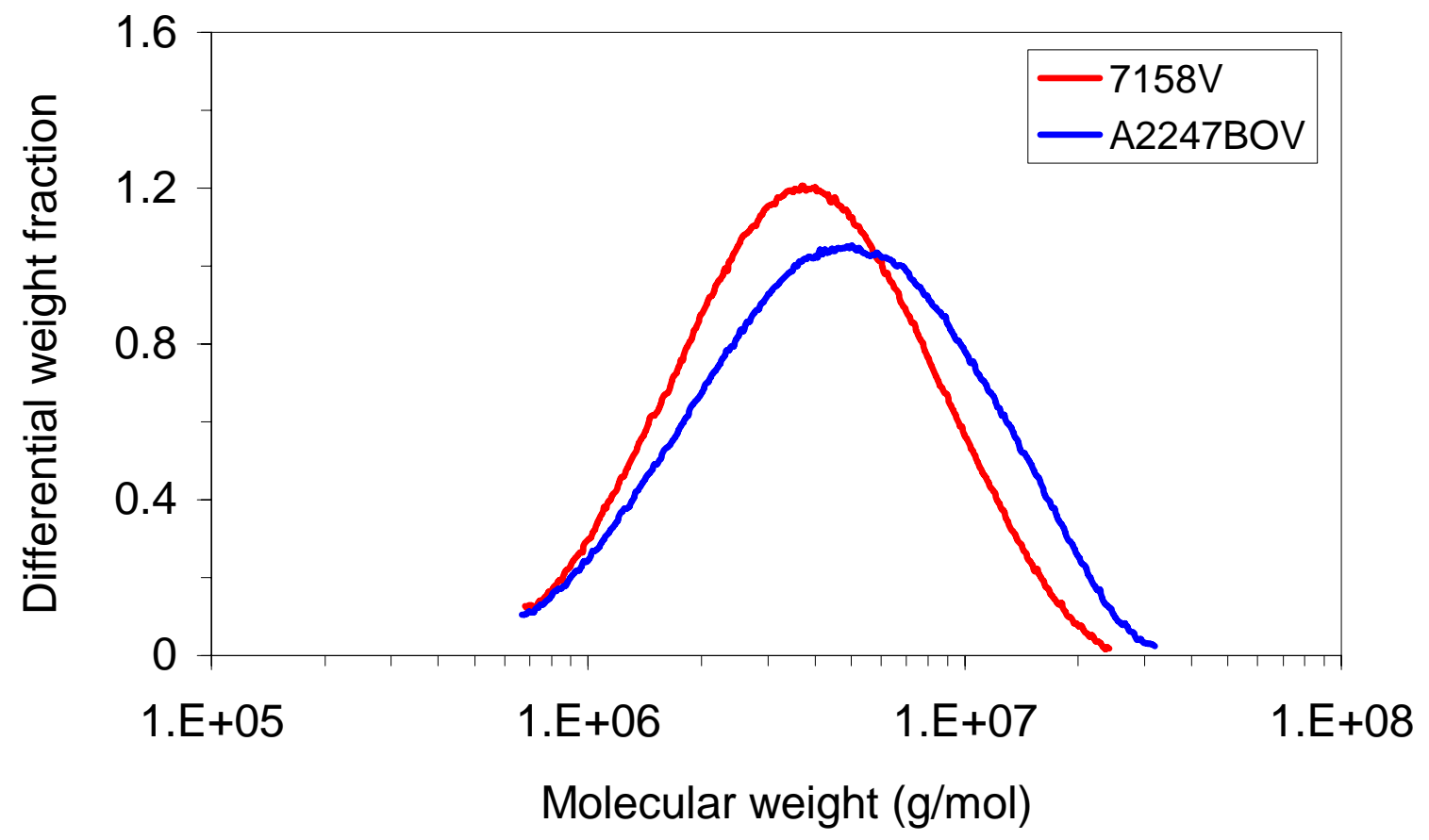

Figure 3.14 - Differential molecular weight distributions of two polymer lots of AlcoFlood 935. 


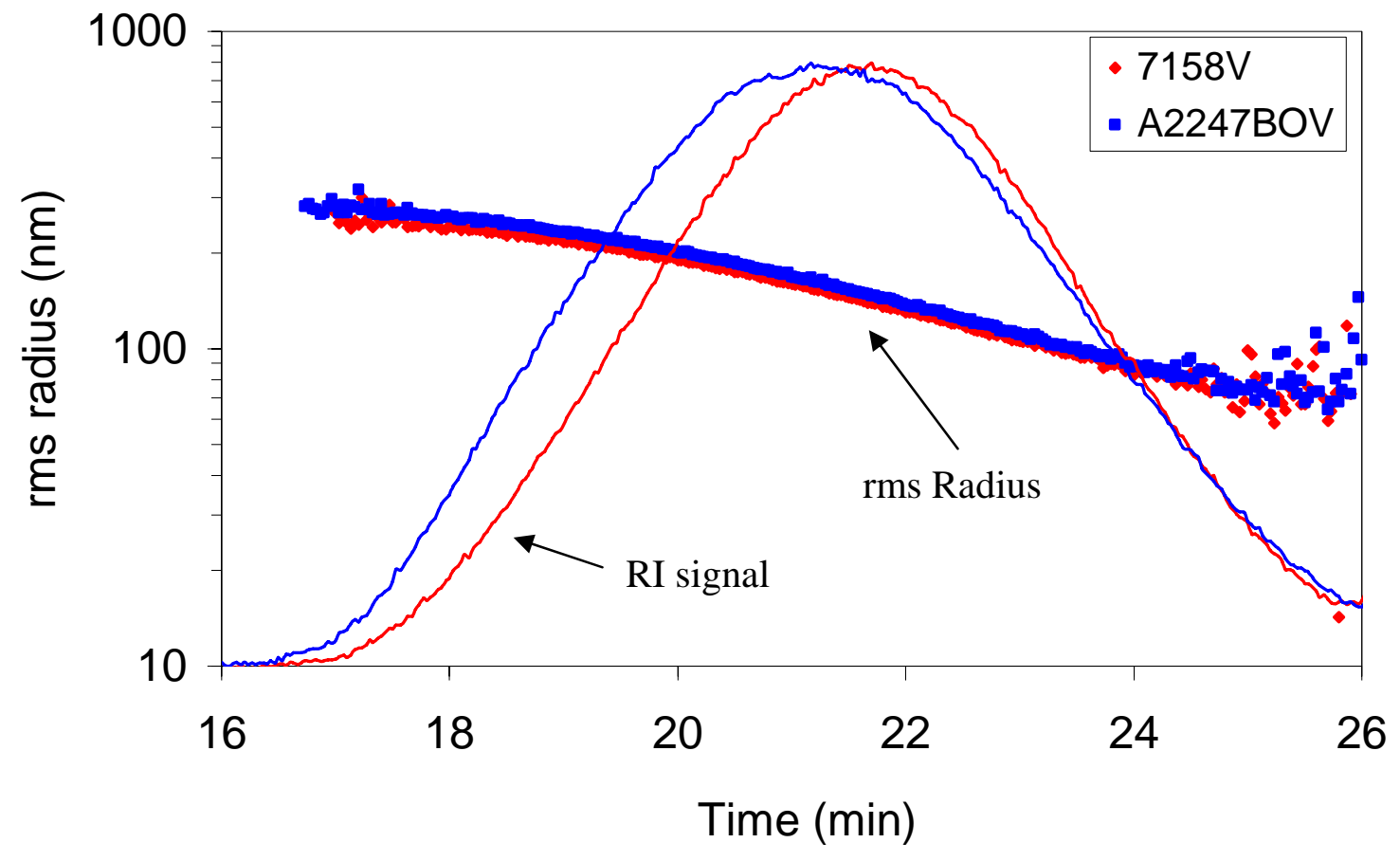

Figure 3.15 - Rms radius versus elution time for two polymer lots of AlcoFlood 935.

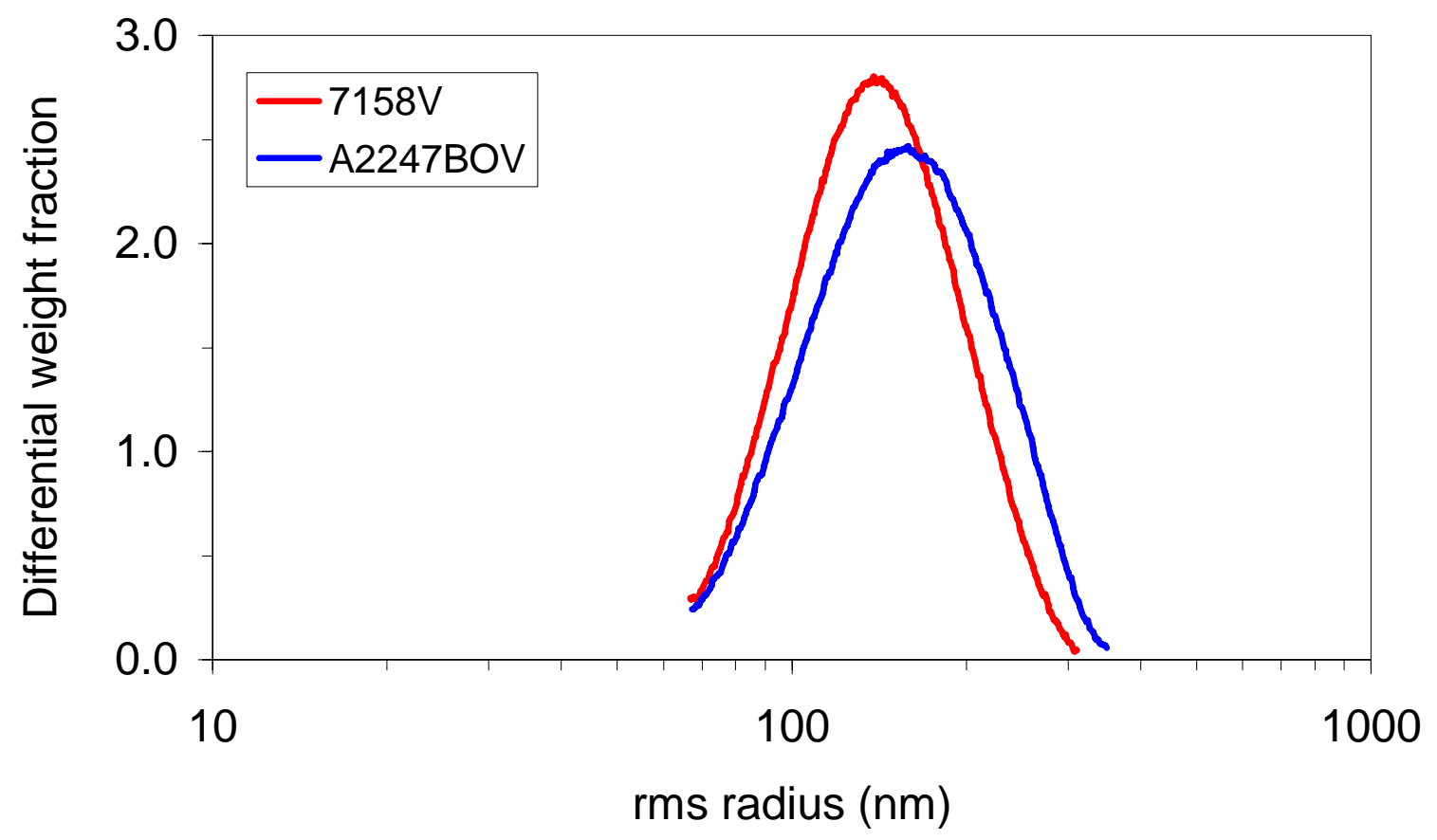

Figure 3.16 - Differential rms radius distributions of two polymer lots of AlcoFlood 935. 


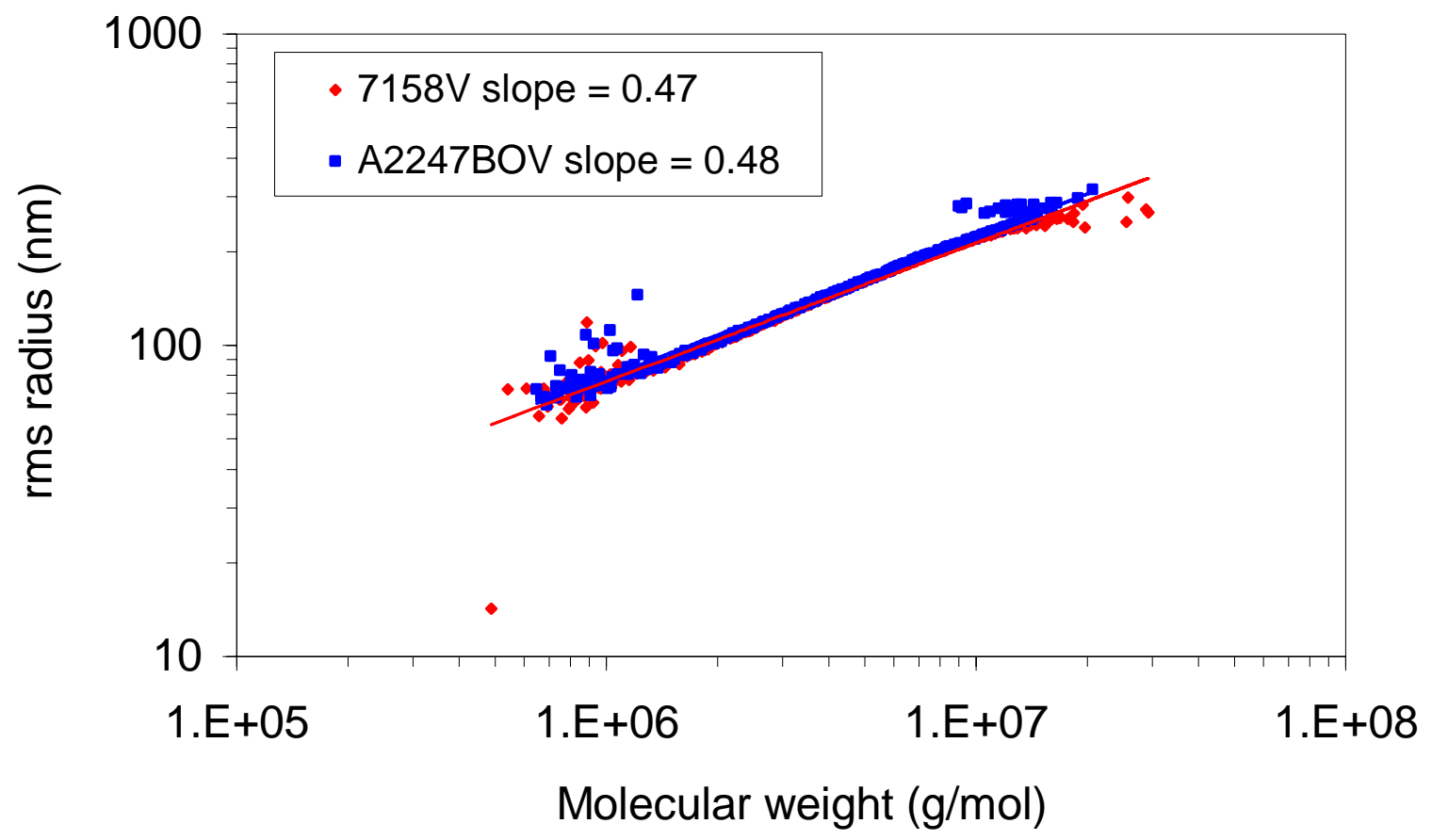

Figure 3.17 - Log-log plot of rms radius versus molecular weight for two lots of Alcoflood 935 polyacrylamide.

\section{Molecular Weight and Size Distribution of Pre-Gel Aggregates}

In mobile phase: $1 \% \mathrm{KCl}, \mathbf{0 . 0 1 \%} \mathbf{N a N}_{3}$. A gel system containing $5000 \mathrm{mg} / \mathrm{kg}$ polyacrylamide (AlcoFlood 935, Lot. A2247BOV) and $100 \mathrm{ppm}$ chromium(III) was prepared. Gelant was sampled periodically and immediately diluted from $5000 \mathrm{mg} / \mathrm{kg}$ (polymer concentration) to $200 \mathrm{mg} / \mathrm{kg}$ by adding the mobile phase before injection into the columns. Polymer solutions were injected between gelant injections to keep the columns saturated and to test proper operation.

The RI chromatograms (proportional to mass) for a gelant at different reaction times are shown in Figure 3.18 and the corresponding chromatograms from the MALLS detector at the $90^{\circ}$ angle are shown in Figure 3.19. The RI chromatograms of the gelant up to a reaction time of 5 hours were similar to the chromatograms for a polymer solution. At reaction times greater than 5 hours, the RI peak height decreased and the peak position shifted to the right (smaller molecules). The $90^{\circ}$ LS signals showed the same trends. Recovery of the injected gelant decreased with reaction time as indicated by smaller areas under the chromatograms and the recovery values listed in Table 3.4.

Reduction of the peak height and the shift of the peak position to the right (smaller molecules) are consistent with results of the model presented in Chapter 2. However, the model predicts that the reduced mass on the left side of the chromatogram should form larger molecules that elute earlier, forming a leading edge on the chromatogram. The leading edge was not detected and presumably the large aggregates were retained in the columns. The columns were saturated with polymer during preliminary injections and additional retention occurred only when chromium 


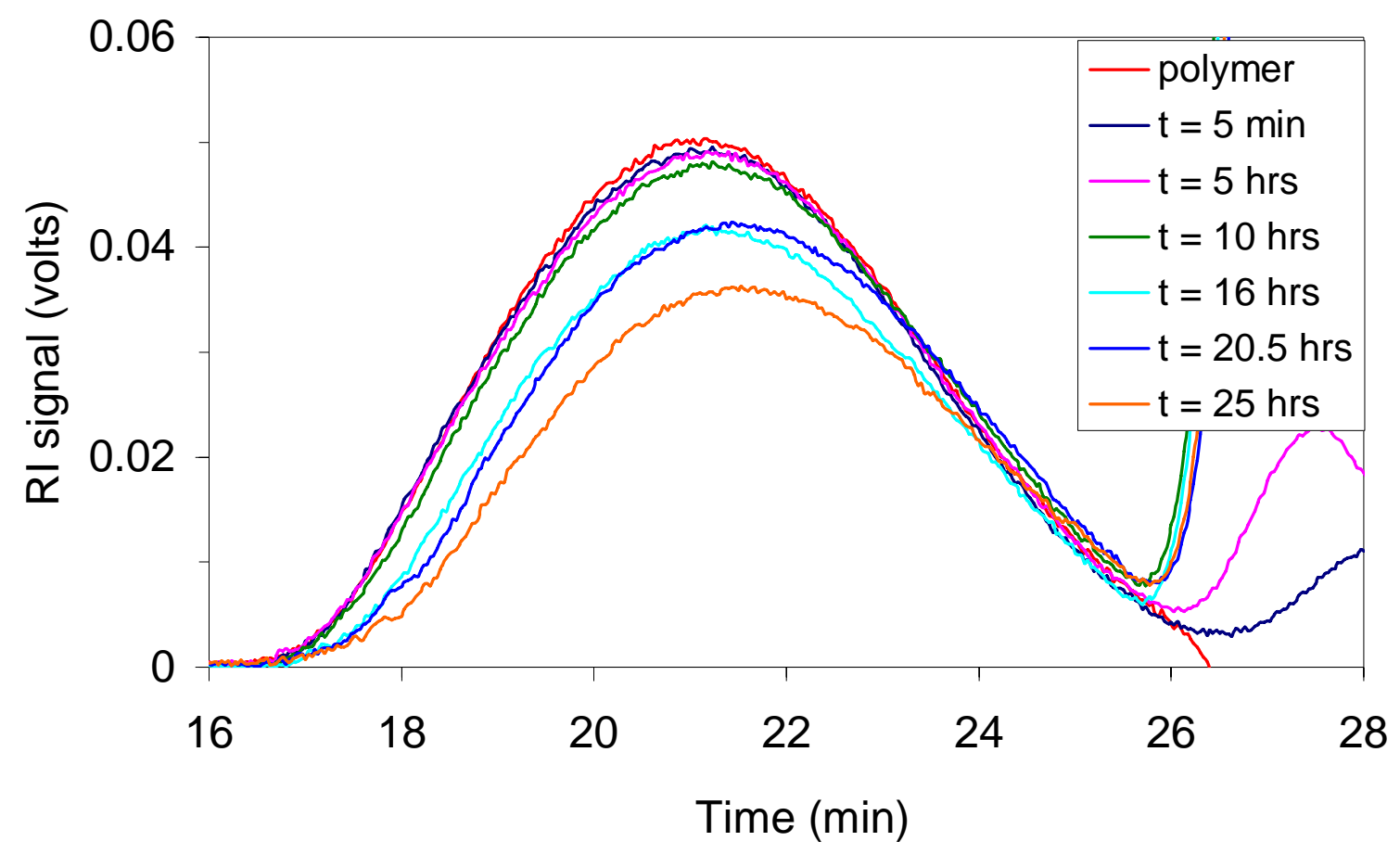

Figure 3.18 - RI chromatograms for gelant runs (Mobile phase: $1 \% \mathrm{KCl}, 0.01 \% \mathrm{NaN}_{3}$ ).

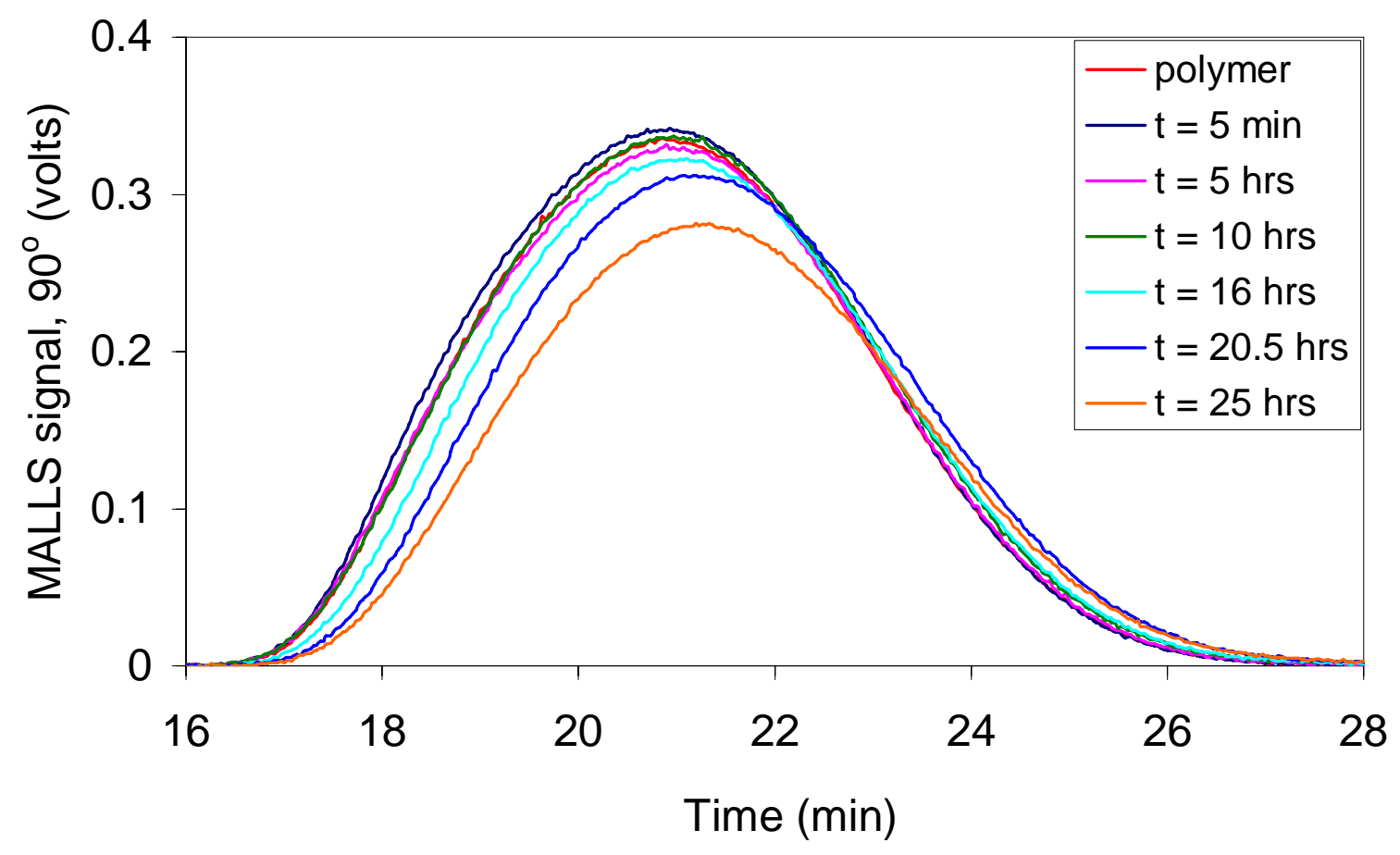

Figure 3.19 - MALLS chromatograms for gelant runs (Mobile phase: $1 \% \mathrm{KCl}, 0.01 \% \mathrm{NaN}_{3}$ ). 
Table 3.4 - Sample recovery of gelant runs (200 mg/kg polymer concentration, $100 \mu \mathrm{L})$.

\begin{tabular}{cc}
\hline Gelling time (hours) & Sample recovery (\%) \\
\hline 0.08 & 84 \\
5 & 84 \\
10 & 82 \\
16 & 68 \\
20 & 69 \\
25 & 59 \\
\hline
\end{tabular}

was present. This indicated that the retention of aggregates was a result of their reactive nature after reaction with the chromium crosslinker.

The system pressure measured upstream of the columns (Figure 3.1) increased after injection of gelants that had reacted for 10 or more hours as shown in the second column in Table 3.5. The increased pressure indicated retention of material in the columns. The gel system was not injected at reaction times greater than 25 hours to prevent plugging of the columns. The columns required cleaning after the series of gelant injections. The mobile phase was changed to D.I. water and the columns were washed by injecting $50 \mu \mathrm{L}$ of $1 \mathrm{M} \mathrm{NaOH}$ solution repeatedly till the theoretical plate number increased to the original value of about 4000 . The plate number was determined by glucose injections according to manufacture’s procedure.

Table 3.5 - System pressure after gelant injections (200 mg/kg polymer concentration, $100 \mu \mathrm{L}$ ).

\begin{tabular}{ccc}
\hline \multirow{2}{*}{$\begin{array}{c}\text { Reaction time } \\
\text { (hours) }\end{array}$} & \multicolumn{2}{c}{ Pressure (psig) } \\
\cline { 2 - 3 } & Mobile phase: $1 \%$ & Mobile phase: 0.2 M \\
KCl, 0.01\% NaN & NaOAc, 0.01\% NaN \\
\hline 0.08 & 42.2 & 45.5 \\
5 & 42.2 & 45.5 \\
10 & 43.0 & 46.0 \\
$15-16$ & 43.4 & 46.3 \\
20 & 44.4 & 46.5 \\
25 & 46.0 & 47.4 \\
\hline
\end{tabular}

RI chromatograms for the injection of polymer solutions that were conducted between the gelant injections are shown in Figure 3.20. The chromatograms indicate proper operation.

In mobile phase: $0.2 \mathrm{M} \mathrm{NaOAc}, 0.01 \% \mathrm{NaN}_{3}$. In an effort to reduce the retention of aggregates in the column, a mobile phase containing $0.2 \mathrm{M}$ sodium acetate was used. The additional acetate reduces chromium-polymer reaction rate. The $\mathrm{pH}$ of the NaOAc mobile phase was adjusted to 6.0 with acetic acid to prevent precipitation of chromium hydroxide. The chromium: acetate molar ratio was $\sim$ 1: 2500 . 


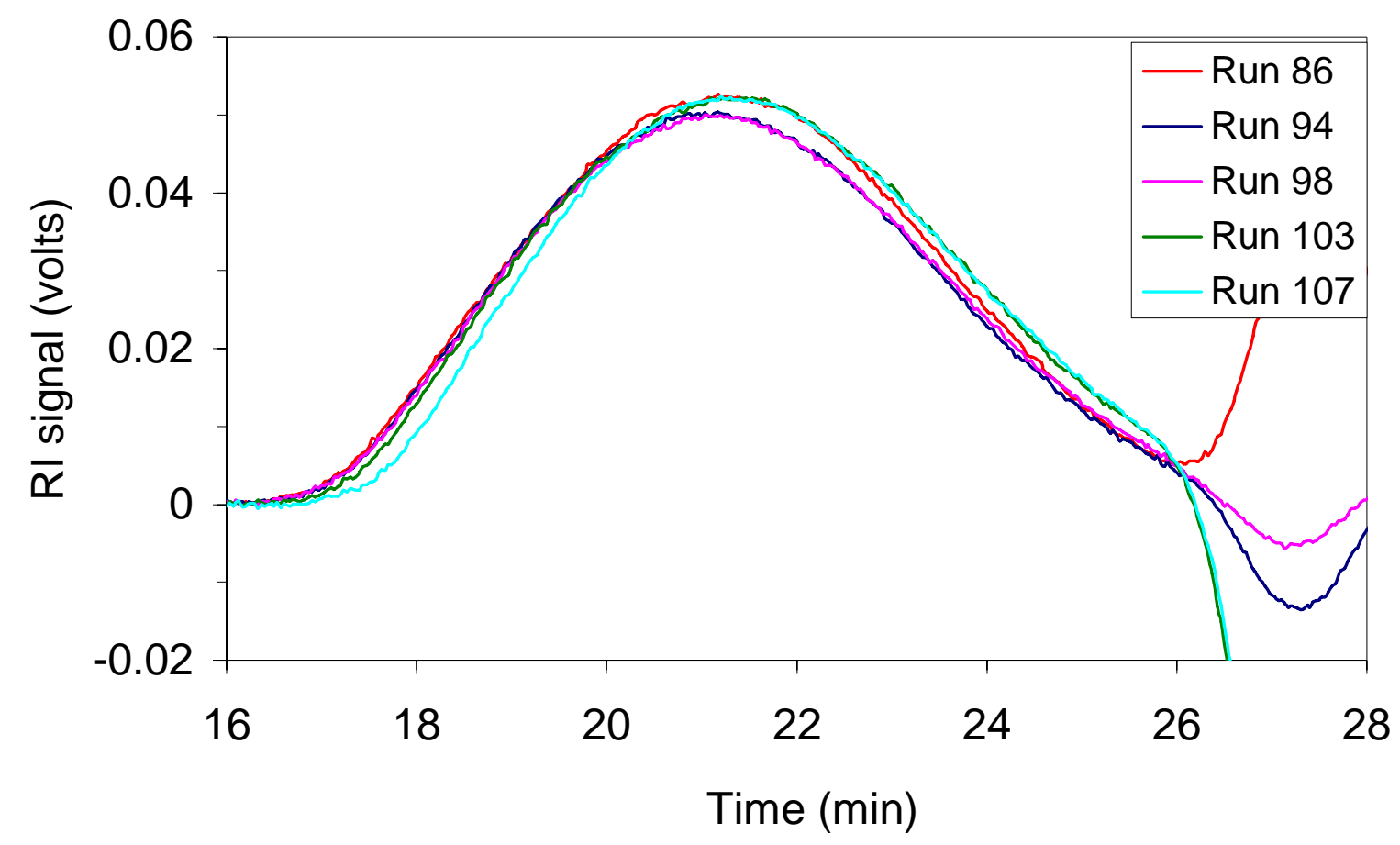

Figure 3.20 - RI chromatograms for polymer runs between the gelant injections.

A gel system was prepared and samples were injected as described above. The samples were diluted from $5000 \mathrm{mg} / \mathrm{kg}$ polymer concentration to $200 \mathrm{mg} / \mathrm{kg}$ by adding the new mobile phase. Between two gelant injections, polymers were injected to keep the columns saturated with polymer.

Results similar to runs with the $\mathrm{KCl}$ mobile phase were obtained as shown in Figure 3.21. Retention was indicated by the increased system pressure as shown in Table 3.5. The addition of acetate did not reduce the retention of aggregates. The Shodex column does not appear to be suitable for fractionating pre-gel aggregates.

\section{Summary}

A SEC-MALLS-RI setup was developed and the measurement of the molecular weight and size distributions of polymers was demonstrated. The Shodex SUGAR KS 807 column separated polymers well, but was not suitable for gelants. After a few hours of reaction time, retention of aggregates was observed. Results indicate that the larger, more reactive, aggregates were retained. Addition of acetate ion to the mobile phase of the measuring system did not impede the retention. A fractionator with less interaction between the sample and the stationary phase is needed. Efforts are being made in our laboratory to evaluate a flow field-flow fractionator (FFFF) for the separation of pre-gel aggregates.

\section{References}

1. DAWN Course Manual, Light Scattering University Lectures, Wyatt Technology Corporation, Santa Barbara, CA (1998). 


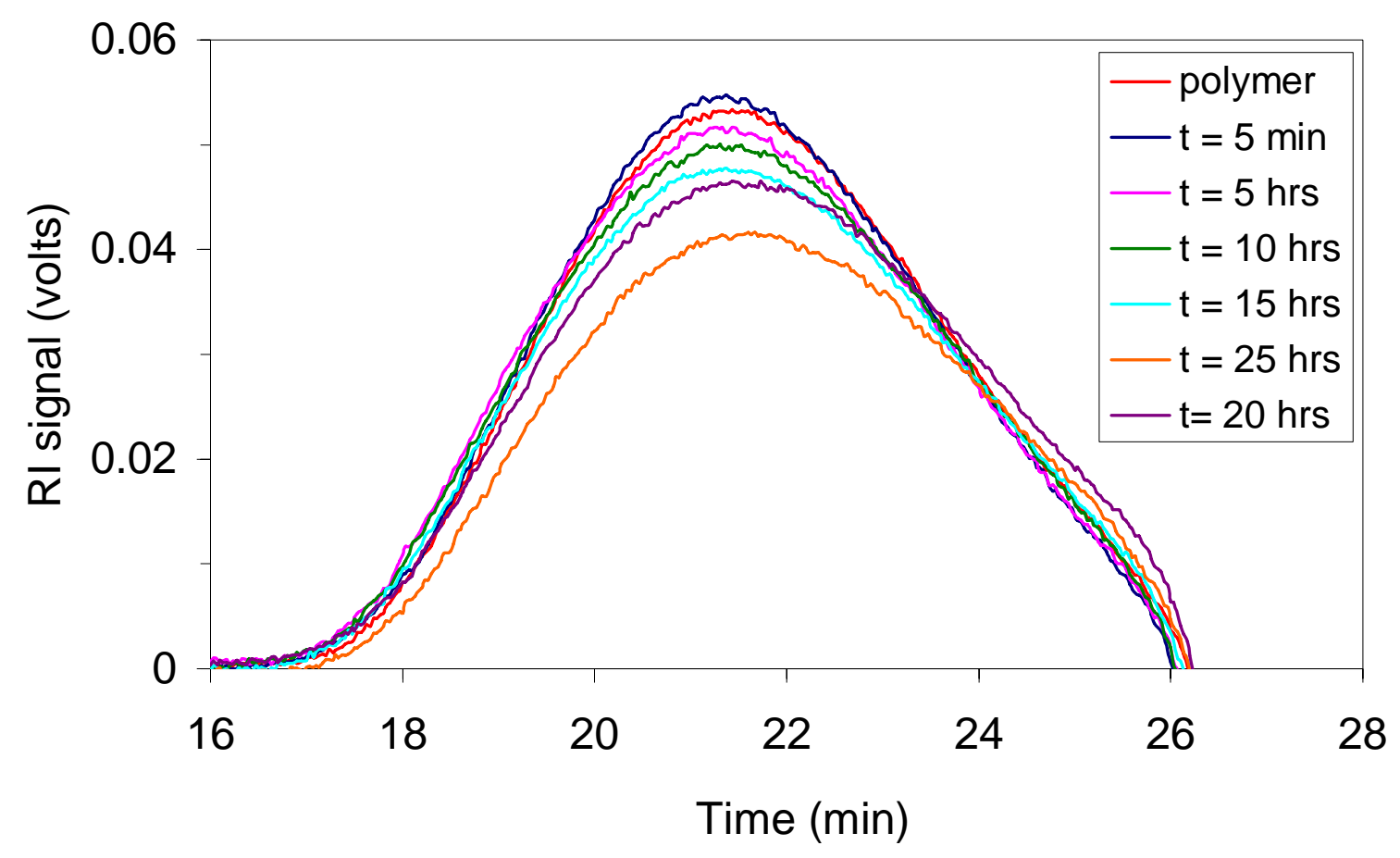

Figure 3.21 - RI chromatograms of gelant runs (Mobile phase: $0.2 \mathrm{M} \mathrm{NaOAc}, 0.01 \% \mathrm{NaN}_{3}$ ).

2. Wang, Tong: "Determination of Weight-average Molecular Weight and Z-average Root Mean Square Radius of Pre-gel Aggregates in a Polyacrylamide-chromium(III) Acetate System using a Multi-Angle Laser Light Scattering Technique.” MS thesis, The University of Kansas, Lawrence, KS (2003).

3. Willhite, G. P., Green, D.W. and McCool, C.S.: "Increased Oil Recovery from Mature Oil Fields using Gelled Polymer Treatments," Annual Report for June 1999 - June 2002, Report No. 99BC15209-5, Contract No. DE-AC26-99BC15209, US DOE, Washington, DC (Dec 2002).

4. Wyatt, P.J.: "Light Scattering and the Absolute Characterization of Macromolecules", Analytica Chimica Acta, 272(1993), 1-40. 


\title{
Chapter 4
}

\section{Transport of Brine and Chromium(III) Through Dolomite Rock}

\author{
Graduate Research Assistant: Feiyan Chen
}

\section{Introduction}

Gelled polymers are commonly used for profile modification of petroleum reservoirs. A major impediment to the success of polymer gel treatment is the extent to which the gel solutions can be placed deep into the reservoir. An understanding of the physical and chemical processes that govern the propagation and in situ gelation of the gelled polymer system in porous media is necessary to design a successful treatment. Carbonate rocks hold a significant portion of the world's petroleum reservoirs. For gel systems, the chemical interactions between the injected solutions and carbonate rocks include the dissolution of rock, the precipitation of chromium(III) due to the increase of solution $\mathrm{pH}$, the retention of polymer and gelled polymer during flow in the carbonate rock.

A mathematical model that simulates the transport of chromium(III) acetate through carbonate rocks was developed and presented in the previous annual report [Willhite et al., 2004]. The following phenomena were modeled: convection, dispersion, kinetic reactions of carbonate dissolution and chromium precipitation and chemical equilibrium for reactions between selected aqueous components. Most of the chemical reactions are dependent on the hydrogen ion concentration, or $\mathrm{pH}$. The transport of brines and chromium(III) acetate solutions through carbonate-containing rocks was simulated by determining the fitting parameters of the rate equations for carbonate dissolution and chromium precipitation. Published results of the injection of brine and chromium(III) acetate through rocks containing carbonate minerals [Stavland et al., 1993; McCool et al., 2000; Zou et al., 2000; Jin, 2001] were compared with the numerical results obtained by simulating these experiments using the model. The previous flow experiments were conducted in Baker dolomite, San Andres dolomite and Brent sandstone (containing carbonate). Dissolution of dolomite, calcite and anhydrite was modeled as appropriate for each of the rock types.

Another objective of this project was to acquire additional experimental data on the transport of chromium(III) acetate through dolomite rock and to simulate the data using the mathematical model. The interactions between dolomite and chromium(III) acetate solution with $200 \mathrm{ppm}$ chromium(III) were studied using continuous-flow experiments. Solutions were flowed through dolomite cores at constant flow rates and the effluents were analyzed for $\mathrm{pH}$, and calcium, magnesium and chromium concentrations. Additional experiments were conducted to study the dolomite dissolution in brine with $\mathrm{pH}$ 2.1, and brine with acetate buffer. The transport of chromium(III) chloride in dolomite was also studied. Results of the experimental work and simulations of the results using the mathematical model are presented in this chapter.

\section{Experimental Materials, Equipment and Procedures}

Materials The rock material used was Baker dolomite from Millersville, Ohio. Chemical analysis for this rock shows that the rock contains $22.6 \% \mathrm{Ca}, 12.7 \% \mathrm{Mg}, 0.1-0.01 \%$ Fe and trace amount $\mathrm{Mn}, \mathrm{Si}$, and Cr. Qualitative XRD analysis of fines separated from dolomite indicates the 
presence of a trace amount of illite, quartz and chlorite [Meister, 1978]. A cylindrical core was drilled and dried in an oven at $105^{\circ} \mathrm{C}$. The core was encapsulated with an epoxy coating and plastic endplates with groves that allowed for distribution of fluids across the face were attached to both ends of the core.

A specified procedure was used to precondition virgin cores. The cores were tested for leaks by pressurizing the core with air to 100 psig and submerging the core in water. The air was then displaced by injection of carbon dioxide for 10 minutes. Carbon dioxide is easier to remove than air during the brine-saturation procedure. Brine $(1 \% \mathrm{KCl})$ was then injected through the core at $1.00 \mathrm{~mL} / \mathrm{min}$ for 12 hours (about 180 pore volumes of brine) to saturate the pore space.

Porosities and pore volumes of the cores were determined by weight difference and the brine density.

A tracer test was conducted to determine the flow characteristics of the dolomite core. Tracer solution was injected through the core at $1.00 \mathrm{~mL} / \mathrm{min}$ for about 3 pore volumes, followed by the injection of $1 \% \mathrm{KCl}$ for about 3 pore volumes. The tracer run was repeated to check reproducibility. Potassium chloride (1\%) was injected through the core and permeability of the core was determined by Darcy's law. Prior to a flow test, brine $(1 \% \mathrm{KCl})$ was injected through the core at $0.03 \mathrm{~mL} / \mathrm{min}$ for 12 hours. Properties of the dolomite cores are listed in Table 4.1.

Table 4.1 - Summary of properties of the dolomite cores.

\begin{tabular}{lccccccc}
\hline Properties & B & C1 & C2 & C3 & C4 & C5 & C6 \\
\hline Diameter, cm & 1.86 & 1.88 & 1.88 & 1.88 & 1.88 & 1.88 & 1.88 \\
Length, cm & 6.50 & 6.55 & 6.02 & 6.00 & 6.42 & 7.15 & 6.83 \\
Porosity & 0.23 & 0.22 & 0.23 & 0.22 & 0.23 & 0.22 & 0.21 \\
Pore volume, mL & 4.14 & 4.06 & 3.83 & 3.61 & 4.13 & 4.34 & 4.03 \\
Permeability, md & 42 & 30 & 27 & 23 & 55 & 24 & 17 \\
\hline
\end{tabular}

All solutions contained 1.0 wt.\% potassium chloride. Chromium(III) acetate solution was prepared by dissolving chromium(III) acetate into a potassium chloride solution and aging the solution for at least two weeks before use. The chromium(III) acetate was obtained from Alfa Chemicals. Concentration of chromium(III) was $200 \mathrm{ppm}$ by weight. The $\mathrm{pH}$ of aged chromium(III) acetate solution was 4.6.

Hydrochloric acid ( $1 \mathrm{~mol} / \mathrm{L}$, Fisher SA48-1) was used to adjust the initial $\mathrm{pH}$ of the $1.0 \% \mathrm{KCl}$ brine and other solutions. A solution containing $0.0114 \mathrm{~mol} / \mathrm{L}$ potassium acetate and $1.0 \mathrm{wt} \%$ potassium chloride was prepared and the $\mathrm{pH}$ was adjusted to 4.6. Potassium acetate was from Fisher ChemAlert (Lot 986360).

A $2 \%$ (by weight) nitric acid solution with $1 \% \mathrm{KCl}$ was used in this project for sample storage purposes. Around one $\mathrm{mL}$ of this solution was put in sample bottles before sample collection to prevent chromium precipitation. The nitric acid solution used in this project was prepared by diluting concentrated nitric acid (70\% by weight) with deionized water. The concentrated nitric acid was obtained from Fisher Scientific, trace metal grade. 
Nitrate was used as a tracer to characterize the flow properties of the cores. The tracer solution was prepared from laboratory grade potassium nitrate and potassium chloride to form a 0.1 mole/L nitrate, $1 \% \mathrm{KCl}$ solution. Nitrate was detected by an in-line spectrophotometer at a wavelength of $302 \mathrm{~nm}$.

Equipment. A schematic of the experimental apparatus used for the flow experiments is presented in Figure 4.1. Two pumps were used to inject solutions at constant flow rates. One pump was used for $1 \% \mathrm{KCl}$ solution injection and the other for injection of the selected solutions: chromium(III) acetate solution, tracer solution, etc. A four-way valve was positioned between the pumps and the core for switching between injected fluids. A six-way valve allowed for the injected solution to bypass the core for calibrations of inline UV/Vis spectrophotometer and the $\mathrm{pH}$ electrode and for shuting in the core without detaching connections. A transducer connected at both ends of the dolomite core was used to measure the differential pressure across the core. An in-line Varian spectrophotometer and $\mathrm{pH}$ electrode were connected to the exit of the core to measure values of the effluent chromium or tracer concentrations as well as $\mathrm{pH}$. A wavelength of $575 \mathrm{~nm}$ was used for in-line measurement of chromium(III) concentration in the effluent. An automatic fraction collector was used at high flow rates to collect samples for the analysis of calcium, magnesium and chromium concentration using atomic absorbance spectrometry. At low flow rates, samples were collected manually by inserting the effluent tube through a tight hole in the cap of sample bottles to minimize evaporation. The experimental setup was enclosed in a constant temperature air bath to maintain a temperature of $25^{\circ} \mathrm{C}$.

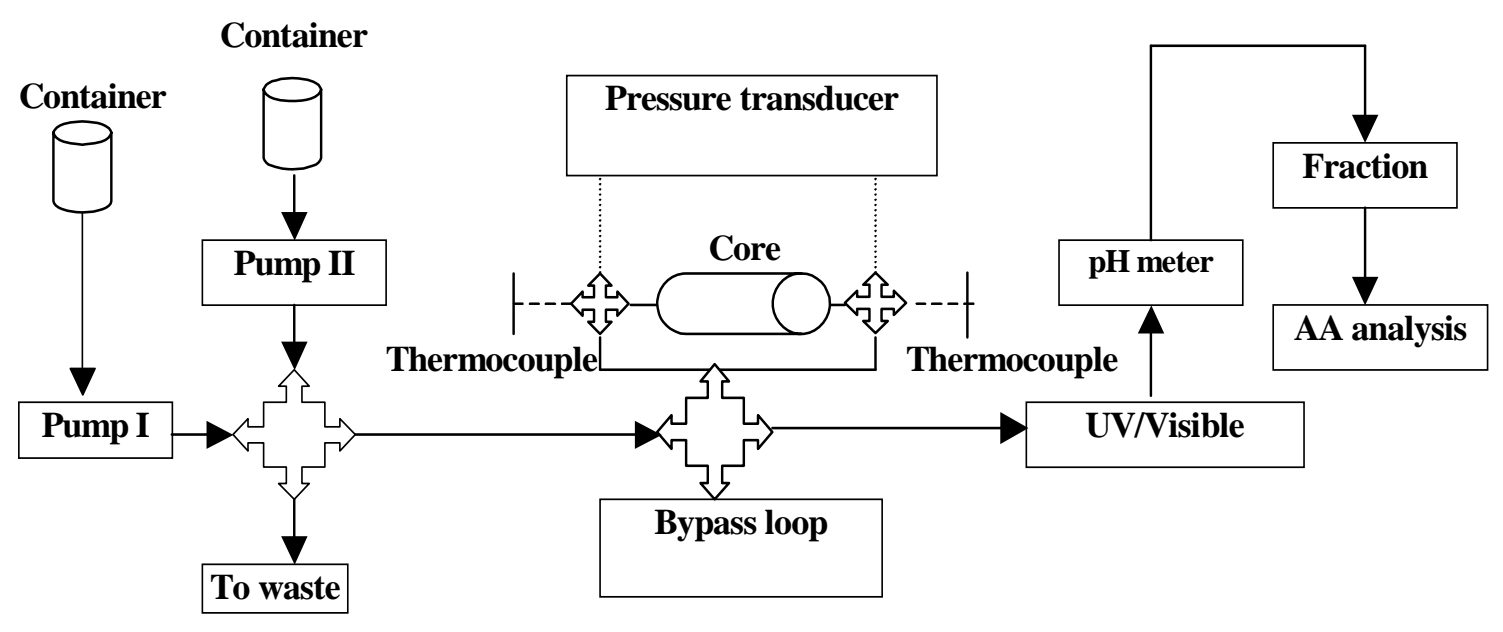

Figure 4.1- Schematic of equipment used for flow experiment.

Procedures. Two types of experiments were conducted: (I) displacement experiments with the injection of a selected solution at a constant flow rate, and (II) shut-in experiments.

The procedure for a flow experiment was:

1. Inject solution at the selected injection rates into the dolomite core that is saturated with brine. For chromium(III) acetate solutions, about five to six pore volumes were injected. The effluent samples were collected every 0.25 pore volume or 0.5 pore volume. The sample size was determined by the estimated calcium, magnesium and/or chromium concentrations. 
2. After the injection of the selected solution, flush the core with $1 \% \mathrm{KCl}$ at 1.00 and 0.03 $\mathrm{mL} / \mathrm{min}$.

The procedure for a shut-in experiment was:

1. Inject the selected solution at fast rate ( 1.00 to $2.00 \mathrm{~mL} / \mathrm{min})$ into the dolomite core that is saturated with brine. For chromium(III) acetate solutions, about five to six pore volumes were injected. Effluent samples were collected every pore volume for calcium, magnesium and/or chromium analysis. This first step of a shut-in experiment also provides results of a "flow experiment" at a high flow rate.

2. Shut-in the core by switching the six-way valve so the solution will flow through the bypass tubing instead of the core. Change the injected solution to brine and flush the bypass tubing and the inline $\mathrm{pH}$ meter and in-line spectrophotometer.

3. After selected shut-in period, switch the six-way valve to inject $1 \% \mathrm{KCl}$ solution into the core at $1.00 \mathrm{~mL} / \mathrm{min}$ to displace the shut-in fluid from the dolomite core. Effluent samples were collected during the first pore volume of brine injection to determine calcium, magnesium and/or chromium concentrations. Values at about $0.5 \mathrm{PV}$ injected were assumed to be representative of the solution that was in contact with the rock for the shut-in (residence) time. (The shut-in experiments are designated in tables presented in the following sections as a flow experiment followed by a shut-in experiment.)

An atomic absorbance spectrophotometer (Perkin Elmer Aanalyst 300 with AS 90 plus auto sampler) was used for calcium, magnesium and/or chromium analysis. An air-acetylene flame was applied. A solution with $2 \%$ nitric acid solution, and $1 \% \mathrm{KCl}$ was used to dilute the samples for chromium analysis. For magnesium and calcium analysis, $0.1 \%$ and $1.0 \%$ lanthanum was added to minimize the interference from silica, aluminum, sulfate etc. Lanthanum solutions were prepared from $\mathrm{LaCl}_{3} .7 \mathrm{H}_{2} \mathrm{O}$ (Fisher Scientific).

The calcium standards were prepared from calcium reference solution (Fisher Scientific Co.), 1 $\mathrm{mg} / \mathrm{mL}$, in the linear range of 0 to $5 \mathrm{ppm}$. The density of calcium reference solution is 1.0088 $\mathrm{g} / \mathrm{L}$. Density correction was made. The wavelength was $422.7 \mathrm{~nm}$. The slit was $0.7 \mathrm{~nm}$ and the current through the lamp was $10 \mathrm{~mA}$. The magnesium standards were prepared from magnesium reference solution (Fisher Scientific Co.), $1 \mathrm{mg} / \mathrm{mL}$, in the linear range of 0 to $0.5 \mathrm{ppm}$. The density of magnesium reference solution is $1.0112 \mathrm{~g} / \mathrm{L}$. Density correction was made. The wavelength was $285.2 \mathrm{~nm}$. The slit was $0.7 \mathrm{~nm}$ and the current through the lamp was $6 \mathrm{~mA}$.

The chromium standards were prepared from chromium standard (ULTRA Scientific), 10 $\mathrm{mg} / \mathrm{mL}$, in the linear range of 0 to $5 \mathrm{ppm}$. The density of chromium reference solution is 1.0444 $\mathrm{g} / \mathrm{L}$. Density correction was made. The wavelength was $357.9 \mathrm{~nm}$. The slit was $0.7 \mathrm{~nm}$ and the current through the lamp was $25 \mathrm{~mA}$.

\section{Results and Discussion}

Seven cores were used in this project. Core B was used as a trial core to test if a restoration process for the core can permit the acquisition of reproducible data. It was determined that the restoration process was ineffective in that results from flow experiments using chromium solutions were different in virgin and "restored" cores. New core material (Cores C1 to C6) were 
used for each injection of chromium(III) acetate solution. Some cores were used after the initial injection of chromium(III) acetate solution to conduct some additional tests.

A tracer test was conducted for each core. The results from tracer tests for all the dolomite cores used in this project demonstrated that the cores used were relatively homogeneous. Some cores that showed atypical flow behavior were discarded. An example of a tracer test on Core C6 is shown in Figure 4.2.

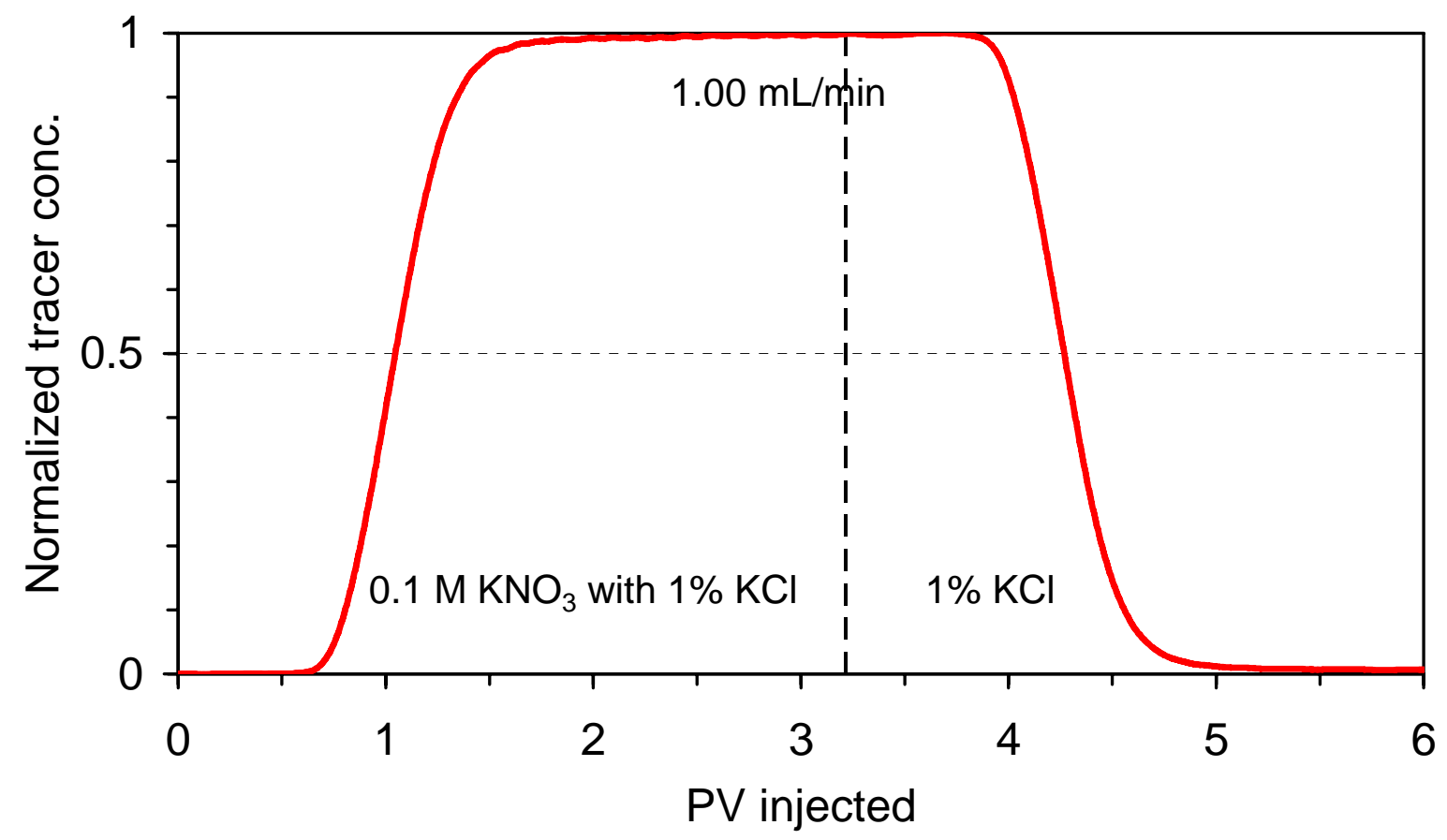

Figure 4.2- Tracer test for Core C6.

Flow experiments using chromium acetate solutions in Core B. From previous work [Jin, 2001], the injection of several hundred pore-volumes of brine was required before the effluent $\mathrm{pH}$ would attain the value of 9.8 after the dolomite core was contacted with a chromium(III) acetate solution. A pH value of 9.8 is the "equilibrium" value that a $1 \% \mathrm{KCl}$ brine (initial $\mathrm{pH}$ between 5 and 9) will attain when in contact with dolomite rock [Zou et al., 2000]. It was thought that the initial condition of the core would be restored when the "equilibrium" $\mathrm{pH}$ value was re-established. To test the restoration procedure, five primary flow experiments using chromium(III) acetate solutions (200 ppm chromium, 1.0\% KCl) were conducted in the Core B at a flow rate of $0.032 \mathrm{~mL} / \mathrm{min}$. These experiments are listed as B-Flow0.032-(1, 2, 3, 4 or 5) in Table 4.2. (Shut-in experiments that were conducted in Core B and listed in Table 4.2 are addressed later.) No chromium was injected prior to Run B-Flow0.032-1. Prior to each of the flow experiments for Runs 2, 3 and 4, many pore volumes of brine (70 to 380 pore volumes) were injected through the core to restore the effluent $\mathrm{pH}$ to approximately 9.5, the equilibrium value for the injection of brine with a neutral $\mathrm{pH}$. Only 6 pore volumes of brine were injected prior to the Run 5 and the effluent $\mathrm{pH}$ had risen to a value of about 9. 
Table 4.2 - Sequence of flow experiments in dolomite Core B.

\begin{tabular}{|c|c|c|c|c|}
\hline $\begin{array}{l}\text { Flow } \\
\text { experiment }\end{array}$ & Injected solution & $\begin{array}{l}\text { Flow rate(s) } \\
(\mathrm{mL} / \mathrm{min})\end{array}$ & $\begin{array}{l}\text { Residence time } \\
\text { (hours) }\end{array}$ & $\begin{array}{c}\text { Volume } \\
\text { injected } \\
\text { (pore } \\
\text { volumes) }\end{array}$ \\
\hline B-Flow0.032-1 & 200 ppm Cr, $1.0 \% \mathrm{KCl}$ & 0.032 & 2.2 & 5.8 \\
\hline Brine postflood & $1.0 \% \mathrm{KCl}$ & 1.00 & 0.07 & 380 \\
\hline B-Flow0.032-2 & 200 ppm Cr,1.0\% KCl & 0.032 & 2.2 & 5.0 \\
\hline Brine postflood & $1.0 \% \mathrm{KCl}$ & 1.00 & 0.07 & 440 \\
\hline B-Flow1-1 & 200 ppm Cr, $1.0 \% \mathrm{KCl}$ & 1.00 & 0.07 & 5.0 \\
\hline B-Shutin2-1 & 200 ppm Cr, $1.0 \% \mathrm{KCl}$ & - & 2.0 & - \\
\hline Brine postflood & $1.0 \% \mathrm{KCl}$ & 0.10 & 0.69 & 70 \\
\hline B-Flow0.032-3 & $200 \mathrm{ppm} \mathrm{Cr}, 1.0 \% \mathrm{KCl}$ & 0.03 & 2.3 & 5.1 \\
\hline Brine postflood & $1.0 \% \mathrm{KCl}$ & $0.03,1.00,0.10$ & $2.3,0.07,0.69$ & 180 \\
\hline B-Flow1.5-2 & 200 ppm Cr, $1.0 \% \mathrm{KCl}$ & 1.50 & 0.05 & 5.0 \\
\hline B-Shutin2-2 & 200 ppm Cr, $1.0 \% \mathrm{KCl}$ & - & 2.0 & - \\
\hline Brine postflood & $1.0 \% \mathrm{KCl}$ & 0.10 & 0.69 & 140 \\
\hline B-Flow1.51-3 & 200 ppm Cr, $1.0 \% \mathrm{KCl}$ & 1.50 & 0.05 & 5.0 \\
\hline B-Shutin4-3* & $200 \mathrm{ppm} \mathrm{Cr}, 1.0 \% \mathrm{KCl}$ & - & 4.0 & - \\
\hline Brine postflood & $1.0 \% \mathrm{KCl}$ & $0.10,0.03$ & $0.69,2.3$ & 90 \\
\hline B-Flow0.032-4 & 200 ppm Cr, $1.0 \% \mathrm{KCl}$ & 0.032 & 2.2 & 6.0 \\
\hline Brine postflood & $1.0 \% \mathrm{KCl}$ & 1.00 & 0.07 & 6 \\
\hline B-Flow0.032-5 & 200 ppm Cr, $1.0 \% \mathrm{KCl}$ & 0.032 & 2.2 & 4.2 \\
\hline Brine postflood & $1.0 \% \mathrm{KCl}$ & 1.00 & 0.07 & \\
\hline
\end{tabular}

\footnotetext{
* Results are not described in this report.
} 
Figures 4.3 and 4.4 present the effluent chromium concentration and the effluent $\mathrm{pH}$ as a function of volume of solution injected for the five primary flow experiments in Core B during the injection at a flow rate of $0.032 \mathrm{~mL} / \mathrm{min}$ of a solution containing $200 \mathrm{ppm} \mathrm{Cr}$ (acetate salt) and $1.0 \% \mathrm{KCl}$. Run B-Flow0.032-1 represent data from a virgin core. The chromium concentration increased just before one pore volume injected and leveled out at a steady-state normalized concentration of about 0.91 . The amount of chromium retained increased with successive Runs 2, 3 and 4. In each successive run, the chromium front was delayed and the steady-state value that was approached was lower. Effluent analysis were not conducted during the brine post flushes so that the amount of chromium remaining in the core could not be determined. The higher values of chromium retention with the successive Runs 2, 3 and 4 corresponded to higher $\mathrm{pH}$ values measured in the effluent as shown in Figure 4.4. These results showed that the history of the core plug significantly affects the retention behavior of chromium(III) and that the re-establishment of the effluent $\mathrm{pH}$ to about 9.5 did not correspond to the restoration of the core to a common initial condition. Also, the amount of chromium retained increased with each successive run resulting in increased retention. (Additional chromium was injected in shut-in experiments conducted before B-Flow0.032-3 and B-Flow0.032-4.) The data suggest that chromium remained in the pack after the brine post flush and affected the subsequent run.

Run B-Flow0.032-5 was conducted after a brine pre-flush in which only six pore volumes of $1.0 \% \mathrm{KCl}$ brine were injected and the effluent $\mathrm{pH}$ value had risen to a value of about 8 . The $\mathrm{pH}$ dropped to about 7.3 at the start of Run B-Flow0.032-5 apparently due to the core being shut-in for a period of time between the runs. Less chromium was retained during the transition period ( 1 to 3 PVI) in Run 5 than in Runs 3 and 4 apparently due to the lower $\mathrm{pH}$ values experience by the injected solution. Thereafter, the chromium concentration appears to approach a steady-state value at approximately the same value as in Runs 3 and 4.

Flow experiments using chromium(III) acetate solutions in virgin cores The sequences of flow experiments with chromium(III) acetate solutions and brine in Cores C1 through C6 are shown in Tables 4.3 through 4.8, respectively. Results for the injection of chromium(III) acetate solutions (200 ppm chromium(III)) into virgin cores at various injection rates are discussed in this section. Parameters for these experiments are listed first in Tables 4.3 to 4.8.

Chromium(III) acetate solution was injected through Core $\mathrm{C} 1$ at $0.032 \mathrm{~mL} / \mathrm{min}$ (residence time $=$ 2.1 hours) in Experiment C1-Flow0.032-1. To test reproducibility, a similar experiment was conducted in Core C2 (Flow0.032-1; residence time $=2.0$ hours). Brine was injected immediately after the injection of chromium solution. The chromium concentration and $\mathrm{pH}$ in the effluent were relatively constant as brine was displaced from the cores as shown in Figure 4.5. At about one pore volume injected, a transition period occurred where the chromium concentration increased and the $\mathrm{pH}$ decreased to values that approached steady-state values. Chromium was continuously retained as shown by the steady-state chromium concentration which was about 170 ppm [0.86×200 ppm]. Reproducible behavior was observed when the flow experiments were conducted in virgin cores.

Calcium and magnesium concentrations in the effluent for both runs and the following brine post-flood are shown in Figure 4.6. Calcium and magnesium concentrations from Cores C1 and 


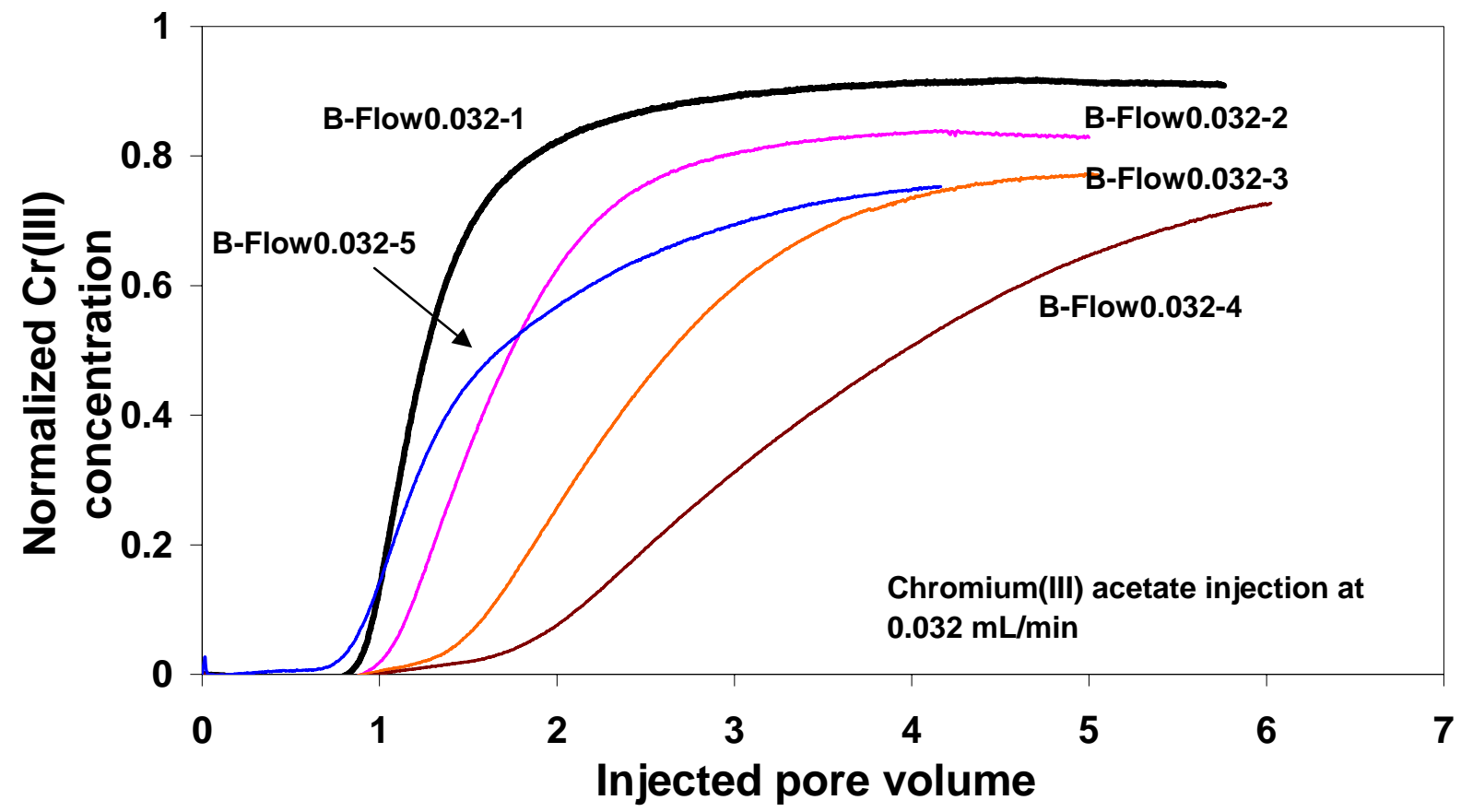

Figure 4.3- The effluent chromium concentration when $200 \mathrm{ppm}$ chromium solution (acetate ion) was injected through dolomite Core B at $0.032 \mathrm{~mL} / \mathrm{min}$.

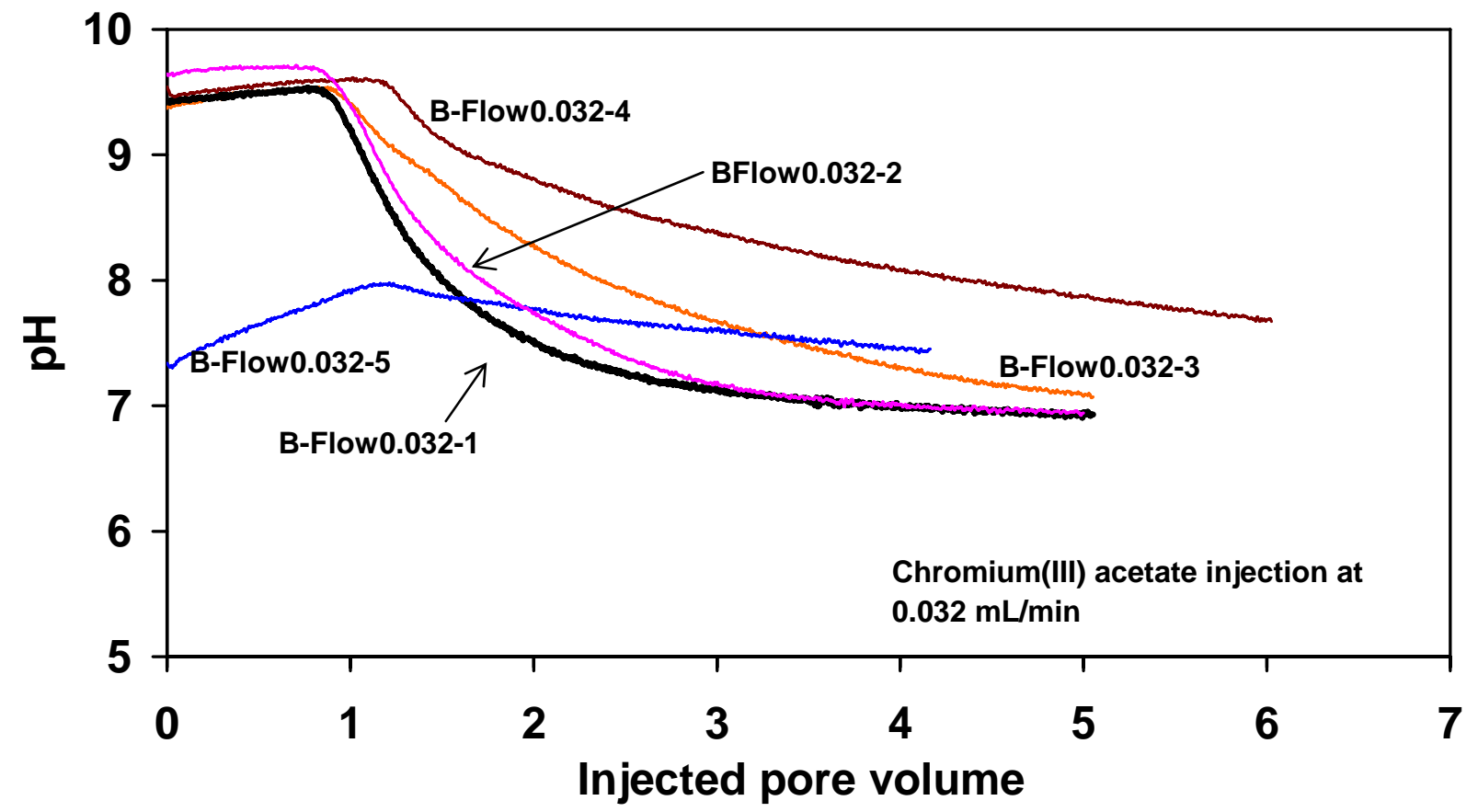

Figure 4.4- The effluent $\mathrm{pH}$ when $200 \mathrm{ppm}$ chromium solution (acetate ion) was injected through dolomite Core B at $0.032 \mathrm{~mL} / \mathrm{min}$. 
Table 4.3 - Sequence of flow experiments in dolomite Core C1.

\begin{tabular}{ccccc}
\hline Flow experiment & Injected solution & $\begin{array}{c}\text { Flow rate(s) } \\
(\mathrm{mL} / \mathrm{min})\end{array}$ & $\begin{array}{c}\text { Residence } \\
\text { time } \\
\text { (hours) }\end{array}$ & $\begin{array}{c}\text { Volume } \\
\text { injected } \\
\text { (pore } \\
\text { volumes) }\end{array}$ \\
\hline C1-Flow0.032-1 & $200 \mathrm{ppm} \mathrm{Cr}, 1.0 \% \mathrm{KCl}$ & 0.032 & 2.1 & 4.7 \\
Brine postflood & $1.0 \% \mathrm{KCl}$ & 1.00 & 0.06 & 6.9 \\
\hline
\end{tabular}

Table 4.4 - Sequence of flow experiments in dolomite Core C2.

\begin{tabular}{ccccc}
\hline Flow experiment & Injected solution & $\begin{array}{c}\text { Flow rate(s) } \\
(\mathrm{mL} / \mathrm{min})\end{array}$ & $\begin{array}{c}\text { Residence } \\
\text { time } \\
\text { (hours) }\end{array}$ & $\begin{array}{c}\text { Volume } \\
\text { injected } \\
\text { (pore } \\
\text { volumes) }\end{array}$ \\
\hline C2-Flow0.032-1 & 200 ppm Cr, 1.0\% KCl & 0.032 & 2.0 & 5.0 \\
Brine postflood & $1.0 \% \mathrm{KCl}$ & 1.00 & 0.06 & 5.2 \\
& & 0.03 & 2.1 & 118 \\
C2-pH2.1-Flow-2 & $\mathrm{pH} \mathrm{2.1,}$ & 1.02 & 0.06 & 6.8 \\
& $1.0 \% \mathrm{KCl}$ & 0.10 & 0.64 & 2.4 \\
& & 0.032 & 2.0 & 5.4 \\
Brine postflood & $1.0 \% \mathrm{KCl}$ & 0.06 & 1.06 & 2.9 \\
& & 1.02 & 0.06 & 5.9 \\
C2- KOAc-Flow-3 & 1.00 & 0.06 & 121 \\
& pH 4.6, 0.0114 M & 0.03 & 2.1 & 229 \\
& KOAc, 1.0\% KCl & 1.02 & 0.06 & 7.5 \\
& & 0.134 & 0.5 & 4.8 \\
& & 0.032 & 2.0 & 11.6 \\
\hline
\end{tabular}

Table 4.5 - Sequence of flow experiments in dolomite Core C3.

\begin{tabular}{ccccc}
\hline Flow experiment & Injected solution & $\begin{array}{c}\text { Flow rate(s) } \\
(\mathrm{mL} / \mathrm{min})\end{array}$ & $\begin{array}{c}\text { Residence } \\
\text { time } \\
\text { (hours) }\end{array}$ & $\begin{array}{c}\text { Volume } \\
\text { injected } \\
\text { (pore } \\
\text { volumes) }\end{array}$ \\
\hline C3-Flow1-1 & 200 ppm Cr, 1.0\% KCl & 1.00 & 0.06 & 6.9 \\
C3-Shutin2-2 & 200 ppm Cr, 1.0\% KCl & - & 2.0 & - \\
Brine postflood & $1.0 \% \mathrm{KCl}$ & 1.00 & 0.06 & 14.4 \\
& & 0.03 & 1.9 & 44.7 \\
\hline
\end{tabular}


Table 4.6 - Sequence of flow experiments in dolomite Core C4.

\begin{tabular}{ccccc}
\hline Flow experiment & Injected solution & $\begin{array}{c}\text { Flow rate(s) } \\
(\mathrm{mL} / \mathrm{min})\end{array}$ & $\begin{array}{c}\text { Residence } \\
\text { time } \\
\text { (hours) }\end{array}$ & $\begin{array}{c}\text { Volume } \\
\text { injected } \\
\text { (pore } \\
\text { volumes) }\end{array}$ \\
\hline C4-Flow2-1 & $200 \mathrm{ppm} \mathrm{Cr}, 1.0 \% \mathrm{KCl}$ & 2.00 & 0.03 & 5.0 \\
C4-Shutin2-2 & $200 \mathrm{ppm} \mathrm{Cr} 1.0 \% \mathrm{KCl}$ & - & 2.0 & - \\
Brine postflood & $1.0 \% \mathrm{KCl}$ & 1.00 & 0.06 & 3.9 \\
& & 0.03 & 2.2 & 31.4 \\
\hline
\end{tabular}

Table 4.7 - Sequence of flow experiments in dolomite Core C5.

\begin{tabular}{ccccc}
\hline Flow experiment & Injected solution & $\begin{array}{c}\text { Flow rate(s) } \\
\text { (mL/min) }\end{array}$ & $\begin{array}{c}\text { Residence } \\
\text { time } \\
\text { (hours) }\end{array}$ & $\begin{array}{c}\text { Volume } \\
\text { injected } \\
\text { (pore } \\
\text { volumes) }\end{array}$ \\
\hline C5-Flow0.003-1 & 200 ppm Cr, 1.0\% KCl & 0.003 & 24.1 & 5.4 \\
Brine postflood & $1.0 \% \mathrm{KCl}$ & 1.00 & 0.07 & 20.7 \\
\hline
\end{tabular}

Table 4.8 - Sequence of flow experiments in dolomite Core C6.

\begin{tabular}{|c|c|c|c|c|}
\hline Flow experiment & Injected solution & $\begin{array}{c}\text { Flow rate(s) } \\
(\mathrm{mL} / \mathrm{min})\end{array}$ & $\begin{array}{l}\text { Residence } \\
\text { time } \\
\text { (hours) }\end{array}$ & $\begin{array}{c}\text { Volume } \\
\text { injected } \\
\text { (pore } \\
\text { volumes) }\end{array}$ \\
\hline C6-Flow0.0056-1 & 200 ppm Cr, $1.0 \% \mathrm{KCl}$ & 0.0056 & 12 & 5.9 \\
\hline Brine postflood & $1.0 \% \mathrm{KCl}$ & $\begin{array}{l}1.00 \\
0.03\end{array}$ & $\begin{array}{c}0.06 \\
2.2\end{array}$ & $\begin{array}{c}6.2 \\
55.2\end{array}$ \\
\hline
\end{tabular}

C2 were in good agreement. Magnesium concentrations were consistently higher than calcium concentrations in the transition period during the injection of chromium and were less than the calcium concentrations during the brine flush. Equimolar concentrations of calcium and magnesium were displaced from the core during steady-state period.

Chromium(III) acetate solution was injected through virgin Core C6 at a low flow rate of 0.0056 $\mathrm{mL} / \mathrm{min}$ ((Run C6-Flow0.0056-1; residence time of 12 hours). Chromium concentration and $\mathrm{pH}$ in the effluent as a function of pore volumes injected are shown in Figure 4.7. The chromium concentration increased and approached a steady value after about $5 \mathrm{PV}$ injected. The $\mathrm{pH}$ decreased and approached a steady value at about the same time. The transition period required to reach steady values spanned a larger volume of fluid injected than shown in Figure 4.5 for 


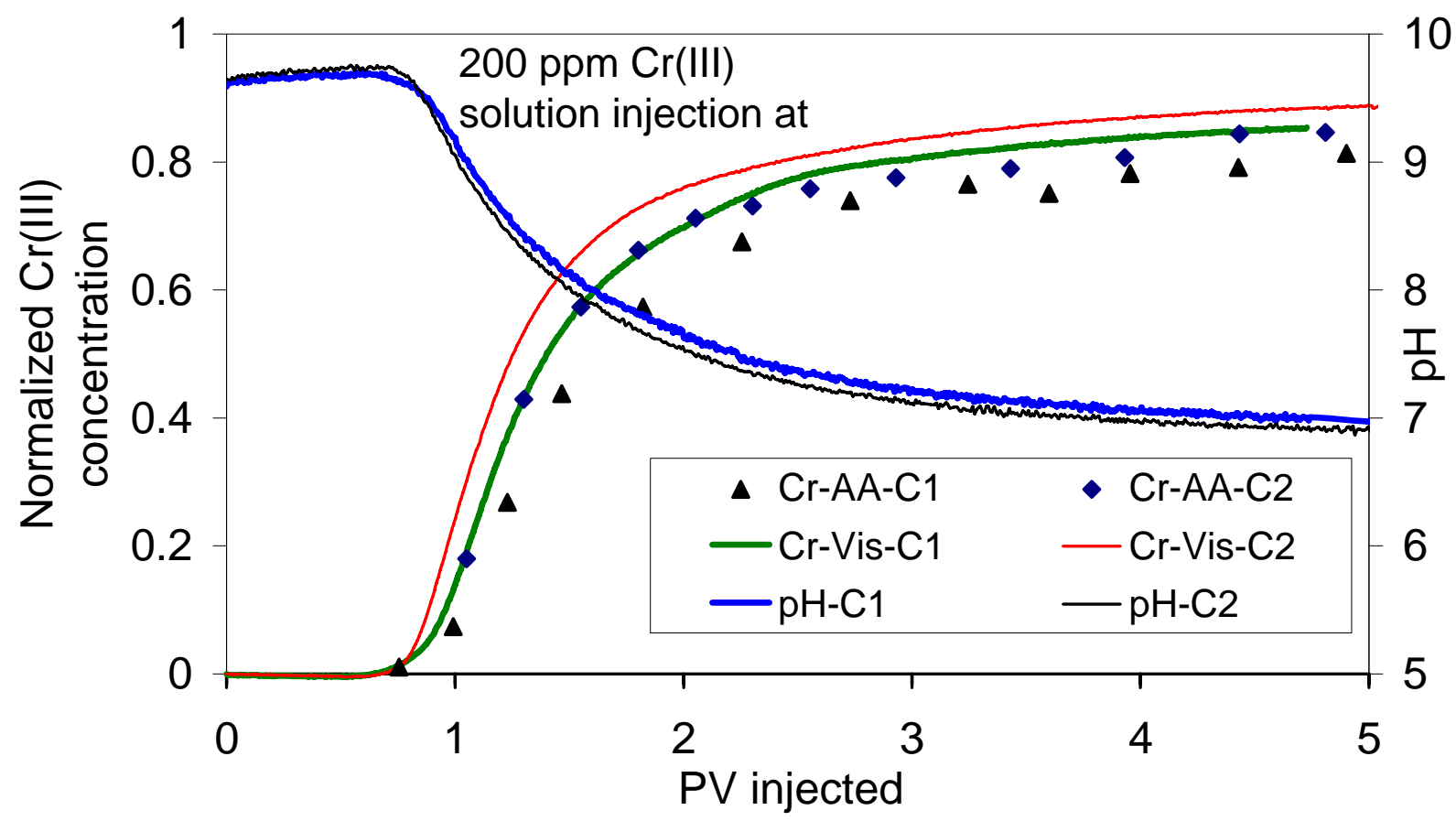

Figure 4.5- The effluent $\mathrm{pH}$ and chromium(III) concentration for runs C1-Flow0.032-1 and C2Flow0.032-1.

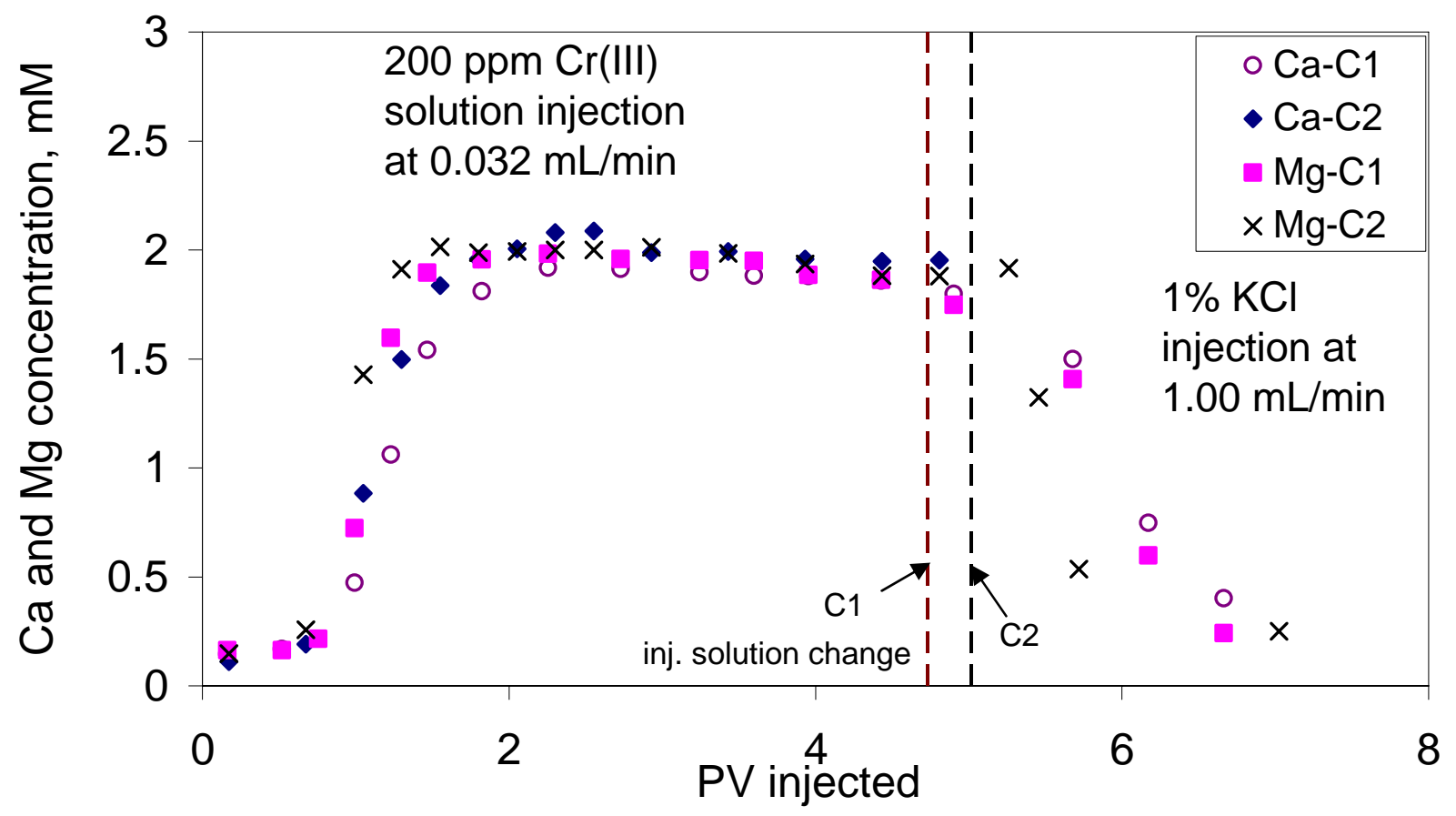

Figure 4.6- The effluent calcium and magnesium concentrations for runs C1-Flow0.032-1 and C2-Flow0.032-1 and the following brine postflood. 


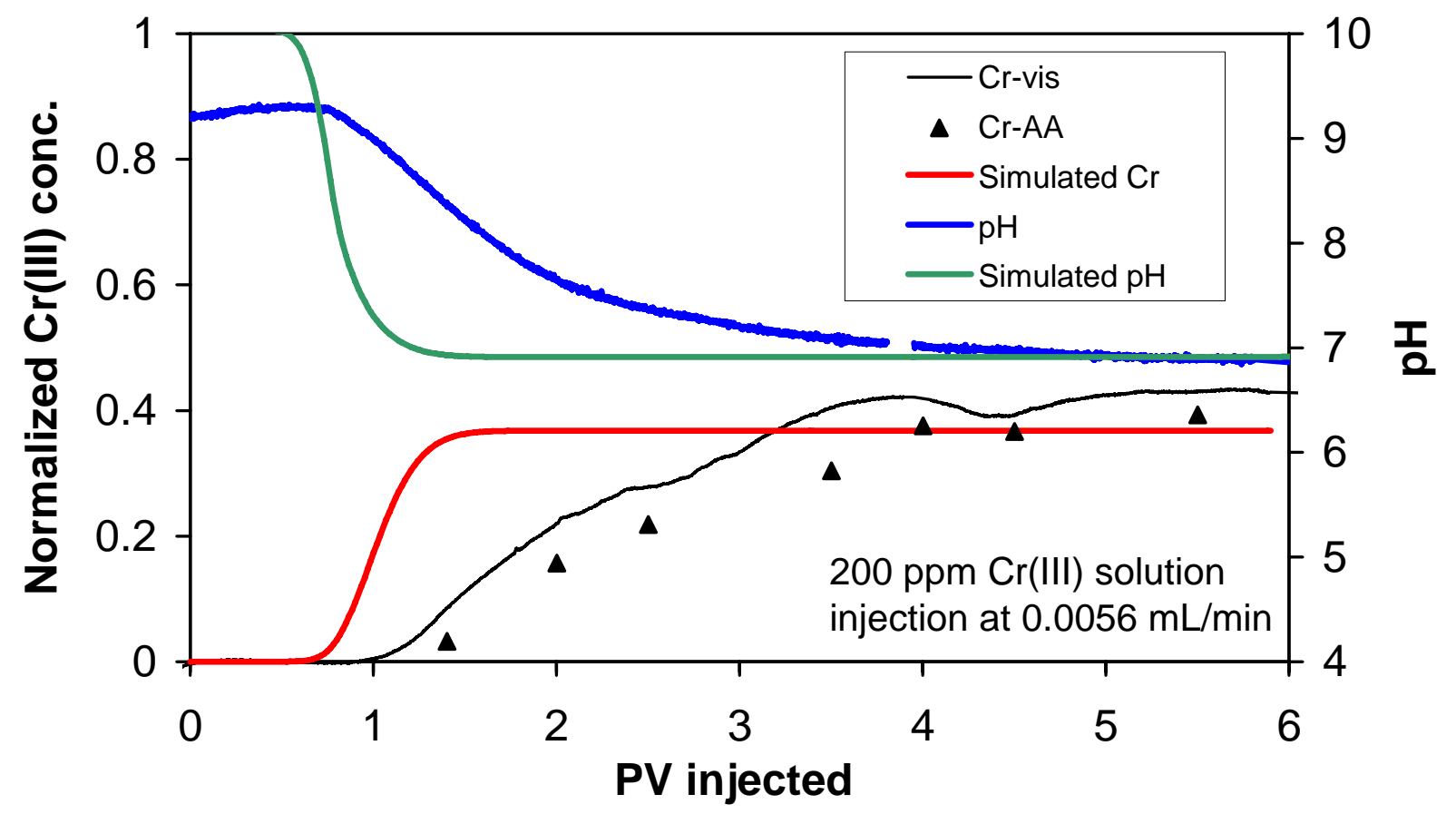

Figure 4.7 - The effluent pH and chromium concentration for Run C6-Flow0.0056-1.

Cores $\mathrm{C} 1$ or $\mathrm{C} 2$ that were conducted at a faster flow rate (shorter residence time). This trend, longer transition period with increased residence time, was observed for all the flow rates tested in Cores C1 to C6 during the injection of chromium acetate solution.

Calcium and magnesium concentrations in the effluent for Run C6-Flow0.0056-1 and the subsequent brine flush are shown in Figure 4.8. Similar to runs in Cores C1 and C2, the magnesium concentration was higher than the calcium concentration during the transition period and lower than the calcium concentration during the brine flush. In the steady-state period during the injection of chromium acetate, the mole ratio of magnesium to calcium was consistently about 1.05, higher the equimolar concentrations observed in Cores C1 and C2 at a shorter residence time. A higher $\mathrm{Mg} / \mathrm{Ca}$ mole ratio of 1.15 was observed during Run C5-Flow0.003-1 which was run at a residence time of 24 hours. Higher $\mathrm{Mg} / \mathrm{Ca}$ ratios during the steady-state period were observed at longer residence times.

A mathematical model of the transport of fluid species through carbonate rocks was used to simulate the flow experiments. The model, described in detail in the previous annual report [Willhite et al., 2004], incorporates convection, dispersion, kinetic reactions of carbonate dissolution and chromium precipitation and equilibrium reactions between selected aqueous components. A simulation for the injection of chromium acetate in Core C6 is shown in Figure 4.7 with the experimental data (Run C6-Flow0.0056-1). The transition period was not simulated well, particularly for this run and the Run C5-Flow0.003-1 that was conducted at a longer residence time. The simulation did match the data during the steady-state period that followed the transition period. Simulation of calcium and magnesium in the effluent for the same run are compared to the data in Figure 4.8. Measured concentrations of both calcium and magnesium are about half of the predicted values. 


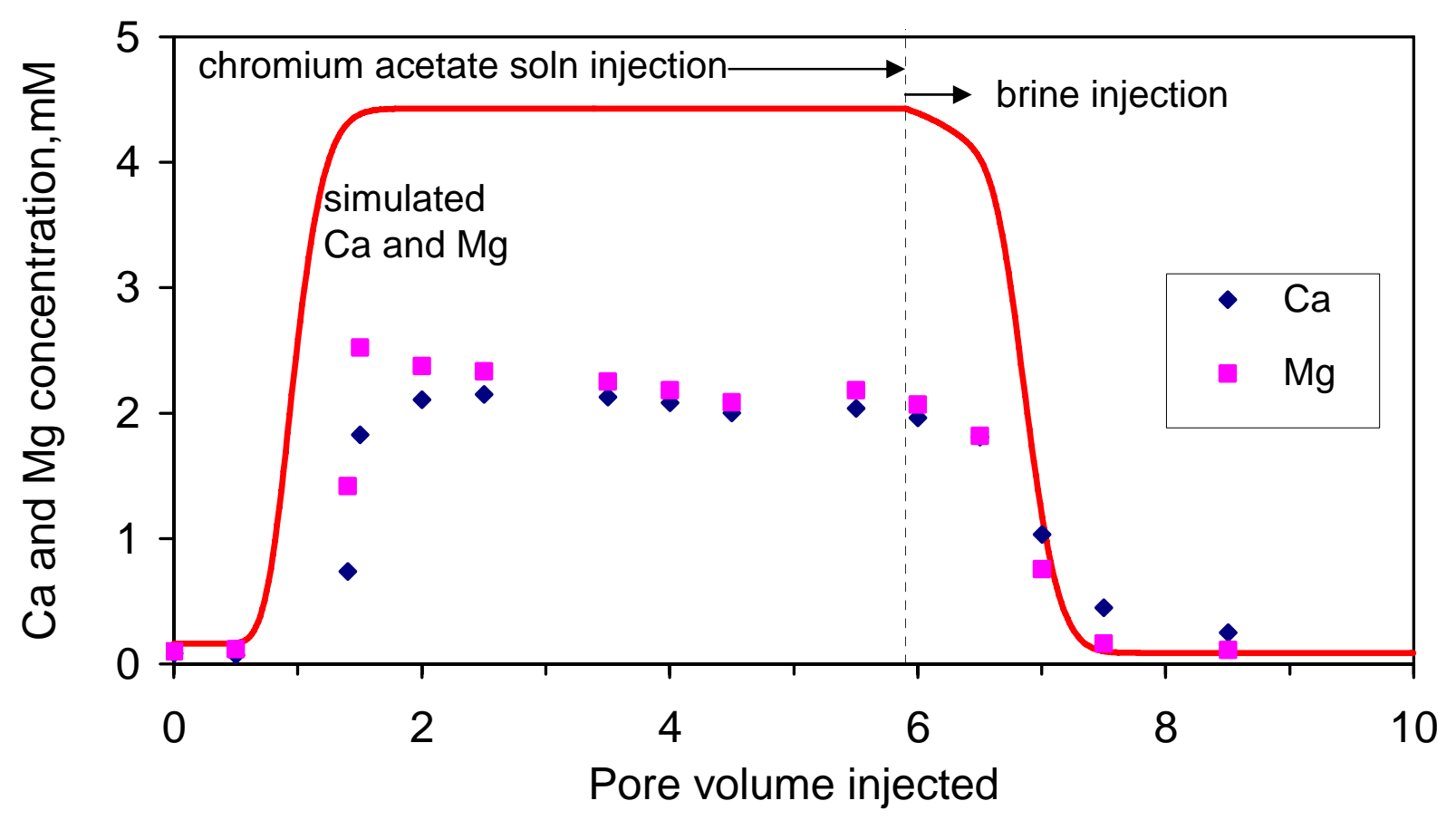

Figure 4.8 - Calcium and magnesium concentrations in the effluent for Run C6-Flow0.0056-1 and the following brine flush.

The steady-state values, both experimental and simulated, during the injection of chromium acetate solutions in virgin cores are listed in Table 4.9. The simulated $\mathrm{pH}$ and chromium concentration matched the experimental data reasonable well for all flow rates (residence times). The simulated effluent state-steady calcium and magnesium concentrations were much higher than the experimental data. The cause of the difference in calcium and magnesium dissolution rates in the presence of chromium acetate solutions is not understood and was explored with additional experiments that are described later.

Shut-in experiments with chromium acetate solutions. Shut-in experiments were devised to collect chromium-retention data, particularly for long residence times when using small cores. The premise was that the in-situ chromium concentration in the rock after a selected shut-in time would be equal to the chromium concentration in the effluent from a flow experiment that was conducted at a residence time equal to the shut-in time. Four shut-in runs were conducted at residence times of two hours. Parameters and results from the shut -in runs and from two flow experiments conducted in virgin cores with residence times of two hours are listed in Table 4.10. More chromium was retained during the shut-in experiments than during the flow experiments. Also, more chromium was retained in the shut-in experiments in Core B than in Cores C3 and $\mathrm{C} 4$, possibly due to the greater volume of chromium solution that was injected through Core B prior to the run. The $\mathrm{Mg} / \mathrm{Ca}$ molar ratio during the shut-in experiments was greater than one, similar to flow experiments conducted at low flow rates. Results from shut-in experiments do not correspond to effluent results from flow experiments that are conducted at a resident time equal to the shut-in time. 
Table 4.9 - Steady-state values of the experimental and simulated results for flow experiments during the injection of chromium(III) acetate solution (200 ppm Cr, $1 \% \mathrm{KCl})$ into virgin cores.

\begin{tabular}{|c|c|c|c|c|c|c|c|c|c|}
\hline \multirow[b]{2}{*}{ Run no } & \multirow[b]{2}{*}{$\begin{array}{c}\text { Residence } \\
\text { time } \\
\text { (hours) }\end{array}$} & \multicolumn{5}{|c|}{ Experimental data } & \multicolumn{3}{|c|}{ Simulated results } \\
\hline & & $\begin{array}{l}\text { Norm. } \\
\text { Cr } \\
\text { conc. }\end{array}$ & $\begin{array}{c}\text { Mg con. } \\
\text { (mM) }\end{array}$ & $\begin{array}{c}\text { Ca con. } \\
(\mathrm{mM})\end{array}$ & $\begin{array}{c}\text { Molar } \\
\text { ratio } \\
\text { of } \\
\mathrm{Mg} / \mathrm{Ca}\end{array}$ & $\mathrm{pH}$ & $\begin{array}{l}\text { Norm. } \\
\text { Cr } \\
\text { conc. }\end{array}$ & $\begin{array}{l}\text { Ca and } \\
\text { Mg conc. } \\
\text { (mM) }\end{array}$ & $\mathrm{pH}$ \\
\hline C4-Flow2-1 & 0.03 & 0.99 & 1.4 & 1.4 & 1.00 & 6.8 & 1.0 & 2.9 & 6.5 \\
\hline C3- Flow1-1 & 0.06 & 0.99 & 1.4 & 1.4 & 1.00 & 6.9 & 1.0 & 3.2 & 6.8 \\
\hline C2-Flow0.032-1 & 2.0 & 0.88 & 1.93 & 1.95 & 0.99 & 6.9 & 0.75 & 3.9 & 7.0 \\
\hline C1-Flow0.032-1 & 2.1 & 0.85 & 1.88 & 1.88 & 1.00 & 7.0 & 0.75 & 3.9 & 7.0 \\
\hline B-Flow0.032-1 & 2.2 & 0.91 & 1.8 & - & - & 6.9 & 0.75 & 3.9 & 7.0 \\
\hline C6-Flow0.0056-1 & 12.0 & 0.43 & 2.2 & 2.1 & 1.05 & 6.9 & 0.35 & 4.5 & 6.9 \\
\hline C5-Flow0.003-1 & 24.1 & 0.23 & 2.3 & 2.0 & 1.15 & 7.2 & 0.23 & 4.7 & 6.9 \\
\hline
\end{tabular}

Table 4.10 - Parameters and results of shut-in experiments; chromium(III) acetate solution (200 ppm $\mathrm{Cr}, 1 \% \mathrm{KCl})$.

\begin{tabular}{lccccccc}
\hline \multicolumn{1}{c}{ Run } & $\begin{array}{c}\text { Residence } \\
\text { or } \\
\text { shut-in } \\
\text { time } \\
\text { (hrs) }\end{array}$ & $\begin{array}{c}\text { Volume of } \\
\text { chromium acetate } \\
\text { injected prior to } \\
\text { exp (PV) }\end{array}$ & $\begin{array}{c}\text { Norm. } \\
\text { Cr } \\
\text { conc. }\end{array}$ & $\begin{array}{c}\text { Mg } \\
\text { conc. } \\
(\mathrm{mM})\end{array}$ & $\begin{array}{c}\text { Ca } \\
\text { conc. } \\
(\mathrm{mM})\end{array}$ & $\begin{array}{c}\mathrm{Mg} / \mathrm{Ca} \\
\text { molar } \\
\text { ratio }\end{array}$ & $\mathrm{pH}$ \\
\hline C3-Shutin2-2 & 2.0 & 6.9 & 0.74 & 2.2 & 1.9 & 1.16 & 6.6 \\
C4-Shutin2-2 & 2.0 & 5.0 & 0.74 & 2.2 & 1.8 & 1.22 & 6.8 \\
B-Shutin2-1 & 2.0 & 15.8 & 0.67 & 2.4 & - & - & 6.9 \\
B-Shutin 2-2 & 2.0 & 25.9 & 0.64 & 2.5 & - & - & 6.8 \\
C1-Flow0.032-1 & 2.1 & 0 & 0.85 & 1.88 & 1.88 & 1.00 & 7.0 \\
C2-Flow0032-1 & 2.0 & 0 & 0.88 & 1.93 & 1.95 & 0.99 & 6.9 \\
Simulation & 2.0 & - & 0.75 & 3.9 & 3.9 & 1.00 & 7.0 \\
\hline
\end{tabular}

Flow experiments for brine and sodium acetate solutions. Two types of additional flow experiments were conducted to investigate the discrepancy between the simulated and experiment values of calcium and magnesium concentrations in the effluent during the injection of chromium solutions. These runs were conducted in cores previously flooded with chromium acetate solutions. The possibility exists that retained chromium might have affected the results.

$1.0 \% \mathrm{KCl}$ brine at a $\mathrm{pH}$ of 2.1 was injected through Core $\mathrm{C} 2$ at several flow rates. The $\mathrm{pH}$ of the injected brine was adjusted so that the effluent $\mathrm{pH}$ from the dolomite core would be in the vicinity of 6.8 to 7.0 , the $\mathrm{pH}$ values measured during the injection of chromium acetate solutions. 
Brine was injected at several flow rates during Run C2-pH2.1-Flow-2. Concentrations of magnesium and calcium and the $\mathrm{pH}$ in the effluent and the corresponding simulated values from the model are shown in Figure 4.9. Simulated values of calcium and magnesium concentrations and $\mathrm{pH}$ were close to the experimental data in contrast to the match during the injection of chromium acetate solutions. These results indicate that the presence of chromium inhibited the dissolution of dolomite. The cause of the reduced dolomite dissolution in the presence of chromium acetate, as compared to the mathematical model, is unknown.

Additional flow experiments were conducted with a solution containing $0.0114 \mathrm{M}$ potassium acetate and $1.0 \%$ potassium chloride at an adjusted $\mathrm{pH}$ of 4.6. This solution contained the same amount of acetate and potassium chloride and was at the same $\mathrm{pH}$ as the chromium(III) acetate solutions used in the flow experiments. The potassium acetate solution was injected through Core C2 at flow rates of 1.02, 0.134 and $0.03 \mathrm{~mL} / \mathrm{min}$ corresponding to residence times of 3.8, 28 and 120 minutes (Run C2-KOAc-Flow-3). Calcium and magnesium concentrations and pH in the effluent as a function the residence time are shown in Figure 4.10. Dolomite dissolution and the related $\mathrm{pH}$ value reached equilibrium before a residence time of 28 minutes. The simulated effluent steady-state calcium and magnesium concentrations and $\mathrm{pH}$ matched the experimental steady-state data. These results indicate that the mathematical model can simulate the dolomite dissolution in the presence of acetate ions. The inhibition of dolomite dissolution in the presence of chromium acetate is caused by chromium.

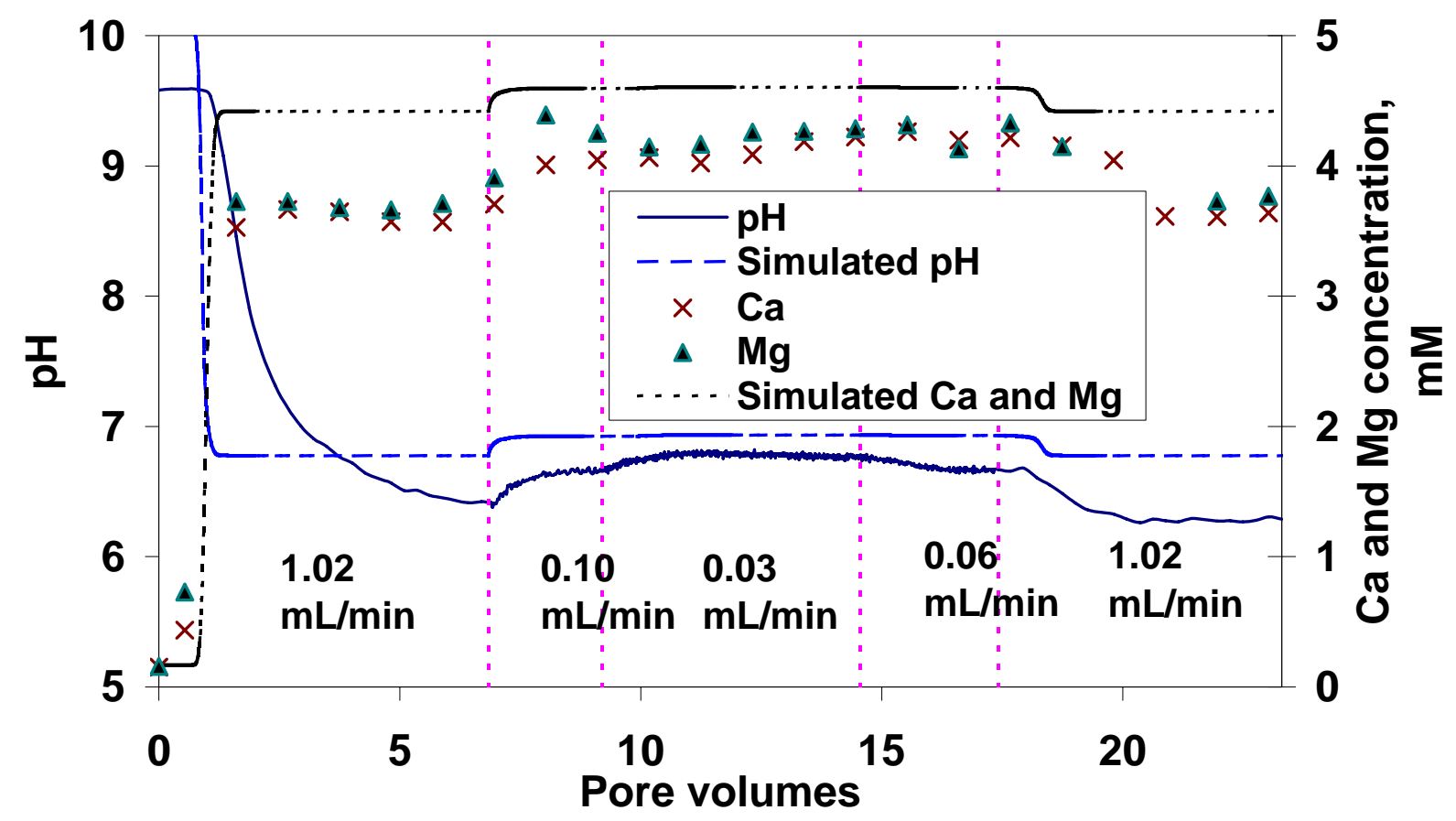

Figure 4.9- Comparison of the effluent $\mathrm{pH}$, calcium and magnesium concentrations for run C2pH2.1-Flow-2 with the simulated results. 


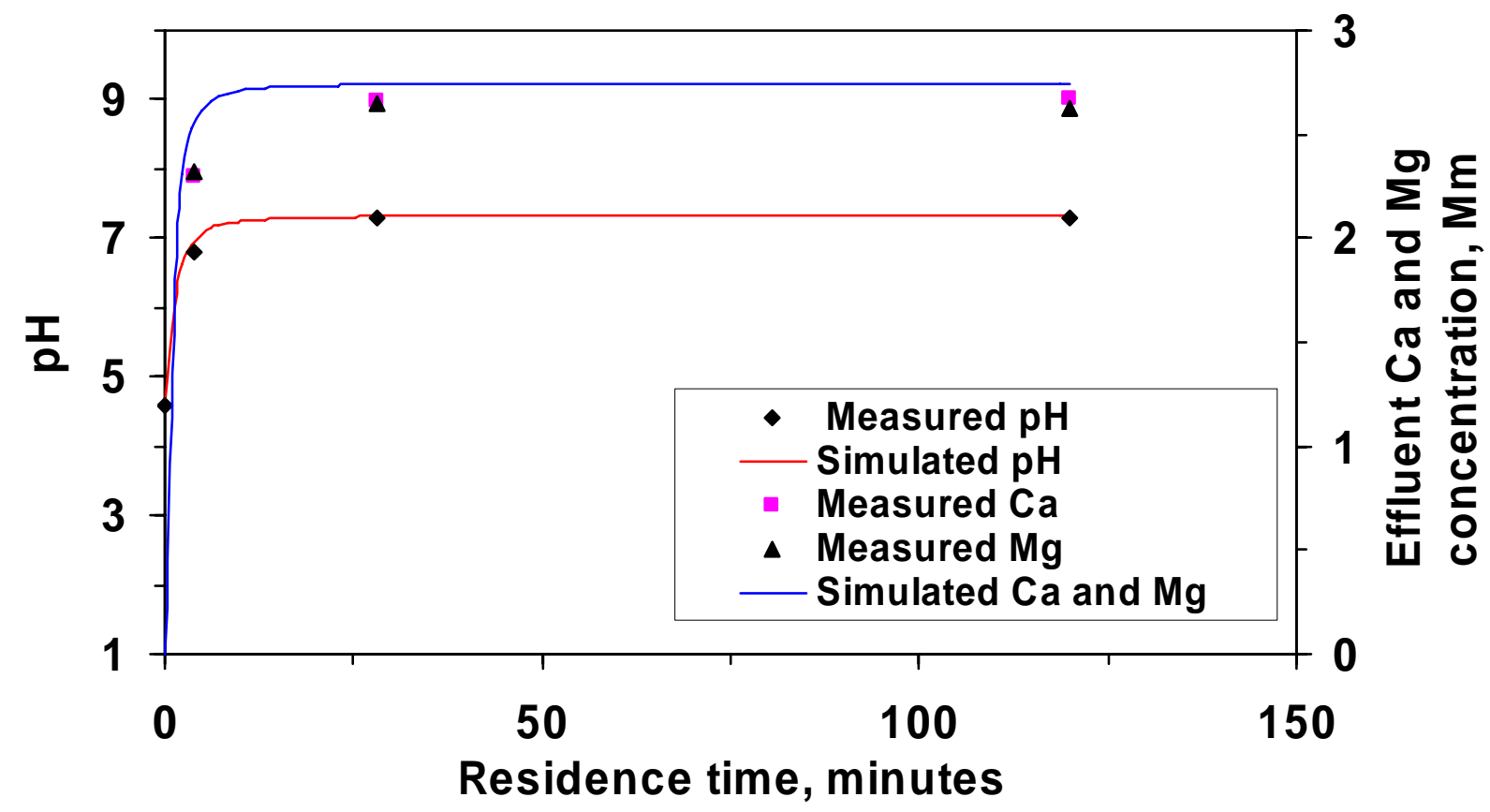

Figure 4.10 - Comparison of the effluent $\mathrm{pH}$, calcium and magnesium concentrations for runs C2-KOAc-Flow-3 and the simulated results.

\section{Conclusions}

1. Chromium retention was continuous and dependent upon the flow rate or residence time.

2. Simulated chromium concentrations and $\mathrm{pH}$ values in the effluent during the steady-state period are in agreement with experimental data.

3. Magnesium and calcium are not removed from the dolomite cores during transition periods in a mole ratio consistent with the stoichiometry of dolomite dissolution.

4. The dissolution rate of calcium and magnesium in the presence of chromium is reduced by about $50 \%$ from the cases when there is no chromium in the injected solution.

5. Chromium acetate inhibits the dissolution of dolomite.

6. Flow experiments in virgin cores are required to investigate chromium retention. Results from shut-in experiments and from flow experiments in cores were previously contacted with chromium solutions do not represent flow experiments in virgin cores.

\section{References}

1. Jin, H., McCool, C.S., Willhite, G.P., Green, D.W. and Michnick, M.J., "Propagation of Chromium(III) Acetate Solutions Through Dolomite Rock,” SPE Journal (June 2003) 8, No. 2, 107.

2. Meister, J.J., "A Porous Permeable Carbonate for use in Oil Recovery Experiments,” Journal of Petroleum Technology (November 1978) 30, 1632.

3. McCool, C.S., Green, D.W., and Willhite, G.P., "Fluid/Rock Interaction Between Xanthan-Chromium(III) Gel Systems and Dolomite Core Material,” SPE Production \& Facilities (August 2000) 15, No. 3, 159. 
4. Stavland, A., Kvanvik B.A. and Lohne A. "Evaluation of Xanthan-Cr(III) Gels for Deep Emplacement: Retention of Cr(III) in North Sea Sandstone Reservoirs", Seventh European Symposium on Improved Oil Recovery, Moscow, Russia, (27-29 October 1993).

5. Willhite,G.P. and McCool, C.S., "Development of Polymer Gel Systems to Improve Volumetric Sweep and Reduce Producing Water/Oil Ratios," Contract No. DE-FC2602NT15363, U.S. Department of Energy, Annual Report (July 2003 - June 2004).

6. Zou, B., McCool, C.S., Green, D.W., and Willhite, G.P., "A Study of the Chemical Interactions Between Brine Solutions and Dolomite," SPE Reservoir Evaluation \&Engineering (June 2000) 3, No. 3, 209. 


\section{Chapter 5}

\section{Technology Transfer}

The following list gives the presentations and technical papers of work conducted under this contract (DE-FC26-02NT15363) during the time period between July, 2004 and July, 2005.

Cheng, M., C. Wang, C.S. McCool, D.W. Green and G.P. Willhite, "Modeling of Pre-Gel Aggregate Growth During the Gelation of a Polyacrylamide-Chromium(III) Acetate Gel System Using the Theory of Branching Processes,” SPE Paper No. 93354, proceedings of the 2005 SPE International Symposium on Oilfield Chemistry, Houston, TX (2-4 February 2005). Min Cheng, PhD graduate student, presented the paper at the symposium.

Jain, R, C.S. McCool, D.W. Green, G.P. Willhite and M.J. Michnick, "Reaction Kinetics of the Uptake of Chromium(III) Acetate by Polyacrylamide," SPE Journal (September 2005) 10, No.3.

Nguyen, T.Q., D.W. Green, G.P. Willhite and C.S. McCool "Effects of Gelant Composition and Pressure Gradients of Water and Oil on Disproportionate Permeability Reduction of Sandpacks Treated with Polyacrylamide-Chromium Acetate Gels," scheduled to be published SPE Journal (March 2006) 11, No. 1. 